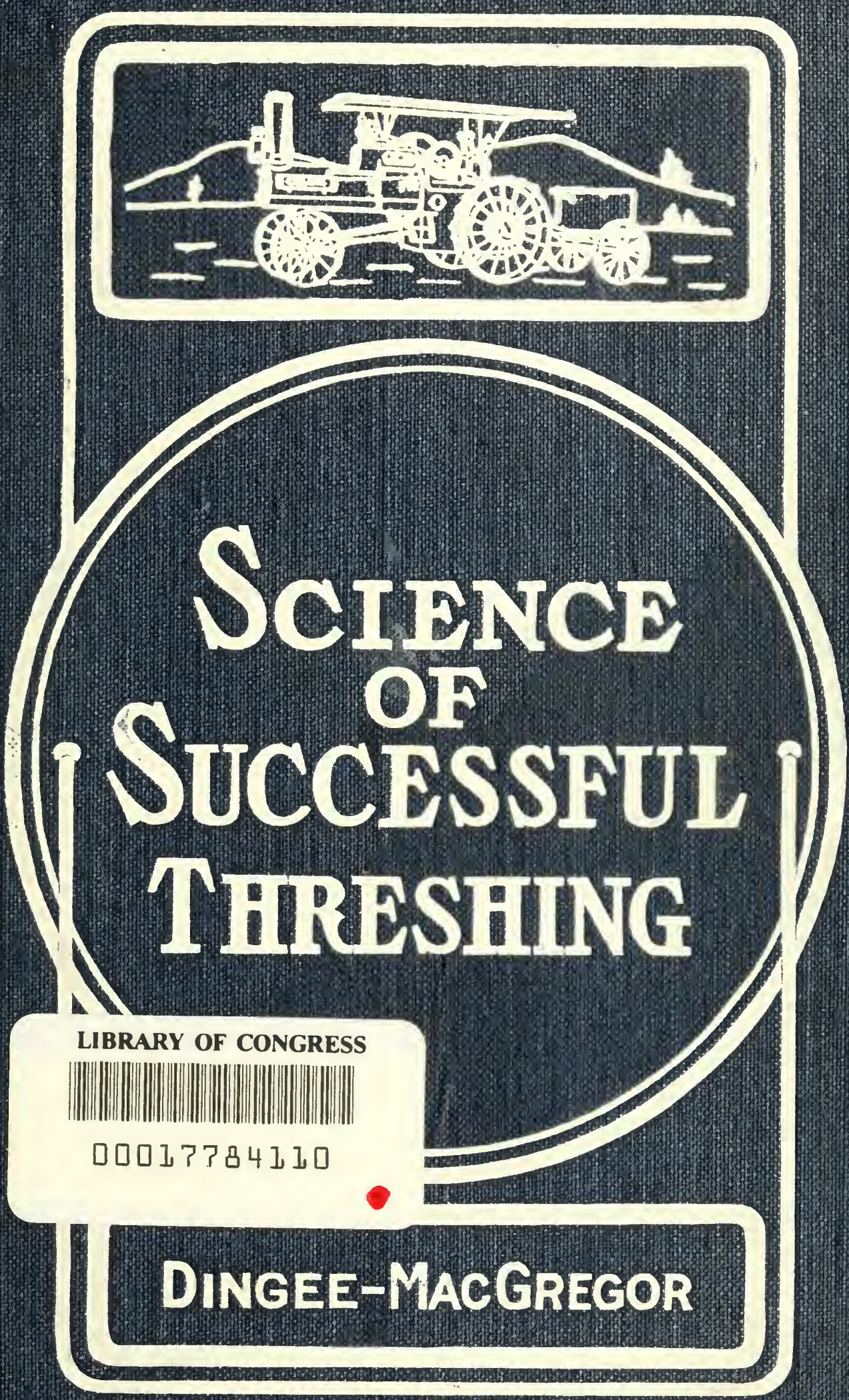




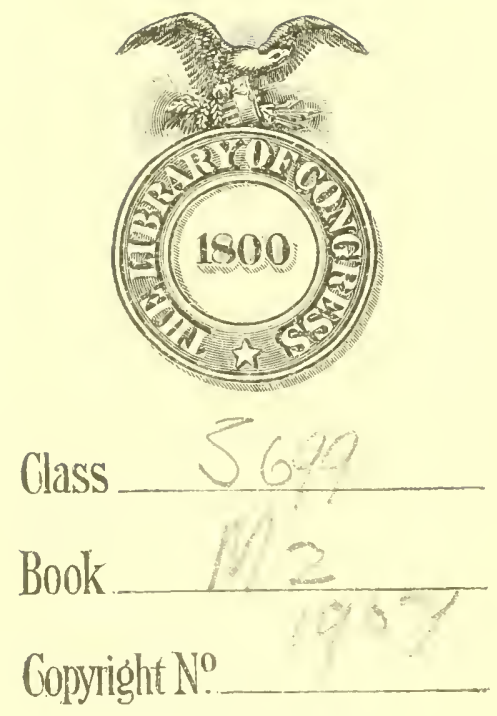

COPYRIGHT DEPOSIT. 




\section{SCIENCE OF SUCCESSFUL THRESHING}

\section{Dingee-MacGregor}

FIFTH EDITION, REVISED AND ENLARGED

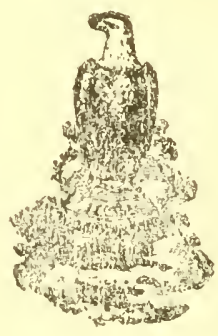

Published by

J. I. CASE THRESHING MACHINE CO.

RACINE, WIS. 1927. 
4.

Copyrighted by

R. T. ROBINSON

1899

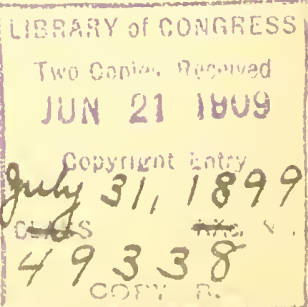




\section{PREFACE.}

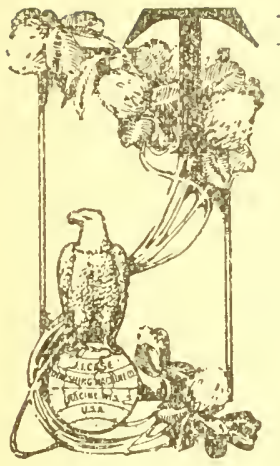

HE object of this book is to enable the owners and the operators of "Case" Threshing Machinery to become faniliar with the construction and operation of their engines and machines. The material has been gathered, not only from the author's personal experience, but also from notes taken during visits to the outfits of a large number of the best and most successful threshermen in various localities. The aim has been to avoid theorizing and to make only such statements as have been demonstrated practical, by actual field experience. The fact is appreciated that it is impossibie to lay down specific rules for operating threshing machinery, under the ever varying conditions of grain, straw and weather, but it is hoped that the suggestions herein cmbodied will enable a man of ordinary intelligence to operate his machine successfully, and to be, to a certain extent, an expert himself.

It is the intention to continue revising it from time to time, and with this aim in view, suggestions and criticisms will be welcomed from threshermen, wherever located, to whom this little volume is respectfully dedicated. 


\section{CONTENTS.}

For Index, sce page 223.

\section{PAR'T 1. INGGNES.}

Page.

\begin{tabular}{|c|c|c|}
\hline hapter & I & Fitting Up and Starting a New Engine..... 9 \\
\hline “ & II & 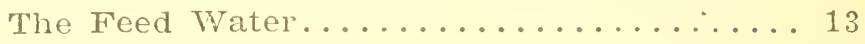 \\
\hline “ & III & Firing with Various Fuels............ 39 \\
\hline$\therefore$ & IV & Lubrication and Adjustment of Bealings.... 35 \\
\hline “ & $\mathrm{V}$ & Ilandling the Engine............... \\
\hline “ & VI & The Engine Proper............... 53 \\
\hline “ & TYII & The Valve Gear............ \\
\hline “ & TrIII & 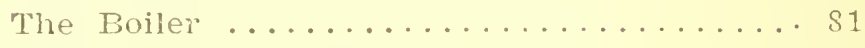 \\
\hline “ & $1 \mathrm{X}$ & The Traction Cearing........ \\
\hline “ & $\mathrm{X}$ & Water ranks ............ \\
\hline “ & XI & $\ldots \ldots \ldots 1$ \\
\hline
\end{tabular}

\section{PART II. SEPARATORS.}

Page.

Chapter I Fitting Lp and Starting a New Separator....121

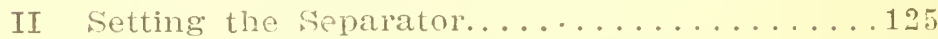

" III The Cylinder, Concaves and Beater.......129

“ IV The Straw-rack and Conveyor...........141

“ $V$ The Cleaning Apparatus..............143

“VI Threshing with a Regularly Equipped Sepa-

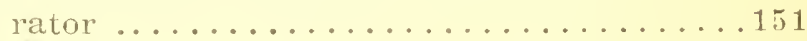

VII Threshing with a Specially Equipper? Sepa-

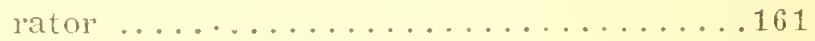

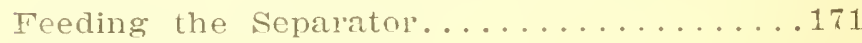

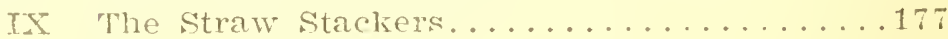

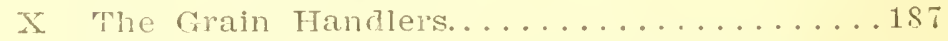

XI Lubrication and Care of the separator. . . . 195

XII The Belting of a Separator.................. 01

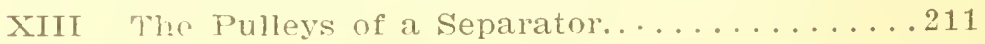

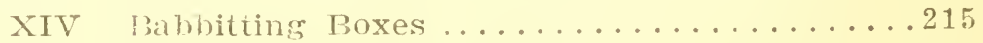

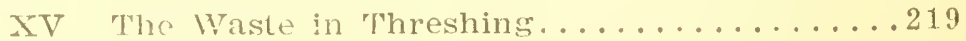


Tig. 1 Left Side Elevation of "Case" Traction Engine..... s

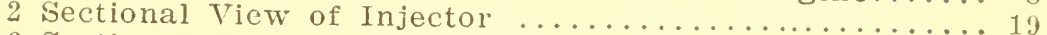

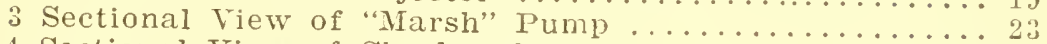

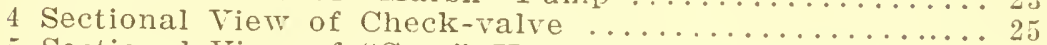

5 Sectional View of "Case" Heater .........................

6 Sectional View of Fire-box for Burning Straw.......... 32

7 Top or Plan-riew of "Case" Traction Engine........... 34

S Sectional View of "Ideal" Cup.........................

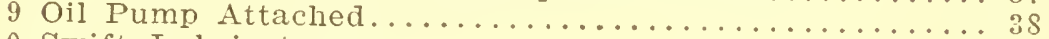

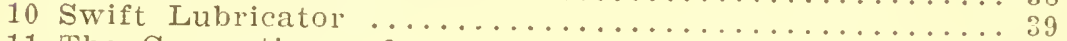

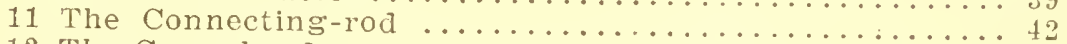

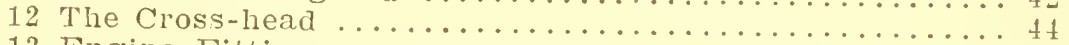

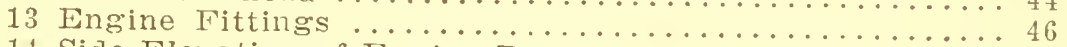

14 Side Eleration of Engine Proper......................... 53

15 Sectional View of Simple Cylinder.................. 54

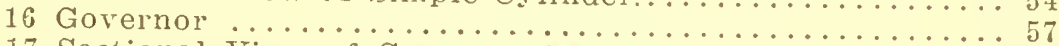

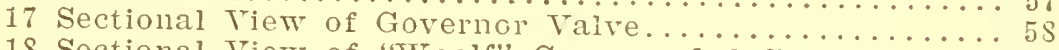

18 Sectional View of "Toulf" Compounded Cylinder....... 64

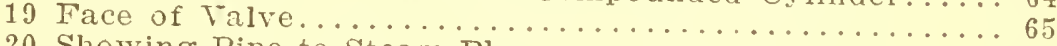

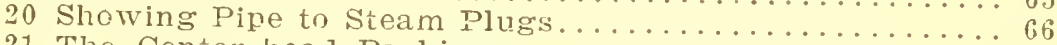

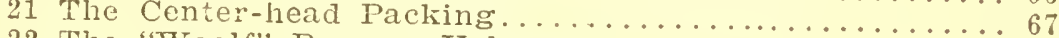

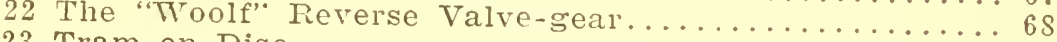

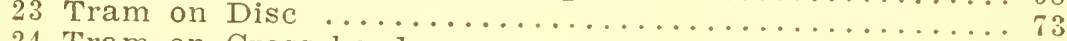

24 Tram on Cross-head ... .......................

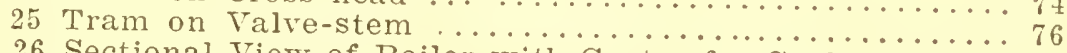

26 Sectional View of Boiler with Grates for Coal or Wood. St

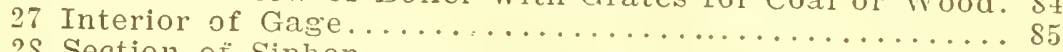

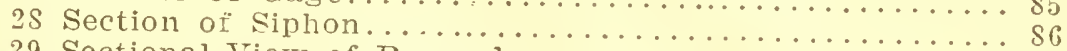

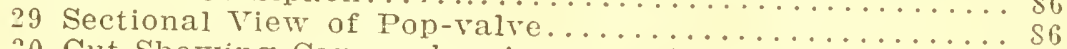

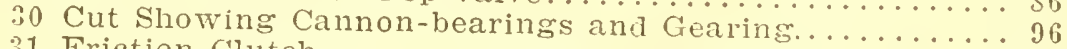

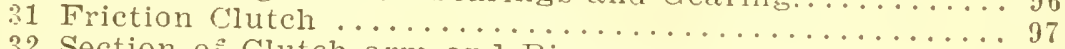

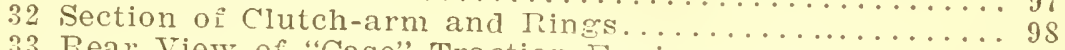

33 Rear View of "Case" Traction Engine...................... 99

34 the Differential Gear, Showing Springs.................... . . . .

35 Top View of Power with Sweeps and Equalizer Attached.103

36 Sectional View of 12 and $1 \mathrm{f}$ Horse Iron-frame Power..117

37 Sectional View of "Case" Separator ....................... 320

38 Right Side of Separator with Common Stacker...........

.10 Right Side of Geared Separator

t1 Shoe Showing Position of Sieve-rods Tind Staclier.....111

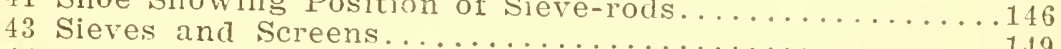

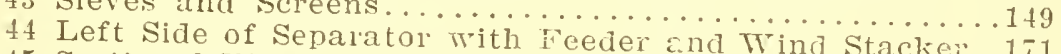

45 Sectional View of "Case" Feeder........ Wind Stacken..171

46 Right Side of Separator with Feeder and Wind Stacler. 17

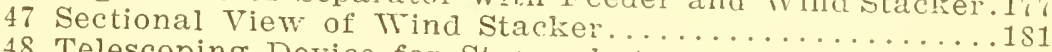

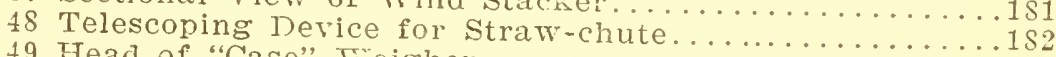

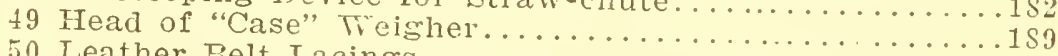

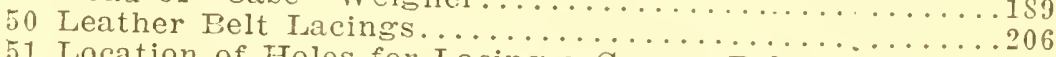

51 Location of Holes for Lacing a Canvas Belt................ 207

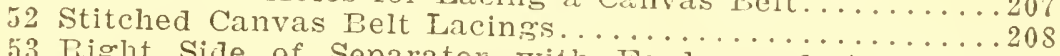

53 Right Side of Separator with Feeder and Attached

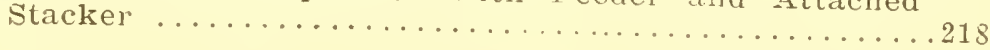



PART I. ENGINES.

[- $-1 .$. 


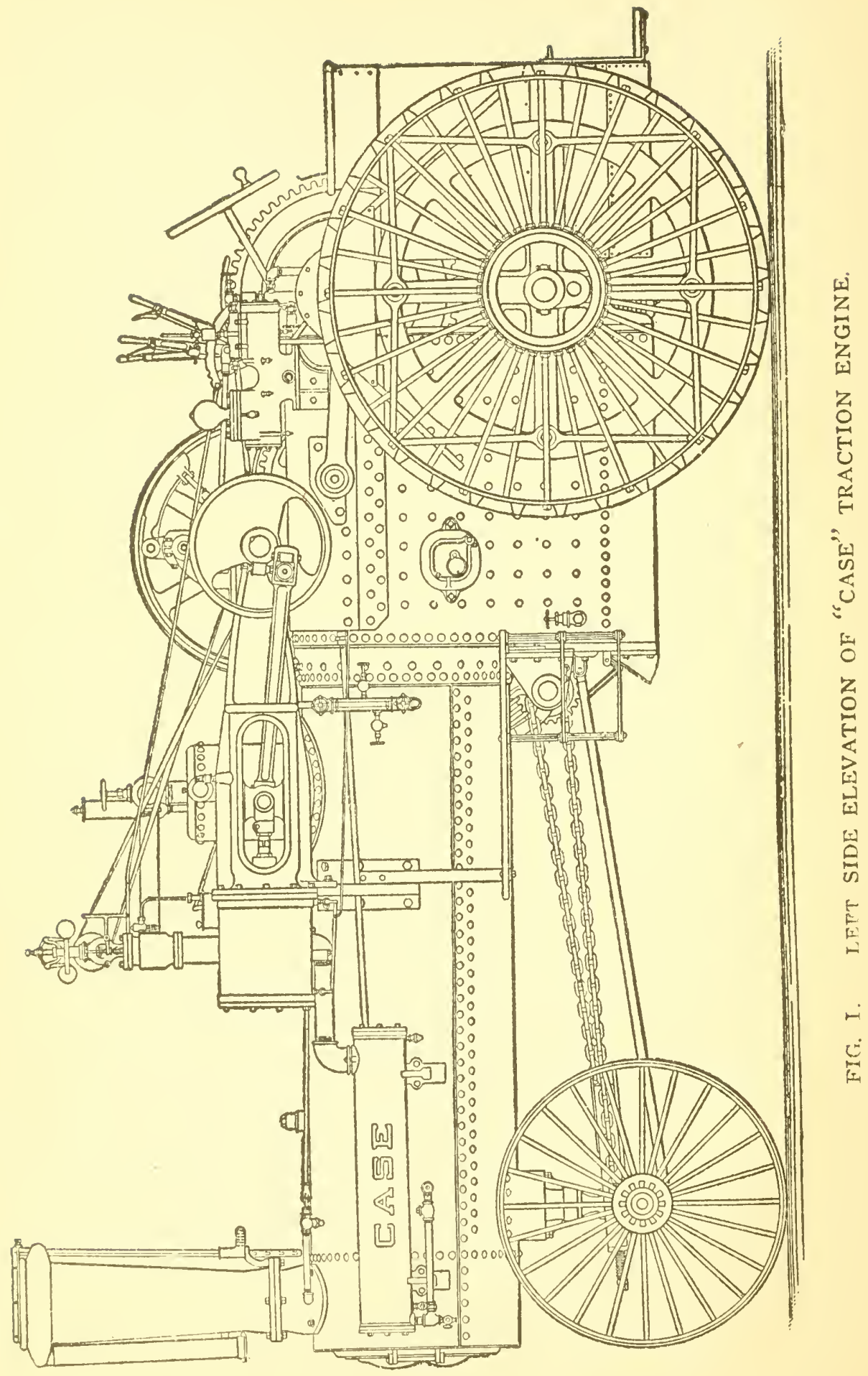




\section{CHAPTER I.}

\section{FITTING UP AND STARTING A NEW ENGINE.}

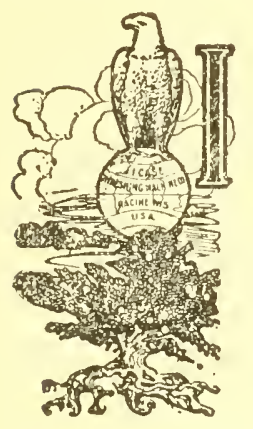

$\mathrm{N}$ packing an engine for shipment it is usual to remove the brass fittings to prevent their being stolen. These, together with the hose, governor belt and wrenches are packed in a box. The rod for the flue scraper (and the straw fork, for straw burning boiler), are placed in the boiler tubes and the funnel for filling the boiler is placed in the smoke-box. The fire-box, ash-pan, tubes and smoke-box should be examined to insure the removal of all loose parts before the fire is started.

Attaching Brass Fittings. In attaching the fittings to the boiler, care should be taken to screw them in tightly enough to prevent leaking. Brass expands more with heat than iron, therefore where a brass fitting screws into iron, the joint will be tighter when hot than when cold: consequently should there be a leakage it should be stopped by screwing the fitting in a little further when cold. In screwing a pipe into a valve or other fitting, the wrench should be used on the end of the valve into which the pipe is being screwed. When the wrench is put on the opposite end, the valve is subjected to a twisting strain that is very liable to distort and ruin it. The blow-off valve and other valves about the engine 
should be so attached that the pressure will be on the under side of the valve seat. Then the packing around the valve stem can leak only when the valve is open, and may be renewed at any time the valve is shut. A valve should not be too tightly closed when cold as expansion due to heating will force the valve so hard against its seat as to injure it.

Starting the Firc. When the fittings are all in place, fill the boiler with water, by means of the fumnel, until the glass gage shows about an inch and one-half of water. This is on the assumption that the boiler is level and if not, allowance should be made accordingly. The water will rum in faster if one of the gage-cocks, the blower or the whistle be opened to allow the air to escape. The boiler being filled, the funnel may be removed and the filler plug replaced. When coal is used as fuel, wood should be used to start the fire, the fire-box being kept full until steam begins to show on the gage. Then, if it be desired to hasten the rise of steam, the blower may be started and coal thrown onto the fire.

Oiling the Engine. While waiting for steam, the dope may be removed from the bright work with rags or cotton waste, saturated with benzine or kerosene. The oil holes and cups are usually filled with grease at the factory to keep out cinders and dirt during shipment of the engine. This grease should be removed, so that the oil may reach the place it is intended to lubricate. All the bearings should be oiled, the oil cups being filled with good machine oil. Where 
the oil box is large enough, it should be filled with a little wool or cotton waste in order to keep out the dirt, and to retain the oil. Good cylinder oil must be used in the lubricator or oil pump.

Starting the Engine Proper. When the gage shows about forty pounds of steam, the cylinder cocks should be opened and the engine started, the throttle being opened gradually so that the water which has condensed and collected in the cylinder may have a chance to escape. The reverse lever should be handled as explained elsewhere in this book. If the engine does not start when the throttle is opened, possibly the governor stem has been screwed down sufficiently to shut off the steam. This sometimes occurs in transportation. As soon as the engine is running, care should be taken to see that the lubricator is started properly. The bearings should be felt of to determine any tendency to heat. The pump and injector should next be tried to see that they are in working order.

The steam pressure should now be raised to the blowing off point, which is usually Izo pounds, to try the pop or safety valve. If it does not open at this pressure, pulling the lever will probably start it. If not, it is out of adjustment and should be re-set, as explained elsewhere in this book.

Starting the Traction Parts. When the engine has been run a sufficient time to insure everything being in good running order (if it be a traction engine), preparations may 
be made for a trip on the road. To do this, the trunnion-ring of the friction-clutch should be oiled and the shoes adjusted to properly engage the rim of the fly-wheel. Any paint that may be on the long hub of the arm should be scraped off to allow the free movement of the ring, which slides thereon, as the clutch is thrown in or out of engagement. All the traction gearing should now be greased, and a quantity of oil poured into the cannon-bearings. Next the stud of the intermediate gear, the bevel pinions of the differential gear, and the bearings of the steering-roller and hand-wheel shaft should be oiled. The steering-chains should be properly adjusted as elsewhere explained.

Cantion. A new engine should have close attention for the first few days until the bearings become smooth. The engine has been run in the testing-room at the factory, and it is probable that the bearings are properly adjusted. However, they should be felt of at short intervals, and should one of them heat to any extent, it will be best to loosen it a little. A fast run should not be attempted the first two or three trips on the road, but the engine should be allowed to run below its normal speed until bearings are smooth and the operator becomes accustomed to handling the engine. During the first few days, it is necessary to use three or four pints of cylinder oil in ten hours in order to keep the valve and cylinder well lubricated. Afterwards the amount may be lessened, but it is essential that cylinder oil be fed continually. 


\section{CHAPTER II. \\ THE FEED WATER.}

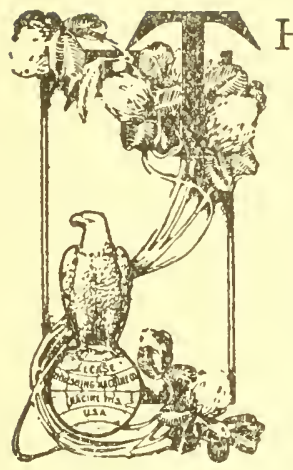

$\mathrm{HE}$ feed water demands the constant watchfulness of the engineer. It is his first and most important duty to know that there is sufficient water in the boiler at all times. If he relaxes his attention to it for even a short interval, disastrous results are likely to follow. A modern traction engine is usually fitted with two separate and independent means of feeding water to the boiler. By this arrangement, if the boiler feeder in use be disabled at any time, the other may be put to work without delay. These feeders should receive close attention and each be in condition to work at a moment's notice. If either fails to work properly at any time, it should be repaired immediately. It is essential to use the cleanest water obtainable, as dirty water always causes trouble. It is a good plan to strain the water as it passes into the mounted tank, by placing a cotton grain sack in the hole so that it extends to the botton of the tank. For this purpose a cheap sack of coarse open texture is the best. The mouth of the bag can be turned over the rim around the hole and tied with a string or strap, but a better way is to have a hoop that just fits over the bag. It is 
important to see that the suction hose and connections are free from leaks. The pipe nipples, which screw into the boiler at the point at which the feed water enters, should be examined occasionally, for with some waters they "lime-up" in a remarkably short time. When necessary to shut down from lack of water, it should be done while the glass shows at least half an inch, as the water-level will fall that much when the engine is stopped, and the water in the boiler allowed to settle.

What to do when water does not show in glass. If you find that the water has been allowed to get below the glass gage and lower gage cock, leaving the crown-sheet bare, when the engine has been standing still for a time, bank the fire and leave the engine alone until it cools. If it be working when you discover the water is out of the glass, the thing to do, is get the front end of the engine up at once. Back the traction wheels into ditch or furrow, run the front wheels up hill or onto a wood or coal pile, or use any means to get the front of the boiler high. If in soft ground there may be time to dig holes for the traction wheels, but be quick about it. In the meantime keep the engine moving in order to slosh the water over the crown-sheet. When you have the front end of the engine up, if water shows in the glass, start the injector and let it run until the boiler is filled to its normal level. If you are unable to get the engine in such a position that the water shows in the glass, cover the fire with a laver of ashes $\mathrm{O}^{*}$ earth three or four inches thick. 
Do not attempt to pull it out, as stirring it up creates intense heat. Having banked the fire, leave the engine alone until the steam goes down. By doing this, you have probably prevented the fusible plug from melting, or, what is vastly more serions, burning the crown-sheet. A crown-sheet that has been burnt is greatly weakened, probably "bagged" or warped, and the stay-bolts so strained at their threads that it is impossible to keep them from leaking. The majority of explosions of boilers of the locomotive type are caused by low water and the consequent burning of the crown-sheet. One experience with low water should be a sufficient lesson for all time.

Since so much depends upon having sufficient water in the boiler, the gage-cocks and water-glass, which indicate the amount of water, should be kept in first-class order.

The Gage-Cocks. These cocks are a more reliable means of indicating the amount of water in the boiler than the water-glass, although not so convenient. The gagecocks, or "try-cocks," as they are sometimes called, should be used often enough to prevent them from beconing filled with lime and should always be in working order. Whenever opened, the steam should be allowed to blow through a sufficient time to clean them. They should then be closed moderately tight, and then, if they leak, they should be opened again to allow any dirt or scale that may have lodged on the seat to blow out. It is not well to force a gage-cock or other valve shut to stop it from leaking, for probabiy it 
is leaking because a bit of scale is preventing the valve from "seating." The forcing simply presses this bit of scale or other foreign matter into the seat and spoils the contact surfaces so the valve will continute to leak until reground. Gage-cocks and other valves on the engine should not be closed very tightly when cold, for when heated, the expansion of the metal will press the valve so tightly against its seat as to injure it.

The Water-Gage. The water-gage should be blown out once each day, to clean the glass and prevent the upper and lower connections from getting filled with lime or sediment. To blow out the lower connection, which is the more liable to become clogged, open pet cock and close upper valve. Then close lower valve and open upper one, which will blow steam through the upper connection and also the glass, thereby cleaning it. On returning to the engine in the morning, or after dinner, be sure that no one has closed the valves of the water-gage during your absence. If this has been done, the glass might show plenty of water, while in reality, the water in the boiler has been reduced to a low level by blowing off or by some other cause. A stoppage in the valves, when the engine is running, can be detected by the water, which will appear quite still instead of moving a little, in consequence of the motion of the engine. The water glass should be kept clean, even if the other parts of the engine be neglected in this respect. A dirty glass indicates that the engineer is careless about one 
of his most important duties. The glass can be cleaned at any time by wiping the outside and blowing steam through the inside. It is only necessary, in wiping, to see that it is not scratched by sand or the like, for scratches are likely to cause it to break. An old glass with a coating on the insicle that steam will not blow out, may be cleaned by removing it from the connections and running a piece of waste or cloth through it with a stick. Tonching a glass on the inside with a piece of metal of any kind is almost sure to scratch it so that it will crack when the steam is turned on.

Packing the Watcr-Glass. The best method of packing the water glass is by means of the rubber gaskets made for the purpose. These may be purchased for a few cents. Candle wicking, hemp or asbestos is sometimes used, but any of these packings is liable to become displaced and cause trouble. The atthor has in mind a case in which a crown sheet was badly burnt on account of the glass not showing the true level of the water in the boiler, because the candle wicking, with which it was packed, was forced, by the tightening of the packing-1nut, over the lower end of the glass, practically shutting off the water.

Broken Water-Glass. In case the water glass breaks when the boiler is under pressure, shut both valves to stop the escape of steam and water. The engine can be run by gage-cocks until a new glass may be obtained. If a new glass be at hand, it may be put in at once, but care should be taken to heat it gradually, for if the steam be turned on suddenly, it will break. 
Injectors. The injector has, of late years, reached such a state of perfection as to make it the most convenient of all the types of boiler feeders. Although economical in itself, it does not equal, in economy, a pump used in connection with a heater. The question naturally arises: if it be economy to use a heater in connection with the pump, why not with the injector as well? IVere the feed water from the injector piped through the heater, but little would be gained thereby, because the injector delivers water so hot, that it would absorb hut little additional heat during its passage through the heater. Consequently, the pump, with heater, is the more economical because it utilizes heat from the engine exhaust (which would otherwise be wasted), to heat the water, while the injector heats it by means of live steam taken from the boiler. It is not usual, therefore, to pipe the feed water from an injector through a heater.

To Start the "Penbcrthy" Injector. With pressure under sixty-five pounds, the valve in the suction pipe should be opened one turn, the steam valve may then be opened wide. The injector will probably start off at once, but should water run from the overflow, the suction valve should be slowly throttled until it "picks up." If hot steam and water issue from the overflow, the suction should be opened wider. A little practice will enable one to set the valve at any pressure, so that it is simply necessary to turn on the steam to start the injector. At a pressure of sixty-five pounds or over, the water supply valve may be opened wide, but it is better partly to close it, as the injector will deliver hotter water 
when the supply is throttled. The injector must be regulated by the suction valve, and not by attempting to regulate it by the stean valve. The "Penberthy" admits of considerable steam variation. At thirty-five pounds steam pressure, the valve in suction may be opened as wide as it will stand and steam can rise to over one hundred pounds without further adjusting.

What to do rehen the Injector Fails to Work. See that the suction hose and connections are tight. The delivery pipe nay be "limed up" where it enters the boiler. A leaky check valve will keep the injector so hot as to prevent it from "picking up" water. Dirt may be lodged in the

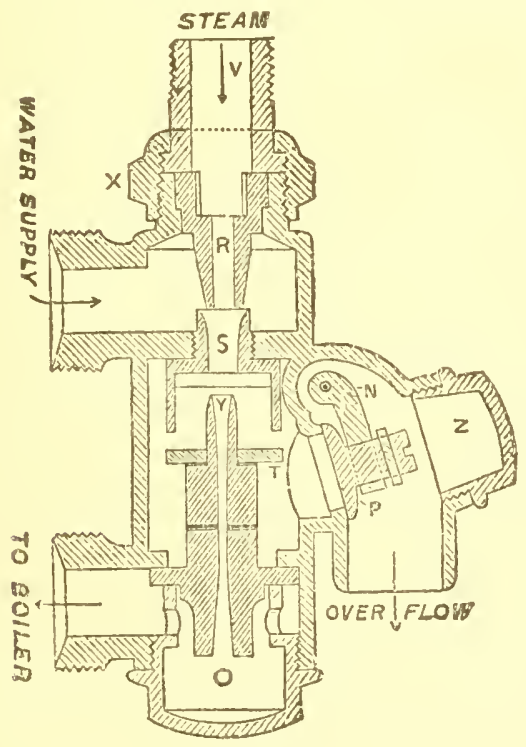

FIG. 2. chamber where jets " $\mathrm{R}$ " and " $\mathrm{S}$ " meet, or in the jet "Y," the drill holes or the min passage way. The jets may be coated with lime, and if so, they should be soaked in a solution composed of one part of muriatic acid to ten parts of water. Occasionally soak the whole injector. Do not expect an injector to work well, especially at high pressure, if the tank be full SECTIONAL View OF INJECTOR. of dirt and rubbish. Sometimes an injector will work well for a long time, and then begin to drizzle at the overflow under the same pressures 
at which it once worked well. This indicates that the passage-ways in jets are either worn or are contracted with lime. If removing the lime does not remedy the trouble, the overflow valve may leak. To regrind it, remove cap " $Z$ " and spread a little flour of emery, mixed with oil or soap, between the valve "P" and its seat. Then with a screw driver, turn valve " $\mathrm{P}$ " back and forth, which will grind it to a seat. If the injector be not improved, it is safe to conclude that some of the jets are woin and must be renewed. These are sold separately, and are listed in threshermen's supply catalogs. If in doubt as to which jet is at fault, procure all of them and try one after another until the injector works properly. Any unused jets may be returned.

Independent Pumps. This is the name given to pumps for feeding a boiler, which are operated independently of the engine. They are, in fact, small engines in themselves, connected directly to double-acting pump plungers. An independent pump can be run whether the engine is running or not, but as the heater is effective only when the engine is running; it is best, on boilers having both pump and injector to use the injector when the engine is not running. The Marsh pump has an exhaust valve for turning the exhaust of the pump in with the feed water. This, of course, heats the feed water and renders the pump more economical. If, for any reason, it is desired to use the pump when the engine is not running, the exhaust should be turned in, to prevent putting cold water into the boiler. At other times, however, 
we advise engineers to allow the pump to exlaust into the air. The most of the trouble with these pumps is due to insufficient lubrication, and the successful operators use plenty of cylinder oil. If the exhaust be turned in at all times, this cylinder oil is carried into the boiler where it accumulates, in some cases in sufficient quantities to render it dangerous to the plates of the boiler. Conseguently, for this reason and also because the pump is more easily "kept up" when exhausting in the air, we do not advise turning the exhaust into the feed water.

Starting the "Marsh" Pump. Before attaching the lubricator, it is a good plan to pour some cylinder oil into the pipe. To start the pump, first see that the valve in the feed pipe, between the check valve and the boiler, is open, and that the exhaust lever is thrown towards the steam end of the pump. The steam may now be turned on, and if the piston rod does not move back and forth, tap the starter-pins very lightly. It is well to rum the pump without water until thoroughly oiled, but as soon as it is running smoethly, the suction may be opened. Opening the cock with the thread for attaching the sprinkling hose or the small air-cock in the water chamber will aid the pump in "picking up" water.

When the Pump Will Not Start. I. If the pump does not start when steam is turned on, push the starter-pins alternately, to see if the valve moves easily back and forth. If the valve sticks, do not hanmer the starter-pins or force them too hard, but remove the valve in order to locate the 
trouble. This is done by removing the steam chest heads through which the starter-pins pass, and unscrewing the valve, which is done by holding one end while unscrewing the other, by means of the two special socket wrenches furnished for the purpose. If the pump has been idle for a time, the valve may be rusty or gummy, in which case it should be cleaned with kerosene oil. Before replacing the caps, push the valve back and forth as far as it will go and see that it is perfectly free. Also see that the starter-pins are free and are not stuck by tight packing or have become loosened. Pull them out as far as they will go. 2. The steam pipe may be obstructed so that the pump does not receive a sufficient supply of steam. A screen gasket is placed in the steam pipe union in order to prevent scale or chips, in a newly connected pipe, from reaching the pump. If steam does not reach the pump, this screen should be examined as it may be partly or entirely clogged. When the pipe has been thoroughly blown out, this screen gasket may be removed and a plain rubber or lead gasket used. 3. Remove the cylinder heads and see that the piston moves freely, and that the nut on the water end of the piston rod is properly tightened. This nut may have worked partly or entirely of:, thus preventing a complete stroke. 4. Remove the steam chest and see that the small "trip" holes near the steam chest and the corresponding holes in the steam cylinder are open. If the pump has been idle for a time, these holes are liable to have become stopper with rust. Before 
replacing the steam chest, see that the packing is in good order. 5 If the pump has been in use some time, or has not been sufficiently oiled, the valve may have become worn and leaky. This is not so likely to occur on the "C" size, as on the smaller pumps. When it does happen, the remedy is a new valve and steam chest.

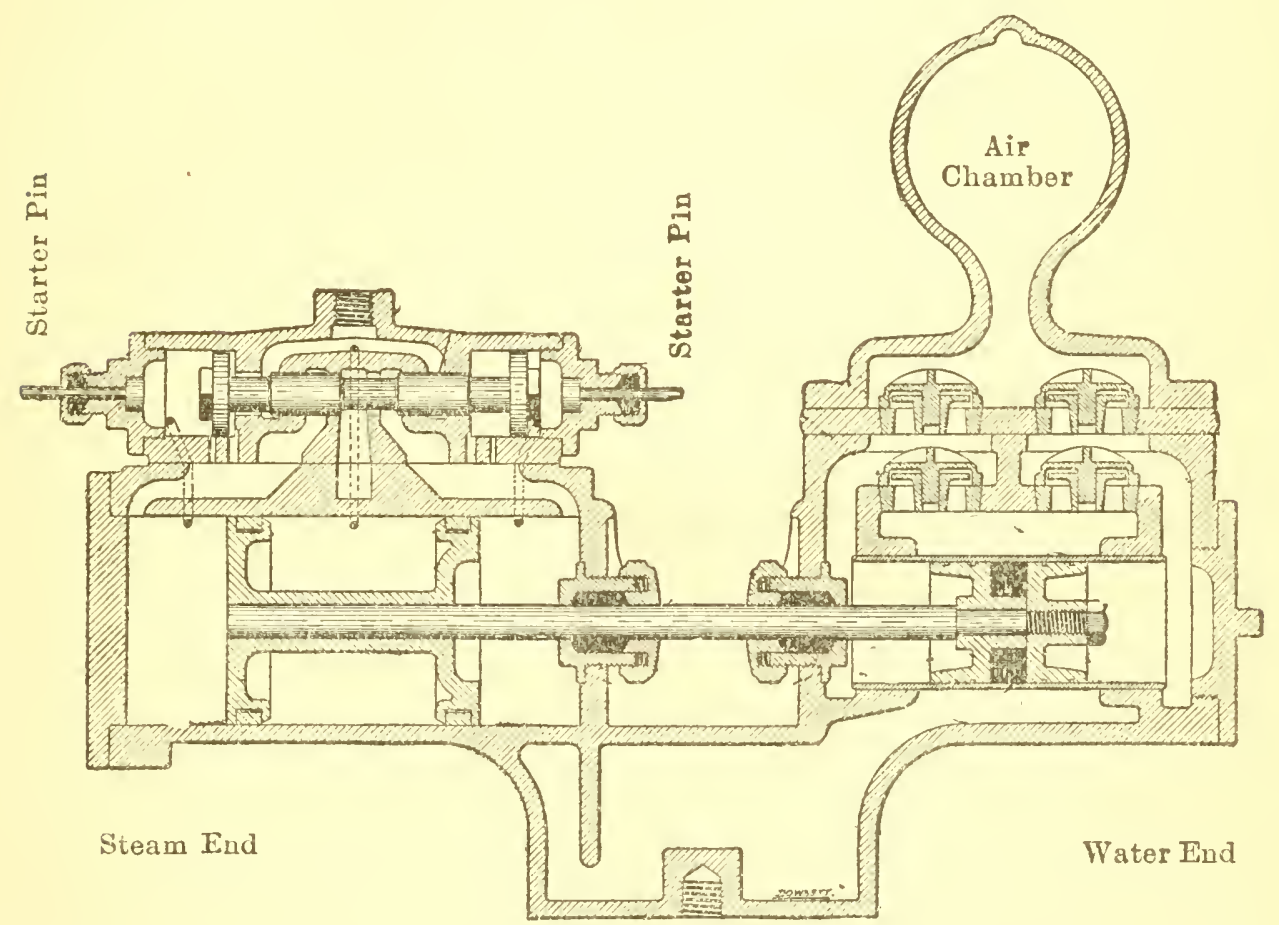

FIG. 3. SECTIONAL IIEN OF MARSH PUMP.

Whon the Pump will not Lift Water. If the pump runs all right when steam is turned on, but will not "pick up" water, opening the drain cock in the boiler feed pipe will relieve the pressure on the discharge valves. I. See that the suction hose and its connections are free from leaks and that the screen is not covered with rags, waste, leaves or the 
1ike. If this hose has been in use for some time, see that it is sufficiently firm not to collapse or flatten, and that its rubber lining has not become loosened so as to choke or stop the water supply. 2. Remove the air chamber and look for dirt muler the water valves. 3. If the pump has been in use for a time the water-piston packing may leak. Where dirty water is used, this packing must be frequently renewed. Directions for re-packing are given below.

IThen the Pump almost stops after lifting water, the trouble is in the delivery or feed pipe. Opening the cock in this pipe will relieve the pressure and allow the pump to run faster. Possibly the angle valve near the boiler has been left closed. The check valve in the feed pipe should be examined, for which purpose the angle valve, between it and the boiler, can be closed. If nothing be found, the stem should be removed from this angle valve, and probably the pipe will be found nearly filled with lime at the point at which it enters the boiler. This may be cleaned by driving a bolt into it. Of course, the angle valve stem can only be removed when the boiler is cold.

Packing the Pump. The successful operation of this pump depents very much upon the manner in which it is packer. In renewing the water piston packing, do not compress the packing too mutch. It should be reduced, if too thick. When properly packed, the piston may be readily moved by hand. The n11t on the end of the piston rod slonkl be tiohtencel to bring the follower to place. The 
packing between the steam chest and the cylinder should be made of heavy manilla paper or light rubber, and must be patterned from the planed surface top of the steam cylinder, (not the lower part of the chest), and all holes must be carefully duplicated, so that the drilled holes at each end are wholly unobstructed at their points of register with the corresponding holes in the chest. The packing under the valve plate must be patterned from the faced top of water cylinder, and the packing orer the valie plate from the bottom face of the air chamber. The steam cylinder head must not be packed with anything thicker than heavy paper or the thinnest rubber. If a thick gasket be used, the piston will overrun the ports, and its operation be interfered with.

Check-Valies. A check-valve allows the water or other fluid to flow in one direction, by raising the valve from its seat, but when water attempts to "back up," or flow in

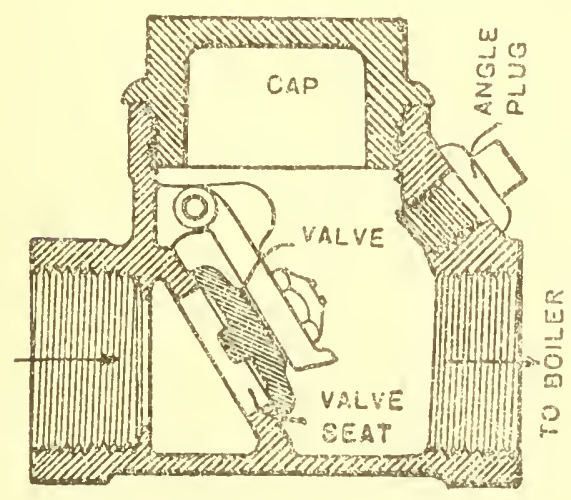

FIG. 4 .

SECTIONAL VIEW OF CHECK-VALVE. the opposite direction, the valve prevents this by closing. With any style of boiler-feeder, a check-valve is placed in the feed-pipe, and usually near the boiler. Between the check-valve and boiler is placed a globe or angle valve which may be closed, allowing the check valve to be opened 
when the boiler is muler steam pressure. If the pump or injector shows, by heat or other indications, that water and steam are "backing up" through the feed pipes from the boiler, it indicates that the check-valve is not acting. When the valve "sticks" and will not close, a very slight tap may" cause it to "seat," but if this does not, close the valve between it and boiler, then take off the cap and remove dirt or scale that may be preventing it from closing tightly. If no forejgn matter be found, exanine the valve and seat to determine if the contact surfaces be perfect. If scale be found arlhering to either. it should be removed, but if it be "pitted," regrinding is necessary. Although a slight tap will often cause a check-valve to seat, it is poor practice to constantly or violently hammer the valve, as the seat may be distorted, and the entire valve ruined thereby. Many valves are also distorted and ruined because a wrench has been used on one end while screwing a pipe into the other. Many valves are burst during cold weather by frost. To prevent this, the angle vaive near boiler must be closed and the check-valve and pipe drained.

Regrinding Check-T alz's. Many engineers discard leaky valves as worthless, in ignorance of the ease with which they may be re-ground. The swing check is easily re-ground withont disconnecting it from the pipe. To regrind, unscrew angle plug, put a little flour of emery, mixed with oil or soap. on the hottom of valve and turn it back and forth with a screw driver until the contact surfaces are perfect. 
Fecd-IVatcr Heatcrs. A feed-water heater heats the feed water delivered by the pump, by passing it through pipes surrounded by exhanst steam from the engine. In this way, the feed water carries into the boiler the heat it has absorbed from the exhaust steam, and which would otherwise be wasted. The interior of the "Case" heater is shown in the accompanying sectional view. Tubes (A), (three or more in number), are tightly calked in the inner heads (B). Gas pipes (C) pass through the tubes, their ends being held in place by sockets cast on the outer heads. The outer heads are secured by four stud bolts, which screw into the heater

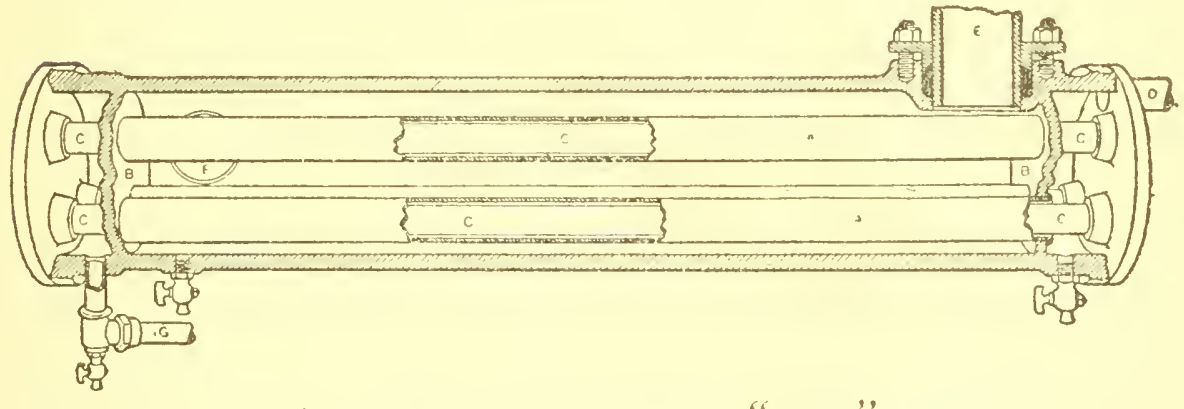

Fig. 5. SECTIONAL VIEW OF "CASE" HEATER.

body, and are made tight by gaskets. The exhaust from the engine enters the heater at E, surrounding the tubes, and passing out at $F$. The water from the pump enters through the head at D, passes out at the other end and into the pipe $G$ to the boiler. In going through the heater, the water is obliged to pass througin the annular spaces, formed by the inside of tubes and the outside of gas pipes, in films about one-eighth of an inch thick. Two cocks are screwed into the bottom of the heater, one of which 
drains the steam space and the other the water space. The steam space may be drained before starting the engine, in order to prevent water from being thrown from the smoke stack. Both water and steam spaces must be drained in cold weather, to prevent freezing.

Testing and Repairing the Heater. If you suspect that the heater leaks, it may be tested by opening cock farthest from the end, letting all the condensed exhaust escape. Next start the pump, but let the engine stand still. If water issues from this cock, it shows that the heater leaks. Repairs are easily made by removing the heads. The tubes may be tightened, or renewed, if necessary, in exactly the same manner as those in the boiler. 


\section{CHAPTER III.}

\section{FIRING WTTH VARIOUS FUEIS.}

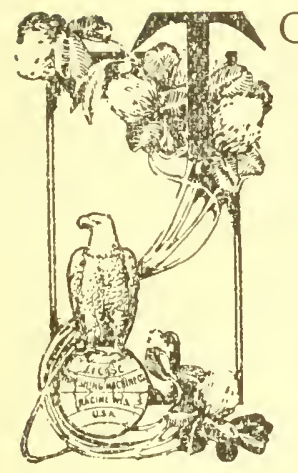

maintain a uniform steam pressure with any kind of fuel, the draft should be sufficient and the fire should be supplied with air from below. No cold air should be allowed to get to the tubes except by passing through live coals that may ignite fresh fuel. The cone screen in the stack should be straight and the exhaust nozzle should be pointed straight with the stack. This latter is of great importance.

With any kind of fuel, the ash pan must not be allowed to fill up, or warped and melted grates are sure to result. There is no excuse for allowing the ash pan to fill up, and a good engineer never permits it to do so.

Firing with Coal. Keep the grates well covered, but with as thin a fire as possible. Do not throw in large lumps of coal or put in very much at a time. A thin fire lightly and frequently renewed is the most economical. The engine should be allowed to blow off once a day to see if the steam gage and pop valve agree, but if the pop valve frequently opens, it is an indication that the freman is either careless or unable to control his fire.

The best way to check the rise of steam is to start the 
injector, but if the boiler be too full, the damper may be closed. Another way is to open the fire door an inch, leaving the damper open, but the door should never be hald open more than this amount. This will do no harm to tubes or boiler, but never open the door and close the damper at the same time, when the engine is running. When the engine is to be shut down for any length of time the smokebox door may be opened to check the fire.

Some grades of coal will form clinkers that cover the grates and shut off the air supply. These must be kept out by removing through the fire door, but do not use the poker when it can be avoided, or keep the door open longer than is necessary. When troubled with clinkers, make it a point to clean the fire at noon or at any time the engine may he stopped. The tubes slionld be cleaned at least once a day.

One or two of the bricks for straw burners can be used to advantage in buming coal. They make better combustion with poor coal, render the fire easier to control and by maintaining a more uniform heat in the fire-box, are easicr on the boiler.

Firing with Wood. The manner of firing with wood depends entirely upon the fuel, and must be learned by experience. When the wood is soft, or the sticks small or crooked, it will be necessary to lay the pieces as compactly as possible, and keep the fire-box full all the time. Straight, heavy sticks of hardwood, on the other hand, must be placed 
so that the flames can pass freely between them. The rear draft door should be opened wide and the front one opened only enough to adnit sufficient air. See that the front end of the grates (next to the tube sheet) is kept well covered. If cold air be allowed to pass through to the tubes at this point, the draft will be destroyed. To get satisfactory results, it is often necessary to cover the front end of the grates, for a space of eight inches, with a "dead-plate." A wood fire requires an occasional "knocking-down," but as with coal it is a good plan not to use the poker more than is absolutely necessary. In "knocking-down" do not disturb the hot coals on the grates. In firing with wood it is advisable to keep the screen in the smoke-stack down as there is more danger of setting fire with wood than with coal.

Firing with Straw. Modern "Case" straw burning engines are all of the direct flue type. They are the same as the coal burners, except that they are fitted with straw grates, dead-plates, a brick arch and a straw chute and the boiler is lagged. (See Fig. 6.) Any "Case" side-crank spring-mounted engine, except the Nine-Horse, can be made to burn straw by making these changes.

When firing with straw, keep the chute full all the time, so that no cold air can get in on top of the fire. Take small forkfuls and let each bunch of straw push the preceding one into the fire. Occasionally turn the fork over and run it in below the straw in the chute to break down and level up the fire. Three grates, spaced equally across the fire bc: are 
better than more. Keep about fifteen inches of the front of the ash pan clean, to allow plenty of draft, but let ashes

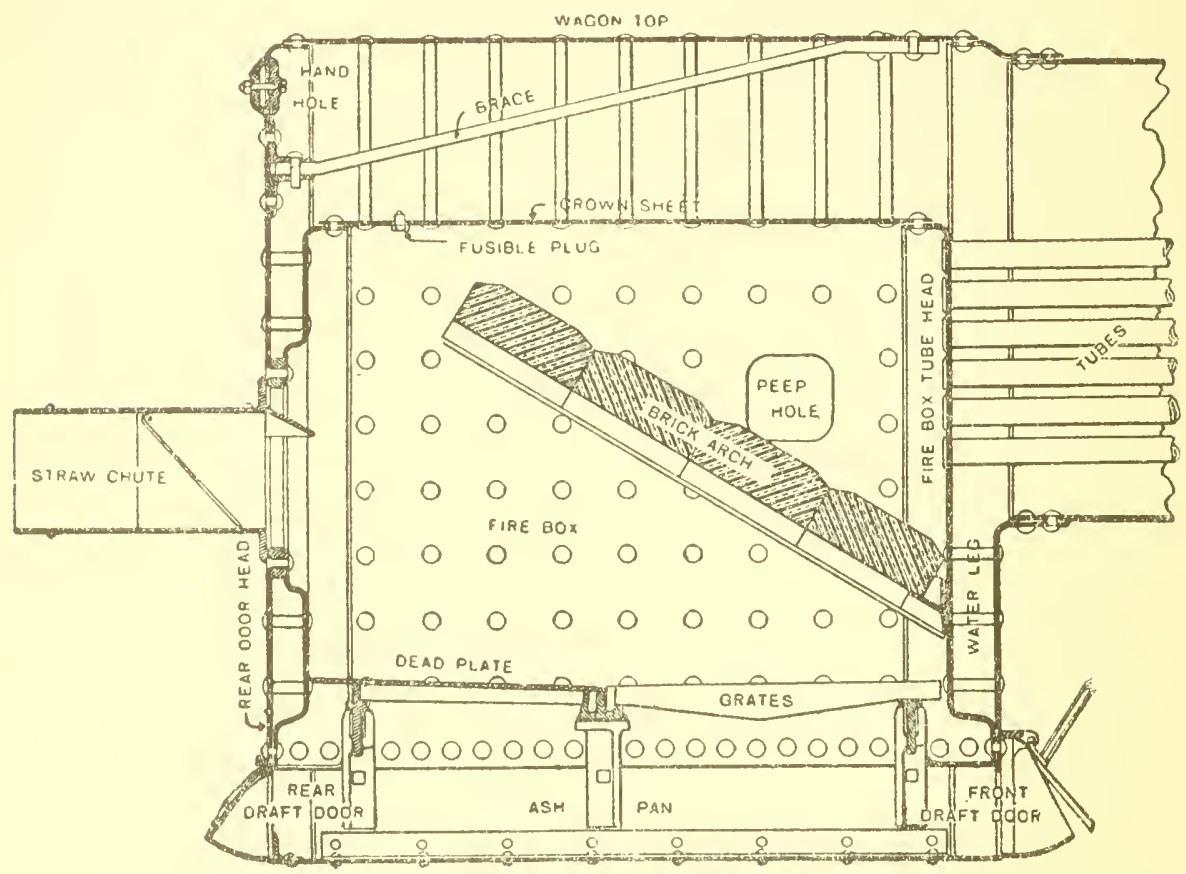

FIG. 6. SECTIONAL VIEW OF FIRE BOX FOR BURNING STRAW.

fill up in the rear part. Four bricks must be used. Keep rear riraft door shut.

The flame coming over the brick arch as seen through the peep hole should appear white hot, and should be continuous and not be stopped or checked each time the straw is prtshed in, as will he the case if fring be too heavy or too much be put in at a time. Sometimes straw, especially when damp, is pulled over against the ends of the tubes. This may be scraped off with the poker, through the peephole. The tubes should be cleaned once a day. 
The draft should be strong enough to make the fire burn freely and at a white heat. It may be necessary to reduce the exhaust nozzle to get the proper draft, but it should never be reduced more than is necessary, as back pressure reduces the power of the engine. If unburnt straw be seen coming out of the smoke-stack, it shows the exhaust nozzle is too small. Do not expect the engine to stean well when the front end of the boiler is low. The engine should be level or a little high in front. If the engine has been steamed up for some time without running, the screen in the smokestack may be so filled up as to seriously interfere with the draft.

Exhaust Nozwles. Case engines are equipped with exhaust nozzles as follows: The Nine-Horse power engines have exhaust elbows with one and one-half inch opening, and brass nozzles for reducing this to one and one-quarter, or one and one-eighth inches. The Twelve-Horse power engines have exhaust elbows with one and one-half inch opening, and nozzles for reducing this to one and threeeightlis, or one and one-quarter inches. The Fifteen and Twenty-Horse power engines have exhaust elbows with one and three-quarter inch openings, and brass nozzles for reducing this to one and one-half or one and one-quarter inches. The Twenty-five Horse power engines have exhaust elbows with two and one-quarter inch opening, and brass nozzles for reducing this to one and three-quarter or one and one-half inches. 


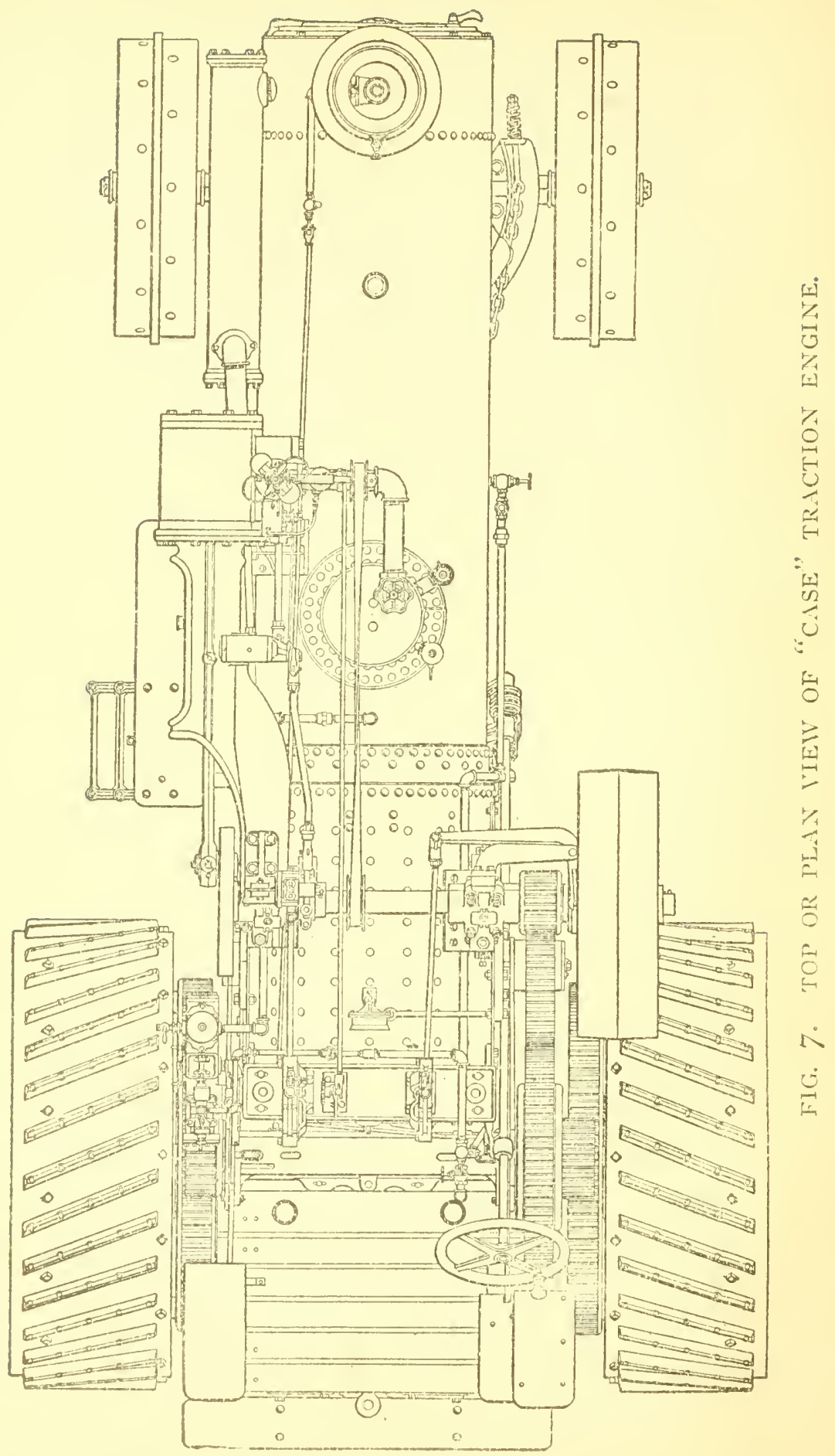




\section{CHAPTER IV.}

\section{LUBRICATION AND ADJUSTMENT OF BEARINGS.}

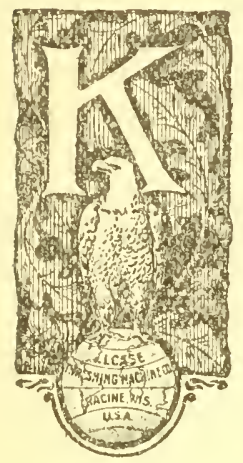

EEP the bearings of the engine well oiled if you would have it last and not cause trouble. By "well oiled" is not meant that it should be "swimming" in oil, but that its bearings should be always lubricated. It does not take very much good oil to keep a bearing properly lubricated, but you should apply it often and be sure that it reaches the place intended. Many of the oils now on the market are largely adulterated with rosin and paraffine, and, though having an excellent appearance, have poor lubricating qualities, are gummy and dry up in a short time. The oil-boxes on the crank-shaft bearings, and wherever possible elsewhere, should be filled with wool or cotton waste to retain the oil and keep out sand and grit. The covers of these oil boxes should be kept closed.

Cylinder Lubrication. Use a good quality of Valve or Cylinder Oil in the lubricator or the oil-pump, as it is very important that the piston and valve should be well lubricated with an oil that will stand the high temperatures of the steam. Do not imagine that a large quantity of cheap oil will do in the cylinder. Nothing but first-class cylinder oil will answer, and it must be used in sufficient quantities. Cylin- 
der oil is quite thick, especially in cold weather, and it is much easier to fill the lubricators if the oil be warmed and the cups heated by blowing a little steam through them. An expert is often called to an engine because of the valve being "off" when the trouble is only poor cylinder lubrication.

Hard Oil has many qualities to recommend it. It stays on the bearing, and as it wears well, a little of it will go a long way. The usual method of applying hard oil is by means of compression cups, of which the one used on the cross-head is an example. Each time the engine is stopped, the cup should be turned to take up the "slack" and force in a little grease.

Approximate Cost of Oils. The price of oil varies so greatly that no specific figures can be given. However, it may be stated that good lubricating oil cannot be purchased in quantities of five- or ten-galloin lots at less than twenty-five cents per gallon, while cylinder-oil, in like quantities, cannot be purchased ordinarily at less than fifty cents per gallon, These are minimum figures, and in localities where commodities in general are high, the retail prices of good oils may be twice as high as those quoted, or even more.

The "Ideal" Spring Grease Cup. This is a compression cup in which the hard oil is forced out by a plunger pressed down by a spring. The action of the spring is limited by a thumb screw so that only the desired amount of grease will be fed. This cup is used on the crank-pin of all Case engines. To fill, raise the plunger by screwing (lown the thumb nut as 
far as it will go. Then remove the cap, fill the cup with grease and replace the cap. Unscrewing the thumb nut will cause the spring to force some of the grease down to the journal. The size of the hole through the shank can be

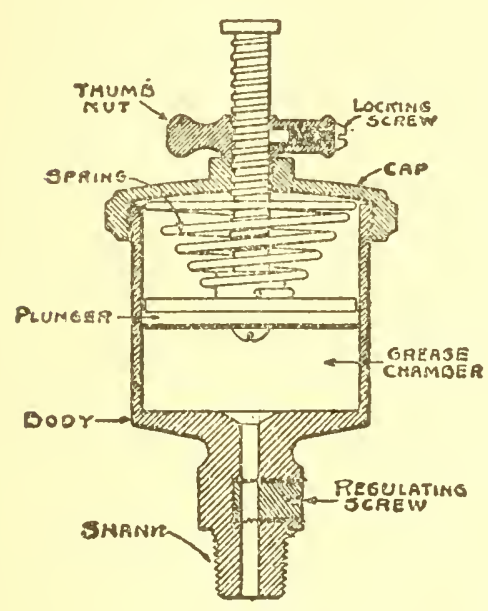

FIG. 8.

SECTIONAL VIEW OF "IDEAL" CUP. adjusted by the regulating screw, to feed the required amount of grease. The hole in the screw is in line with the slot in its head. If it be desired to stop the flow of grease, turn the thumb nut down to the cap which will relieve the spring of tension. If the plunger turns when screwing the thumb nut, it may be held by the knurled head of the screw.

To Attach Oil Pump to "Case" Engines. The body of the pump is attached to the steam chest by a stud bolt, which is located one inch from the top of the chest, and one and three-quarter inches from the back of the chest cover flange. When the hole for the stud bolt is drilled it must be tapped so that the five-eighth inch stud bolt will screw in steamtight. The rod for operating the ratchet may be attached to the rocker-arm of any "Case" simple engine. To locate the hole for the shoulder-bolt in the rocker-arm. measure five inches below the center of rocker-arm bearing, and one-half inch from the edge of the arm. This hole should be three- 
eighths inch in diameter. Compound engines, (exccpting the $25 \mathrm{H}$. P.), have a slicle in place of the rocker-arm, and on these engines the ratchet-rod is attached to the

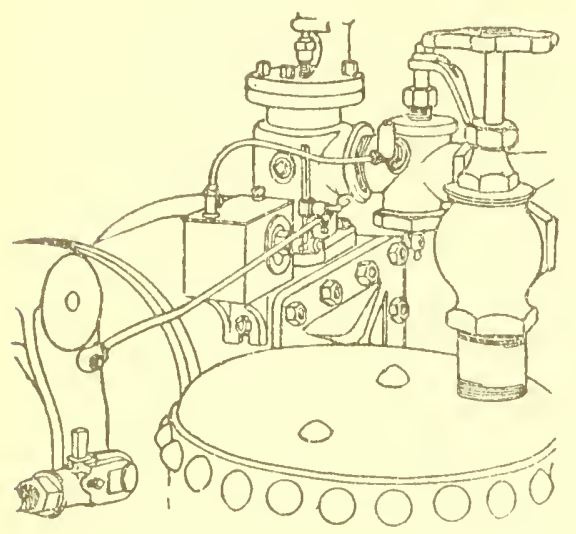

FIG. 9. OIL PUMP ATTACHED. eccentric-rod by means of a clamp, provicled for this purpose. On portable engines, the ratchet-rod must be attached to the valie slide, the three-eighth inch hole for the shoulder bolt being located two and one-half inches from the top and seven-eighths inch from the front edge of the slide. After the pump body is attached, the ratchet-rod may be placed in position, one end being on the shoulder bolt of the rocker-arm or clamp, anr, the other passing through the knuckle-joint on the sliding ratchet-arm. Having connected the ratchet-rod, screw the gravity check valve into the hole in the throttle, using a bushing to bring it to the right size. The soft one-quarter inch tubing may be bent to bring its ends in proper position in order to make the connections at the mions.

Instead of placing the oil pump on the steam chest, it may be attached to the cylinder flange of the engine frame. To do this, one of the studs must be replaced by another of sufficient length to take the lug on the bottom of the pump body. This avoids the necessity of boring a hole into the steam chest; but in all cases, it is best to have the pump-body rest 
on the steam chest, for by this method, the oil is kept warm and fluid in cold weather.

To Attach the "Sacift" Lubricator. The cylinder-oil for lubricating the cylinder and the valve should be introduced into the steam-pipe and if possible in such a manner that the oil passes through the throttle and the governor thus lubricating them. The lubricators have a litile brass pipe extending beyond the shank as shown in the cut at $H$. This pipe discharges the oil and must extend into the interior of the steam-pipe or the libricator will not work. If lost out or injured, it must be replaced. In case the lubricator does not work properly, examine this pipe.

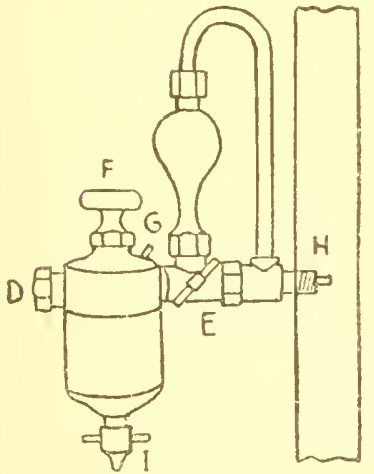

FiG. IO.

To Opcrate "Sivift" Lubricator. Close valves $\mathrm{E}$ and $\mathrm{G}$, remove cap $\mathrm{F}$ and fill the oil reservoir full of oil to the very top. Replace cap F. The bright plate that shows the sight feed should be completely covered with oil. Now open valve $E$ about one-half turn, then open valve $G$ very carefully "SIWIFT" LUBRICATOR. and drops of water will commence to roll down over the bright plate: avoid opening too wide, as a stream could be run over the plate and the oil ivasted. When the oil is nearly exhausted from the cup, water commences to show at the bottom of glass D, and gradualiy rises until it reaches the lower edge of the bright plate. The cup should then be refilled. To do this, close valves $E$ and 
$G$, open the drain and remove cap $F$ to drain the water, then close I and proceed as above. When the engine is shut down, close valve $\mathrm{G}$.

When Lubricator Fails to W Tork. If the Lubricator should become clogged from impurities in the oil, remove cap $F$ and glass D, then open valves $G$ and $E$, and the passages wiil be cleaned by steam pressure. In blowing remove cap $F$ and glass $D$, then open valves $G$ and $E$, and the passages will be cleaned by steam pressure. In blowing live steam through the Lubricator to clean out the passages, always take off the nut $\mathrm{D}$ holding the sight feed glass beforc doing so. for if this be not done, the sieam would heat the glass and render it liable to break when the oil cones in contact with it. Many cups are ruined by two causes, viz: By freezing and by straining. In cold weather the cups should be drained before leaving the engine. The valve $\mathrm{E}$ should be slightly opened, except when filling, for if left closed, the expansion of cold oil having no relief will strain the cup.

The little bright plate that shows the sight feed drops should be kept clean and bright by an occasional wiping with a little silver polish; if this be not done, it becomes tarnished and does not show the feed properly. When a glass breaks, if an extra one be not at hand, a coin may be put in and the cup run "blind feed"- until a new one is procured. A quarter is the right size for the large lubricator and a five-cent piece for the one on the pump.

Packing. The nut that hoids the sight-feed glass must 
not be screwed up too tightly. If screwing up moderately tight does not stop leakage, put in new gaskets on both sides of the glass. In repacking the sight-feed glass, first remove every particle of the old packing. Two kinds of gaskets are furnished. Put a soft rubber one next to the glass on both sides and a red fibre one next to the nut. Usually this nut can be screwed up with the fingers tight enough to prevent leaking. The valve stems may be packed with Italian hemp or candle wicking.

Adjustment of Bearings. In adjusting the bearings of the engine, take up just a little of the lost motion at a time, until the pounding is stopped. Do not attempt to take it all out at once, for in so doing there is risk of heating and cutting. The young engineer often finds it difficult to locate a "pound" in an engine, but an experienced man can usually tell where it is by taking hold of the connecting-rod or eccentric-rod as the engine runs. A good plan, and one that will often show where the trouble lies, is to have a man take hold of the fly-wheel and turn it an inch or so back and forth. By watching the crank-box, cross-head, main bearings and the reverse, any lost motion can be seen.

The Connecting-Rod Brasses are edjusted by loosening the jam nut at the bottom and turning the head of the bolt, which will raise the wedge, and crowd the two halves of the box together. When the halves of the brasses touch, they must be taken out and filed. To take out the brasses for filing, remove the connecting-rod in the following manner: 
Tum the engine so that the cross-head pin comes opposite the liole in the engine frame nearest the crank. Take off the vasher on the crank pin and remove the grease cup and the nut from the cross-head pin. Drive the cross-head pin out with a wood block, turn the engine on rear dead center, and the connecting-rod may be lifted off. Set the redges down as far as they will go, and take out the adjusting bolts.

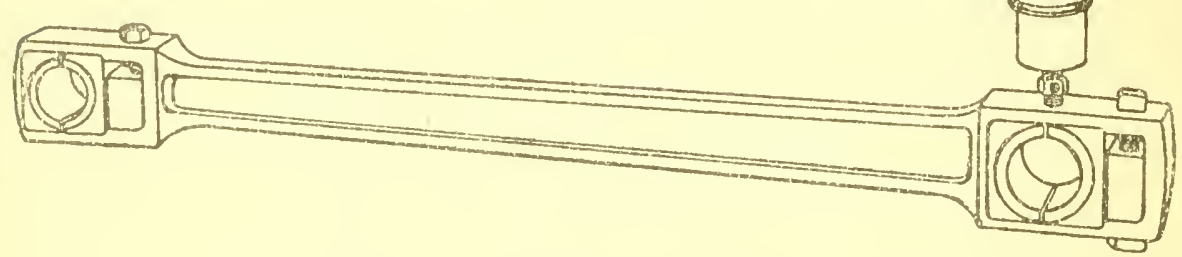

FIG. IT. THE CONNECTING-ROD.

The wedge and half of the box next to it may be diriven out from the inner side with a wood block. Before taking off the connecting-rod, make a scratch across the wedges and the ror end, so that in putting them back the wedge may be set in the same position as before.

As the pressure is nearly all endwise on the rod, the holes in the brasses will tend to wear in an oval shape. so that when the boxes are tightened, they will bind at the top and bottom, causing then to heat, while they still pound endwise. To obviate this diffeulty, the boxes should be "relieved" at the top and the bottom by filing with a half-round file. They should not touch the pin for a clistance of one-half to threequarters of an inch each side of the joint. In time, the hrasses will have worn so much that the wedge strikes against 
the top. Shims made of sheet-iron of the proper thickness must now be inserted. These should be put in on both sides of the brasses so as to not change the length of the rod, and make it necessary to re-divide the clearance.

It is best to take off the connecting-rod when the engine is cold; if it be taken off when the boiler is under steam pressure, and the throttle should accidentally be left open, or should leak, the piston may be driven through the cylinder with force enough to do serious damage.

To Dizide the Clearance. The clearance of an engine is the cubical contents of the port, from the face of the valve to the cylinder, including the space between the piston and the cylinder head when the engine is on dead-center. To divide the clearance, loosen the clamp bolt and the jam nut on the piston rod and unscrew the rod from the cross-head until the piston striles the cylinder-head as the crank passes the liead dearl-center; then screw in the rod until the piston strikes the other cylinder head as the engine passes the other dead-center carefully counting the number of turns of the rod. Now unscrew the rod half the number of turns counted and the clearance will be divided. Tighten the clamp bolt and the jam nut.

The Shoes of the Cross-Head are adjusted by loosening the four cap screws, (E), and screwing up the four set screws, (F), to force the shoes against the guides. This will leave a space between the shoes and cross-head into which sheet-iron shims should be inserted. If these shims 
be of the right thickness to just fill the space, loosening the set-screws and tightening the cap-screws will leave the shoes free to run and with no lost motion. When the engine runs "under," as in threshing, the wear is mosily on the upper

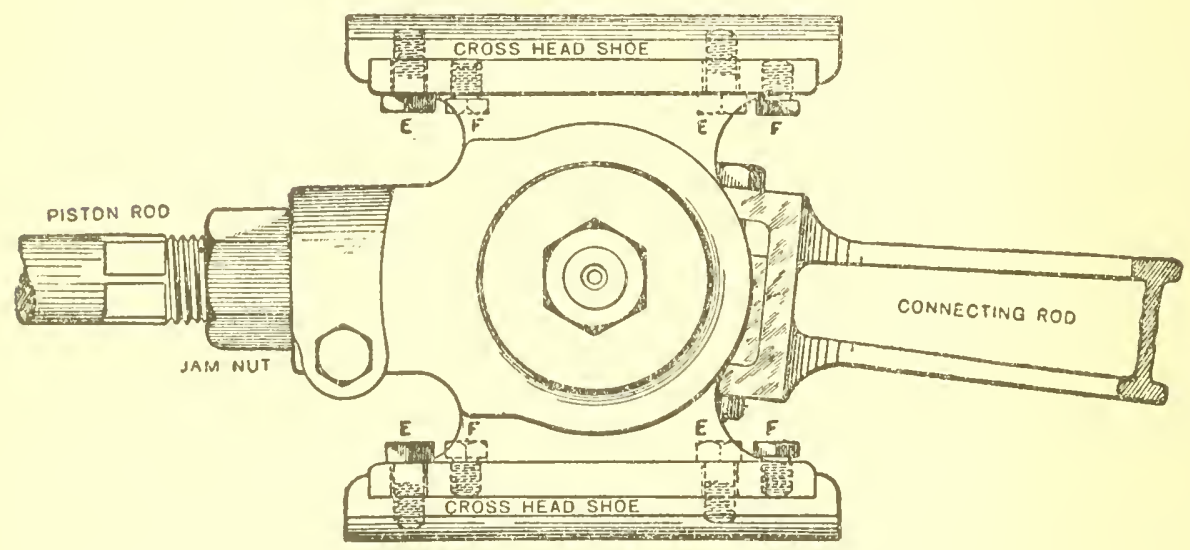

FIG. I2. THE CROSS-HEAD.

shoe and guide, and when engine runs "over," as on the road, the wear is nearly all on the lower shoe and guide. Usually the wear being nearly the same on both, they should be set out equally.

The Main Bearings are adjusted by removing paper liners. Take out only a little at a time. If one of the bearings heats and does not cool when the nuts are loosened, remove the cap and clean out any grit or dirt that may be found. If the babbitt be rough and torn up, it should be scraped smooth. It is well to "relieve" the main bearings a little at their edges, as explained for the connecting-rod brasses. When the paper liners have all been removed, and the shaft lias lost motion, the boxes will require re-babbitt- 
ing. No one but a good mechanic, skilled in this work should undertake to babbitt the main bearings. The difficulty lies in the alignment, which must be perfect, before the babbitt is poured. The babbitt should be of the best quality.

The Eccentric Strap is tightened by removing the paper liners. When the halves come together, they should be taken to a machine shop and a little planed off. The eccentric rod brasses and valve rod brasses on engines having rocker-arms are taken up by driving down the wedges or keys. 


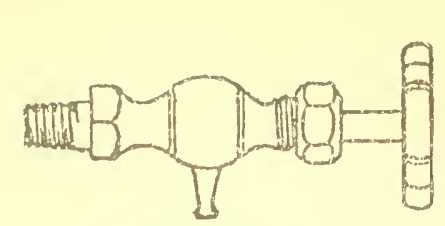

GAGE COCK

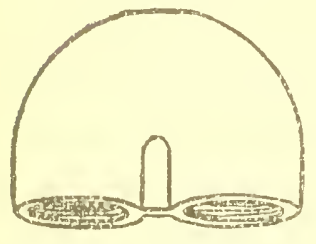

RETURN BEND

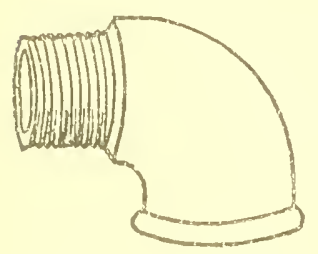

STREET ELBOW

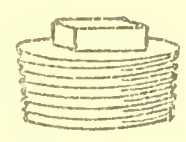

PLUG

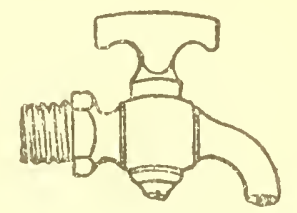

BIBB COCK

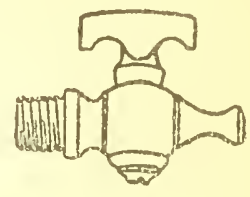

AIR COCK

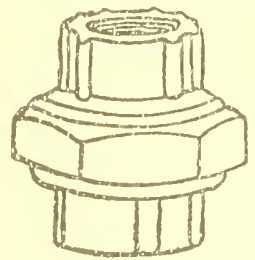

UNION

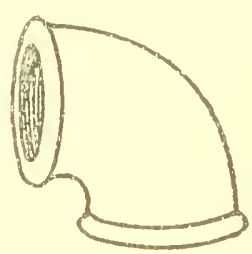

ELBOW

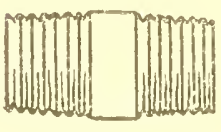

NIPPLE

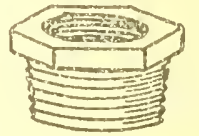

BUSHING

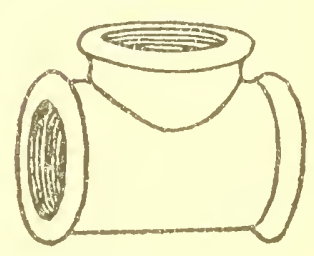

TEE

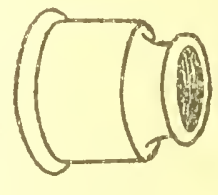

REDUCER

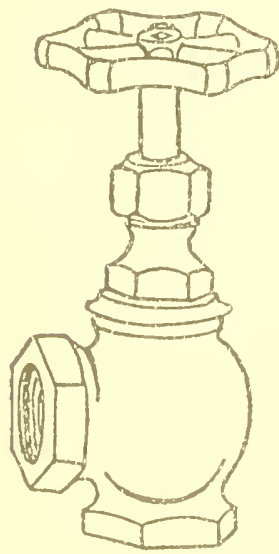

ANGLE VALVE

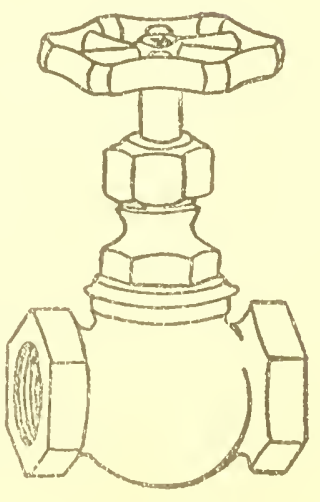

GLOBE VALVE

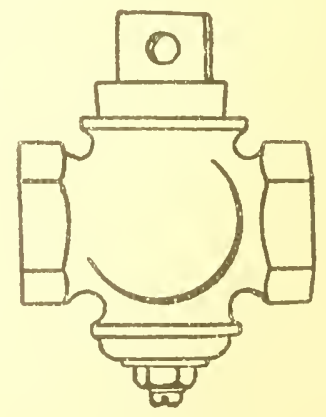

STOP COCK

FIG. I3. ENGINE FITTINGS. 


\section{CHATTER T.}

\section{HANDLING THE ENGINE.}

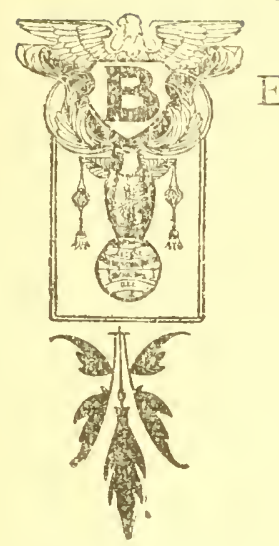

EFORE starting the engine always see that the cylinder cocks are open. Then if the crank pin be in the right position (that is, past the dead center in the direction in which the engine is to run), open the throttle just enough so the crank pin will pass the next center. After a few revolutions, gradually increase the throttle opening until the governor controls the speed. If the crank pin be not in the right position to start, take the throttle-lever in one hand and the reverse lever in the other. Admit a littie steam into the cylinder, reverse, and then before the engine can pass that center throw the reverse lever back, and the engine will start. Occasionally an engine will stop on the exact dead-center, and when this occurs it is necessary to turn it off by taking hold of the fly-wheel. If on the road, releasing the friction clutch will generally turn the engine off center because the strain on the gearing is released.

Never start the engine suddenly. Take sufficient time to allow the water in the cylinder to escape through the cylinder-cocks instead of forcing it through the exhaust. If the engine be working in the belt, a sudden start is very liable 
to throw off the main belt; if traveling, a sudden start throws unnecessary strain on the gearing and the connections between the engine and its load. When the engine has been rumning a sufficient time to allow any water that may be in the cylinder to escape, cylinder-cocks may be closed. When the engine is at work leave the throttle wide open, allowing the governor to control the speed.

An engine provided with a friction clutch is much easier handled when traveling than one without, but the clutch is seldom used by a good engineer. If used continually it requires attention to keep it adjusted.

Steering. An engine cannot be properly guided unless the steering-chains are correctly adjusted. If too tight they cause the stcering-wheel to turn hard. while if too loose, the guiding is much more difficult and the control uncertain. The chains are properly adjusted when one turn of the steering-wheel takes up the slack. Double nuts are used on the eye bolts connecting the chains to front axle and these should be jammed together so that there is no liability of their coming off. A weak steering-chain is clangerous and if one has been broken by ruming into something, or from any other cause, it should not be allowed to go indefinitely, temporarily repaired with a bolt or piece of wire, but should be fixed so that it is as strong as ever.

In guiding an engine many make the mistake of turning the steering-wheel too 1 much. It is well to remember that a turn in one direction always means a turn in the opposite 
direction. Theoretically, the engine would follow a smooth straight road without turning the wheel at all, but in practice it is always necessary to turn it a little. It is important to keep your eye on the front wheels of the engine.

Setting the Engine. A little practice is necessary to enable the operator to quickly line and set the engine, but this is acquired by most men in time. On a calm day the engine and the separator should be "dead in line," that is, in such a position that a line drawn through the edges of the fly-wheel rim would pass through the edge of the separator cylinderpulley rim on the same side, and a line drawn through the edges of the cylinder-pulley rim would pass through the edge of the fly-wheel rim on the same side. Allowance for the wind must be made, a heavy side wind requiring a setting of the engine sometimes as much as two feet out of line. When the rig has been set during a calm and a wind comes 11 , it is not necessary to stop, throw the belt and reset the engine in order to make the belt run on the pulley. Take a jack-screw or lifting-jack, set it obliquely under the front axle of the engine and move it in the direction the wind is blowing until the belt runs properly on the fly-wheel. Move the front end of the separator in the same manner until the belt runs properly on the cylinder pulley. If trouble be experienced in getting the engine in line, this method may be used to correct the alignment until practice enables the operator to set the engine so that the belt will run in the center of both pulleys. This "jacking over" of the front 
of the engine or of the separator should be done while the belt is ruming. The friction-clutch should always be used in tightening and in backing the engine into the belt.

Asconding Hills. In coming to a steep hill the engineer should see that he has about the right amount of water in the boiler. that is, enough to show two inches in the glass when the boiler is level. With the boiler too full there may be langer of priming; which shotild be especially avoided on a hill. It is also necessary to exercise judgment in regard to the fire. It should be hot enough to insure sufficient steam pressure to climb the hill without stopping. On the contrary, the engine should not be allowed to blow off when pulling hard on a hill, as this is liable to cause prining, necessitating stopping. In short, when approaching a steep hill, prepare for it so that you know you can ascend without stopping. In ascending a hill, avoid running fast, as a moderate rate of speed gives best results. If the engine shows a tendency to prime, the speed should be limited by means of the throttle so that the engine may run just fast enough to pass its deadcenters.

Descending Hills. Important as it is to ascend the hill withotit stopping, it is doubly important in descending to reach level ground before stopping. Every man in charge of a boiler of the locomotive type should know the danger of stopping with the front end low. In descending a very steep hill leave the throttle partly open to admit a little steam and if the engine runs too fast control the speed with reverse lever. 
Gravel Hills. In going up steep gravel hills there is danger of breaking through the surface crust, thereby letting the traction wheels into the soft gravel, which they will push out from under them. simply digging holes instead of propelling the engine. When this occurs, stop at once, before the engine buries itself. Block the wheels of the separator, or other load behind the engine and uncouple and it will move out all right. If it does not, put cordwood sticks in front of the traction wheels so that the grouters will catch. Another method is to hitch a tean and start the team and engine together.

Mud Holcs. The statements regarding gravel hills apply in general to soft mud holes. Stop the engine when the wheels slip, and put straw, brush, stones, sticks or anything else that may be handy in front of the wheels so that the grouters can take hold of something. When the engine is on a "greasy" road where the wheels slip without digging much, get a couple of men to help roll the front wheels and you will be surprised how much good this does.

With one traction wheel in a greasy mud hole or old stack bottom, and the other on solid ground, the differential gear may be locked, but unless you understand the consequences of doing this, as elsewhere explained in this book, it will be better to get out some other way.

The Use of a Cable. It is a good plan to carry a steel cable or heavy rope with the outfit. Then when the engine stalls, it can be uncoupled and run onto solid ground where 
it can pull its load out of the hole by the long hitch, and then be coupled up short again. A cable or rope is elastic and therefore better than a chain, which is liable to snap with the shock of starting the load. Where a rope is used, it should have a ring spliced in one end. The other end may be tied into a shackle or clevis on the engine draw-bar in a "bow-line" knot, which will not slip and is easily untied after being strained. If a chain be used the engine must be moved very slowly, by means of the friction clutch, until all the slack is out of the chain.

Special High Grouters. Engines for Louisiana, and other swampy localities, are usually fitted with pressed-steel grouters or "mutl-hooks," as they are called, which bolt to the traction wheels, in addition to the regular grouters. These are about five inches high and consequently must be taken off before crossing bridges. (They are furnished at an additional price.) 


\section{CHAPTER VI.}

\section{THE ENGINE PROPER.}

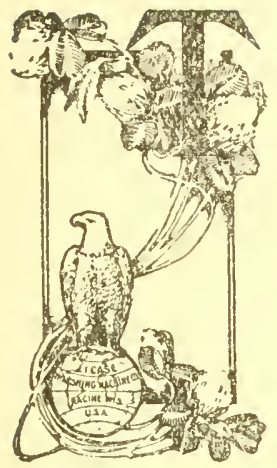

HE term "traction engine" commonly includes, not only what is, strictly speaking, the engine, but the boiler and traction parts as well. In this book, the term "engine proper" will be used to designate those parts which are actually concerned in converting the energy of steam into rotary motion. The boiler changes water into steam by adding to it, heat, taken from the fuel. The engine proper, consumes steam and delivers motion.

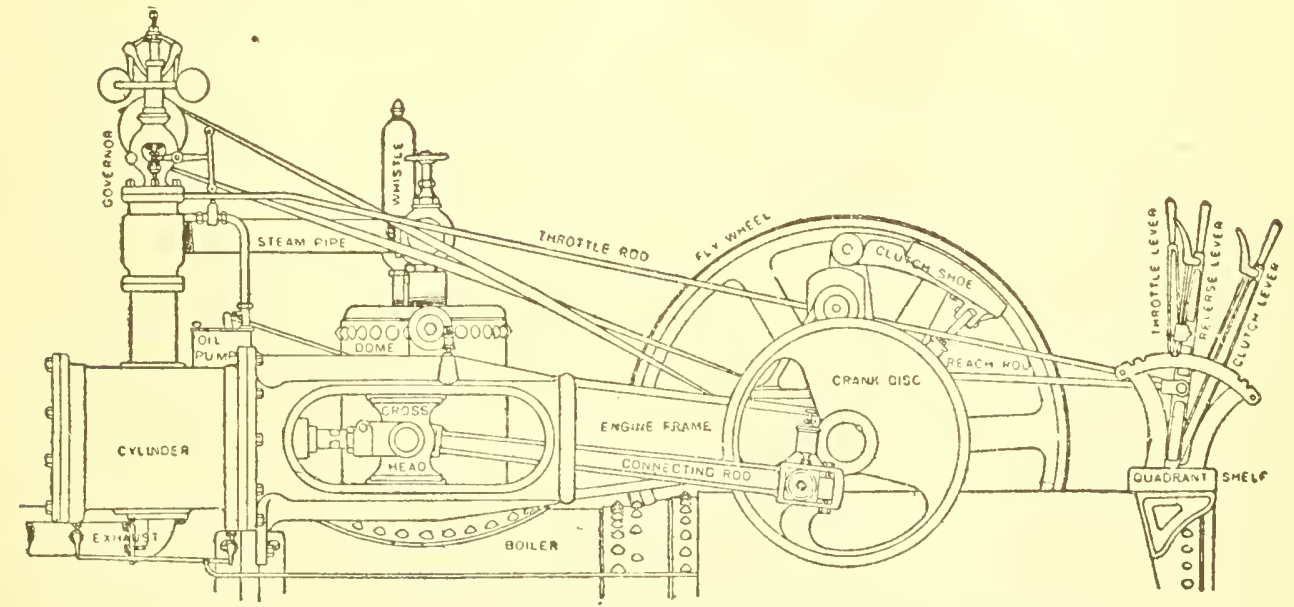

FIG. I4. SIDE ELEVATION OF ENGINE PROPER.

The Cylinder. It is in the cylinder that the actual change of heat into motion takes place. Here the steam 
is alternately admitted on opposite sides of a piston, which is driven back and forth, thereby. This reciprocating motion of the piston is changed into the rotary motion of the shaft, by the crank and connecting rod. The admission of steam to the cylinder is controlled by the "slide-valve," which slides upon a planed surface, called the "valve-seat,"

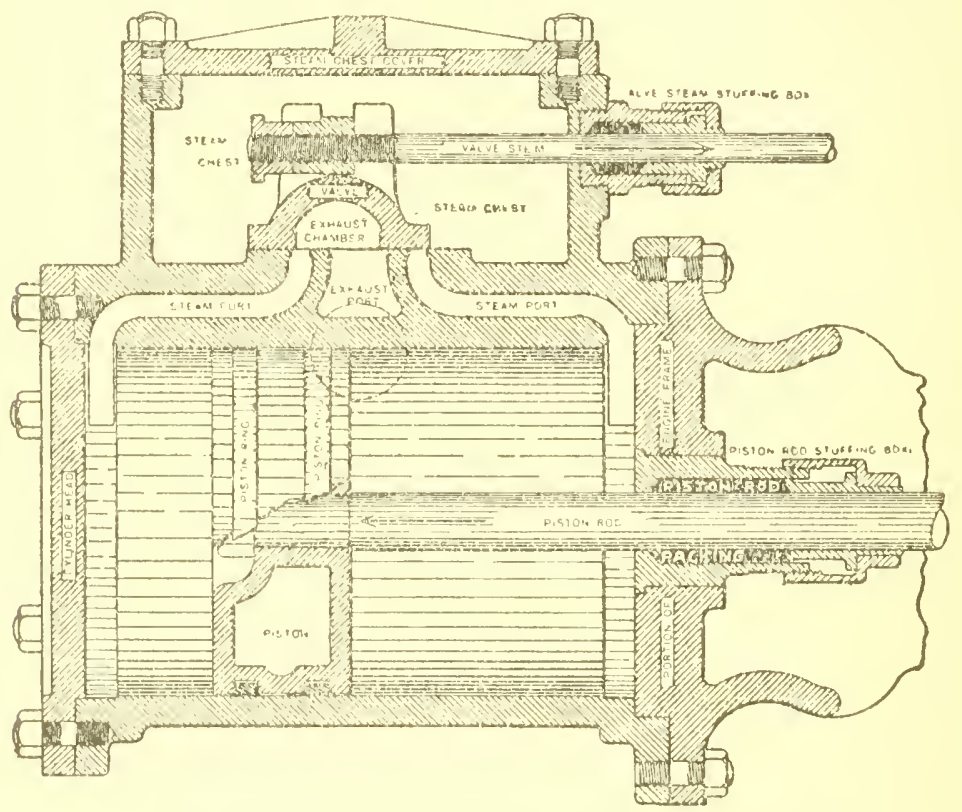

FIG. I5. SECTIONAL VIEW OF SIMPLE CYLINDER.

in a chamber, called the "steam-chest," which is adjacent to the cylinder. Passages, called "ports," lead from the valve seat to the ends of the cylinder and to the outside air, called the "exhaust." The valve alternately uncovers the ports and allows the steam in the chest to flow into the ends of the cylinder. The undersicle of the valve is chambered in such a manner that when the piston is being driven away 
from one end of the cylinder, this chamber connects the steam port of the opposite end with the exhaust port, and allows the steam to flow through the exhanst pipe into the air. The valve does not admit steam to the cylinder during a complete stroke of the piston, but only during a part, which is known as "admission." When the piston has traveled a certain distance, the valve closes the port. shutting off the steam, at what is called the point of "cut-off." Since steam is elastic, it continues to act, with gradually decreasing pressure, upon the piston until the end of the stroke is reached. This part of the stroke and action of the steam is known as "expansion." In the same manner in which the admission of live stean is stopped before the piston completes its outward stroke, the exhaust is closed shortly before the return stroke is completed. The stean caught between the piston ard the end of the cylinder is compressed as the piston nears the end, raising the pressure of the stean and forming what is called the "cushion." The part of the stroke after the exhaust has closed is called "compression." The steam is carried from the boiler to the steam chest by means of the steam pipe, in which the throttle and governor are located.

The Piston. The piston is always a little smaller than Whe inside diameter of the cylinder. It is made steam tight, however, by rings which are fitted into grooves on its circumference. These rings are originally made slight!y larger than the bore of the cylinder, and are afterward cut apart, so that they may be compressed sufficiently to enter the 
cylinder. This gives them some tension so that they fit the inside of the cylinder closely, thuts preventing lealiage of the steam. The cylinder is bored slightly larger at the ends"counter-bored" as it is called. This is done to guard against the wearing of a shoulder, at the points, near each end of the cylinder, at which the outer edge of the piston ring stops. The forming of such a shoulder (which would cause the engine to pound), is prevented by allowing part of the ring to pass into the counter-bore. The entire width of the ring must not be permitted to enter the counter-bore. however, or the ring would expand and catch against the shoulder.

The Throttle. The throttle controls the flow of steam from the boiler to the steam chest. It should be left open after the engine is started, and the control of the speed left to the governor. The only exception to this rlile is when the engine is working hard, as when traveling up a hill, with its boiler showing a tendency to prime. In this case, the engine should be made to run very slowly by means of the throttle. The skill with which some operators handle the throttle enables them to drive an engine up a hill which one less skilled could not make the engine climb. This applies principally to localities in which the water is so bad that it makes all boilers liable to prime. The throttle should be drained in cold weather to prevent damage by frost. 
The Governor. The "throttling" governor regulates the speed of the engine by limiting the amount of steam admitted

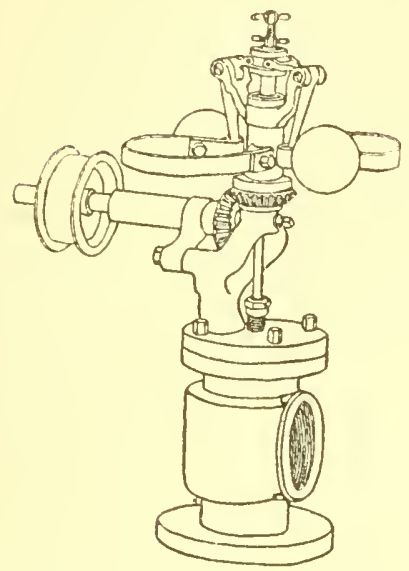

FIG. I6. GOVERNOR. to the cylinder. It consists of balls which tend to fly apart when in motion, which tendency is resisted by springs. The cut shows how the valve closes as the balls move apart. The valve connection to the stem is flexible, but has no play endwise, thus allowing the valve to align itself by its seat.

Speed. To increase the speed of the engine, loosen the check nut at the top of the governor and turn the screw up. To decrease the speed, screw it down. Be sure to set the check nut tight after altering.

Packing. For packing the stuffing box, candle wicking is excellent; soaked in a mixture of taliow and black lead or graphite, it will work well and last a long time. Do not screw the stuffing box down too hard on the packing. It is well to allow a slight leakage to insure its not being too tight.

Oiling the Gozemor. Oil the governor thoroughly with good oil, especially the shaft and barrel. If oil has been used which gums or causes the parts to stick, a little benzine or ' kerosene poured into the oil holes, once a week after shutting down, will keep the parts clean and in good order.

The Governor Belt. Use a thin flat belt and see that the 
lacing or fastening is hammered down flat, so that no bunch remains to cause an uneven working of the governor. The beit should be sufficiently taut to prevent slipping,

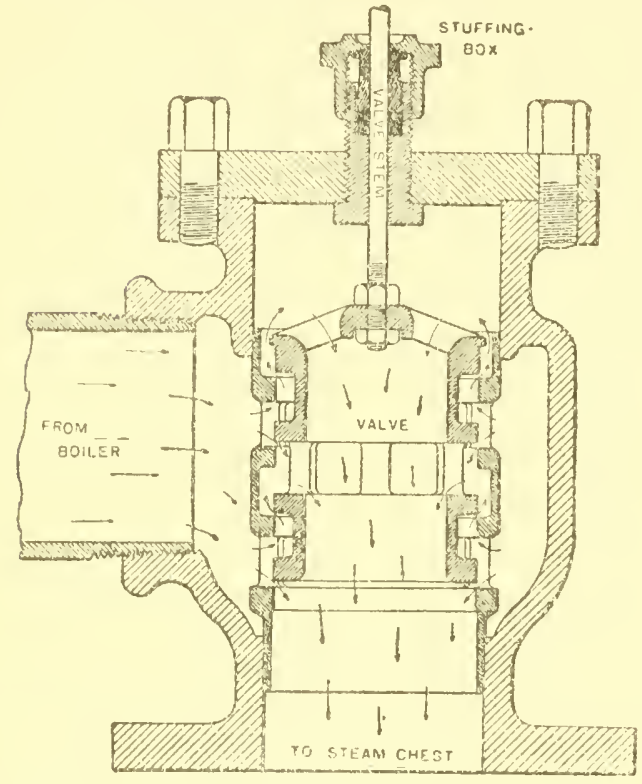

FIG. I\%. SECTION OF GOVERNOR VALVE but not so taut as to

cause undue friction.

If the governor "jumps" or is irregular, it is probably occasioned by one of the following causes: first, because the valve is a little tight; second, because the valve stem is bent; or third, because the stuffing-box nut is screwed down too tightly. Turning the valve sten up and down, while the governor is running, will show whether the valve works freely in its seat. If it binds at all, take it out, and rub it with fine emery cloth, isut never attempt to file it. In taking the governor apart, the top must be lifted off as "true" as possible, so as not to bend the valve stem. If the valve stem becomes bent where it passes through the stuffing-box, it will be best to procure a new stem.

Rated Horse-Pozer. Stationary engines are rated at about their actual horse-power, as determined by brake test. Fanm and traction ensines, on the other hand, are rated very 
much below their actual or brake horse-power. which is a condition of affairs to be regretted. However, it would be a difficult matter to change this at the present time and to educate the users of these engines to comprehend the true size of the unit "horse-power," since the practice of underrating has existed since engines for driving threshing machines were first built, and it has grown up with the business. If we look into history and causes, we find that the early method of driving threshing machines was by horse-power, and when engines were first used for threshing, a ten horsepower engine was supposed to supply about the same amount of power as a lever-power driven by ten horses. From the time of those early engines, to the present, the competition of different manufacturers, all endeavoring to furnish the most powerful engine of a given rating, and the raising of the steam pressure from 60 to 130 or even I6o pounds, (which was done without reducing the size of the cylinder of a given rating), has caused engines of this class to be more and nore under-rated. Nost threshing engines, now built in the United States, will casily develop from two to three times their rated horse-power, and the relation which the rated horse-power bears to the actual size of the engine varies so greatly, that, in reality. the "rated horse-power" gives only a very indefinite idea of the actual size of an engine. There are reasons why it is preferable to indicate the size of an engine by size of its cylincler, instead of by its rated horse-power ; for example to say, a "Nine by Ten," 
rather than a "Fifteen Horse" engine. However, besides the cylinder size, the steam pressure carried and the speed are also important factors in determining the amount of horse-power an engine will develop. English engines are more under-rated than those built in the United States, but in comparing the engines of these countries, the difference in stean pressure and speed must be taken into consideration. as well as the difference in the size of cylinders. The methods of obtaining the exact horse-power of an engine with the indicator or the Prony brake are becoming better known, but it is probable, however, that engines will not be correctly rated for some time to come.

Engine Horse-Power. The unit of power is a "horsepower" which is defined as the amount of power necessary to raise thirty-three thousand pounds one foot in one minute. The horse-power of an engine is equal to the average, total, effective pressure on the piston multiplied by the number of feet it travels per minute, and divided by thirty-three thousand. The total effective pressure on the piston is equal to its area in square inches, multiplied by the effective pressure per square inch, which is not constant, but varies, being nearest boiler pressure during the early part of the stroke and decreasing after the point of cut-off is passed, as the steam expands, until the end of the stroke is reached. The effective pressure is the pressure remaining after subtracting the back pressure of the exhaust.

Indicated Horse-Power. The pressure at the different parts of the stroke can be measured only by means of the 
steam-engine indicator. This instrument has a small piston, connected to a pencil point in such a way that movement of the piston is registered on a card. Since the movement of the piston is resisted by a calibrated spring, its position depends upon the amount of pressure it is subjected to, and therefore, the amount of pressure at all points may be known from the diagram made by the pencil point. Know* ing the pressures at the various points of the stroke, it is easy to multiply the average by the travel of the piston in feet per minute and thus determine the horse-power. The result so obtained is called the "indicated" horse-power. The indicator measures the power developed in the cylinder and, of course, it takes a part of this to run the engine itself. The amount so consumed is, roughly, ten per cent. of the whole.

Brake Horsc-Poucer. The net horse-power delivered at the fly-wheel may be actually measured by means of a device known as the "Prony brake." 'This consists of a brake band for applying friction to the rim of a pulley. The brake band is prevented from turning by an arm which rests on a weighing scale. From the scale reading, the speed of the pulley and the length of the brake arm, the horse-power can be figured, and the result so obtained is called the "brake" horse-power. It is evident that the difference between the indicated and brake horse-power is the power required to run the engine.

Calculating the Horse-Power. Although, as already stated, the mean effective pressure can be measured only by 
the indicator, we can, for calculation, assume a value which approximates the correct one. This we will take to be fifty per cent. of the boiler pressure. Then, with a boiler pressure of one hundred and thirty pounds, our average effective pressure (or "mean effective pressure," as it is called) per square inch will be fifty per cent of one hundred and thirty pounds, or sixty-five pounds. This, multiplied by the area of the piston, will give the total mean effective pressure on the piston in pounds. The area of a circle is equal to its diameter multiplied by itself and the product by .7854. The travel of the piston is equal to twice the stroke (there being two strokes to each revolution), multiplied by the number of revolutions per minute. As the length of the stroke is usually given in inches, this product must be divided by twelve to reduce the result to feet per minute.

The following example is of an engine with a Nine by Ten cylinder, a speed of two hundred and fifty revolutions per minute and a boiler pressure of one-hundred and thirty nonnds--the size of the Case engine, rated at liffeen horsepower.

250 revolutions per minute.

20 travel of piston in inches per revolution.

12)5,000 travel of piston in inches per minute.

416.6 travel of piston in feet per minute. .7854

$8 \mathrm{r}=(9 \times 9)$, square of diameter of piston.

63.6174 area of piston in square inches. 
63.6174 area of piston in square inches,

$65=(50 \%$ of 130$)$, the "mean effective" nressure (pounds per square inch.)

3180870

3817044

4135. I3 10 tota1 average pressure on piston in pound.s.

4 r6.6 travel of piston in feet per minute.

24810786

24810786

4 I 35 I 3 I

16540524

33,000)1722695.5746(52.20 ("Whe "calculated" horse-power corresponil165000 ing to the "indicated" horsepower.

72695

66000

66955

66000

95574

Deducting ten per cent. for the friction of the working parts of the engine, we have forty-seven horse-power as the restult. This remainder is a little more than three times the rated horse-power and represents the power actually delivered at the engine fy-wheel, and corresponds to the "brake" horse-power.

Compound Engines. A compound engine is one in which the steam is expanded in two or more cylinders. Threshing engines, when compounded, are "two-cylinder" compounds, but large stationary and marine engines are often "triple" and sometimes "quadruple" expansion. There are different types of two-cylinder compounds, viz.: the "cross," where 
the cylinders are abreast and each piston connected to a separate crank; the "trunk," in which two pistons of the same size are connected by an enlarged rod or trunk, the high-pressure cylinder being in the form of an annular ring between the pistons, and the low-pressure at the ends of the long cylinder which is the same bore throughout; and the "tandem," having one cylinder behind the other, with both pistons on the same rod. The latter has proved to be the type best adapted for use on farm and traction engines.

The IVoolf Compound. The illustration below shows a sectional view of the "Woolf"-tandem-compound cylinder now used on "Case" compounded engines. Its operation is as follows: The steam from the boiler enters the valve, (which is hollow), through the large opening at the

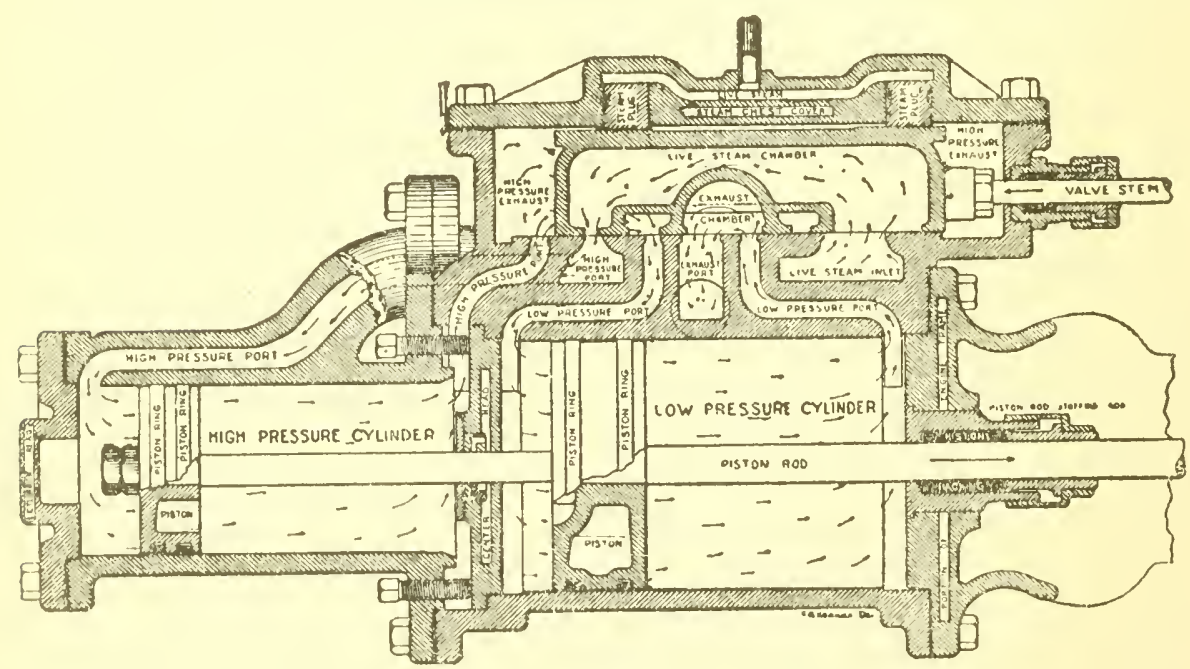

FIG. I8. SECTIONAL VIEW OF "WOOLF" COMPOUNDED CYLINDER.

crank end, passes through the valve and out at the narrow opening near the head end, which, as the valve moves, alter- 
tely connes opposite tine two ports leading to the chels of the small or high pressure cylinder. The valve in moving also alternately uncovers these ports, allowing the highpressure cylinder to exhanst into the stean chest. The low-

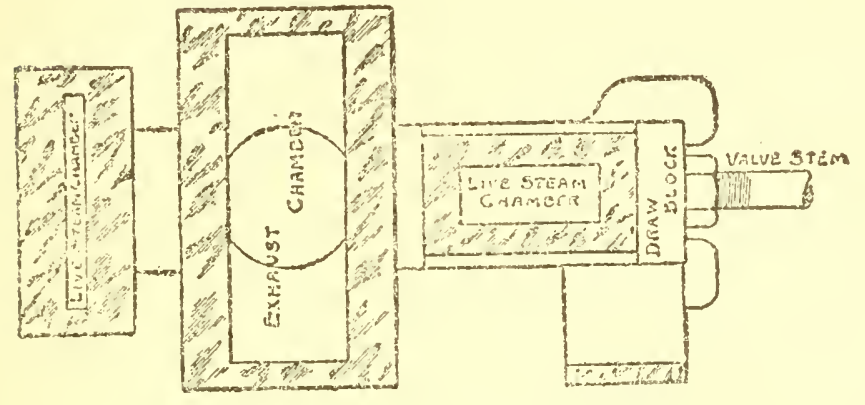

FIG. I9. FICE OF VALVE.

pressure crlinder receives the stean from the st e a $m$ chest, and exhausts. (through the heater), into the stack, in exactly the same manner as a simple engine. The valve is "halanced" because high-pressure steam is under and tending to lift it. while the low-pressure steam is on top, and pressing

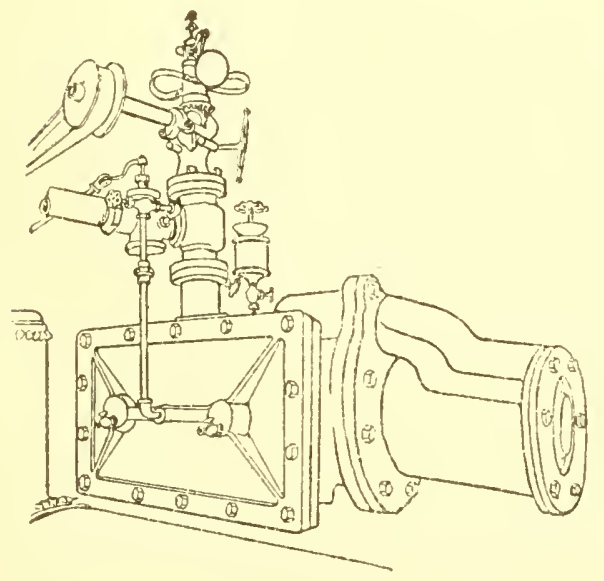

FIG. 20. it against its seat. When the engine is running with a light load, the pressure is sometimes insufficient to hoid the ralre against its seat, in which case a loud clattering noise is macie by the valve as it raises from and returns to its seat. To prevent this,

SHOWTA PIP TO STEM PLUGS. two steam plugs are placed 
in the chambered stean1-chest cover, so that, when the valve in the snall steam pipe connecting this chamber with the main stean-pipe is open, the live steam pressure against the plugs holds the valve against its seat.

To Take Apart the Componnd Cylinder. To take out the pistons for renewing the piston-rings or for other purposes, first mbolt and remove the high-pressure cylinder. Then loosen the jam-nut and unscrew the rod from the cross-head by turning the pistons. The rod with the two pistons and the center-head may now be pulled out. In replacing the cyinder, loosen the three, (or four), set-screws, which hold the center-head in position, and after the highpressure cylinder is bolted in place, tighten them up in order to hold the center-head in position and prevent leakage. If the asbestos gasket has been injured, it will be necessary to put in a new one.

Center-Head Packing. Leakage around the rod, between the two cylinders, is prevented by metallic packing, which will, with sufficient lubrication, remain tight during the life
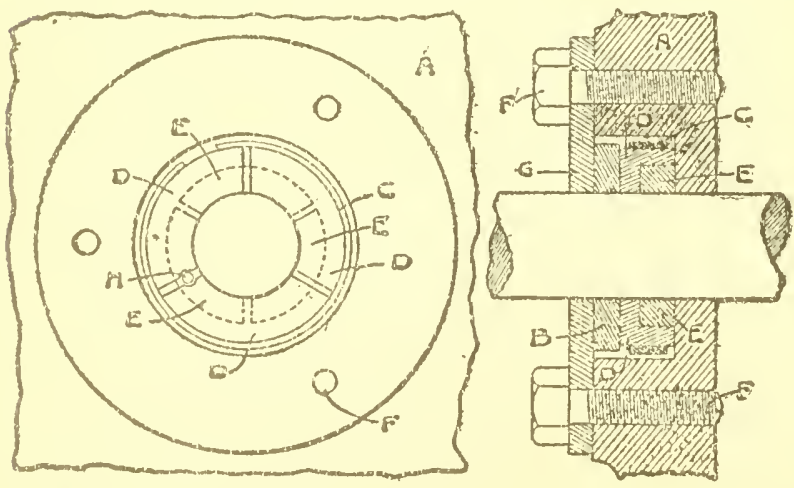

FIG. 21. TIIE CENTER-IIEAD PACKING. of the engine. The accompanying cuts show a side and a sectional view of the metaliic piston-rod packing which is located in the center-head 
between the high- and low-pressure cylinders. In the side view, the rings $G$ and $B$ are removed. The center-head is represented by $A$. The iron-packing rings $D$ and $E$ are each in three parts or segments and are held in their proper places by the spring $C$. These segments of rings are so placed that they "break joints," as can readily be seen from the side elevation. They are held in position, relative to each other, by the dowel pin, $H$. These packing rings are held in place by the ring $B$, and also by the ring $G$, which is fastened to the head with three cap-screws. F. The head is held in its position between the cylinders by set-screws, as can readily be seen from cut on page 64.

To Test the Center-Head Packing, set the reverse lever $f(p$, say, the threshing motion and turn the engine in the direction in which it would run, just past the crank-end dead-center. Block the cross-head so that the crank-shait cannot revolve, disconnect the cylinder-cock rod, and open the throttle. This will admit steam on the crank-end of the high pressure cylinder, and if the cylinder-cock on the headend of the low-pressure cylinder blows steam when opened. it can come only from leakage of the metallic packing in the center-head. 


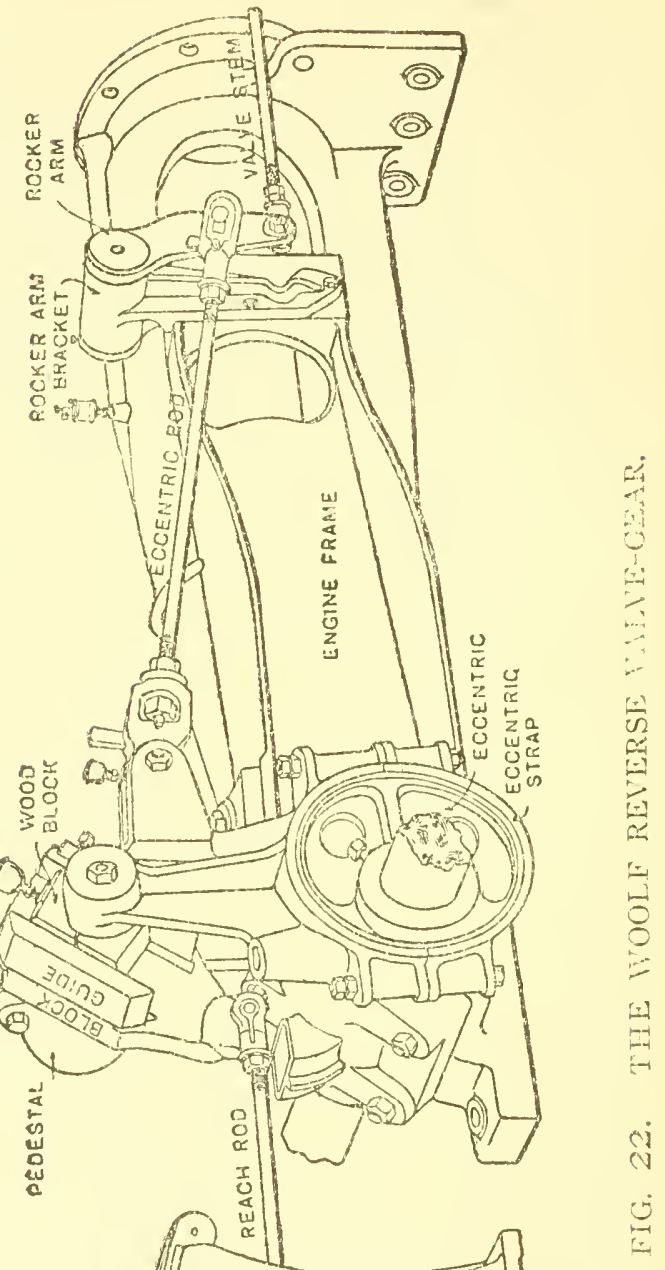




\section{CHAPTER VII. \\ THE VALVE-GEAR.}

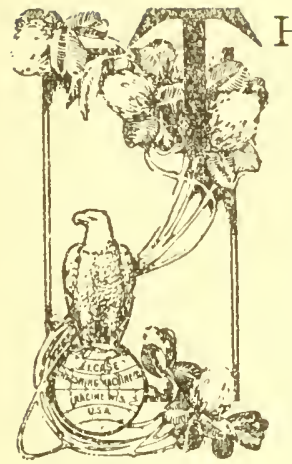

HE mechanism that operates the valve of an engine is known as the "valve-gear." On stationary or portable engines, which are only required to run in one direction, the valve gear consists simply of an eccentric on the crank shaft, (to which the valve stem is connected by means of the eccentric-rod), and a guide to keep the valve-stem in alignment. As traction engines must be rum in both directions, a reversing valve gear is required, which necessarily renders the valve gear more complicated. There have been numerous mechanisms invented for this purpose, but most traction engines are equipped with either the "link" or the Woolf reverse, as these are almost the only ones that have withstood the test of time.

It is apparent, that, in order to use stean? cconomically, it must be allowed to pass in and out of the cylinder at precisely the right moments, and during certain intervals. Consequently, the economy of a steam engine depends almost entirely upon the valve-gear, which should, therefore, be liept in good repair. The ease with which the valve is moved, denends largely upon its lubrication. If the valve be allowed 
to run dry, the valve gear is subjected to an immense amount of unnecessary work, which soon wears it, so that the valve loes not move as it should, and the engine becomes wasteful in its use of steam. The valve should be well lubricated at all times, the wearing parts of the valve-gear should be oiled frequently and every precaution taken to keep the valvegear in first class condition. The wear should be taken up as fast as it appears so that the parts are not allowed to pound.

The Woolf Valve-Gear. The Woolf valve-gear possesses advantages over the other devices used for reversing traction engines, which entitle it to rank as the most popular and satisfactory means for this purpose known at the present time. It is very simple, consisting of a single eccentric, the "strap" of which is extended to form ail arm; to the end of this arm is pivoted a block. which slicles in a gruide connected to the hand lever and pivoted in such a way that the angle of the block's path depends upon the position of the hand lever; the eccentric rod transmits the motion from the eccentric arm, (to which it is connected), to the valve stem through a rocker arm or guided "slide." It will be seen that the angle of the "block suicle" determines the amount of travel of the valve. By placing the reverse lever at or near the center of the quadrant, the reverse gear acts as an efficient brake in controlling the engine when descending hills, or at any time when it is desirable to suddenly check the speed of the engine. This reverse allows of "hooking 
up," that is, placing the lever in notches between the end and center of the quadrant. In these positions, the valve travel is reduced and the points of "cut-off" made earlier, which, of course, lessens the amount of steam required. It is, therefore, economy to run the engine "hooked up" whenever its load will allow. Provision is made for taking up lost motion in the parts subjected to wear. All the joints should be kept well oiled, but the only parts which require frequent attention in this respect, are the eccentric and the sliding block. When the valve is sufficiently lubricated, and the vaive-gear is properly oiled and adjusted, the reverse lever is easily handled, when under a full head of steam.

Caution Against Disturbing the Valve Setting. It so often happens that an expert, when called to an engine, finds that the valve has been re-set after the engine left the factory, that it seems best, at this point, to say a few words of caution against disturbing the valve of a new engine. Let us advise you not to jump to the conclusion that your valve is incorrectly constructed or improperiy set. Remember that the engine has been designed and built by experienced men, thoroughly competent to make it all that it should be. Remember, too, that the engine has been tested at the factory, in the belt and on the road with heavy loads, within sight and hearing of a dozen men, whose long experience has made them so critical that they could not fail to detect anything wrong in the engine's performance. Let us add that in nine cases out of ten. where an expert is called to re-set 
a valve, he funds that it has been disturbed since it left the testing roon. Do not, then, conclude that your valve is "off." until you have carefully investigated whatever trouble there nay be.

There are men in nearly every locality throughout the country, who are confident that they themselves know nnore about setting valves than do the manufacturers. These men affirm that whatever trouble they may have is due to the working of the valve, and, when no improvement is shown after they have re-set it, they say that the valve-gear was not properly constructed and designed originally. If they had carefully investigated the irouble before disturbing the valve, they would have discovered the real cause, due probably to either insufficient cylinder and valve lubrication, or to a priming tendency of the boiler. The causes of, and the remedies for these difficulties are discussed elsewhere in this book.

Finding the "Dead Centers." An engine is on its "deadcenter" when a line drawn through the center of the pistonrod will pass through the center of the crank-pin. 'There are two, the "crank" dead-center, when the piston is at the end of the cylinder nearest the crank-shaft, and the "head" dead-center, when the piston is at the opposite end. An engine is said to be running "over" when the top of rim of fly-wheel runs away from the cylinder and running "under" when the top of rim of fly-wheel runs towards the cylinder. "Case" engines are marked for finding the dead- 
centers at the factory, and by applying one of the company's trams, as indicated in Fig. 22, they may be readily placed on either dead-center. It may be necessary to scrape

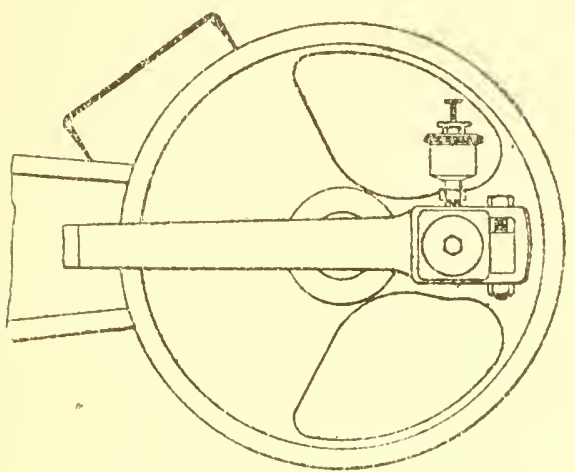

FIG. 23. TRAM ON DISC. off the paint to find the prick-punch marks on the frame and on the crank-disc.

The tram shown in the illustration measures eight and three-sixteenths inches between the points, which size has been used by the "Case" company for many years. It wiil be seen that a "Case" engine may be put on its dead centers by using a pair of dividers set to this distance, bit they do not serve the purpose as well as the tram. The following method of finding the dead centers is the one used at the factory, and is generally used on all styles of engines. To put it into use, first take lip all lost motion in the connecting-rod brasses, crank-shaft bearing and cross-head shoes. Then turn the engine until the piston lacks an inch or so of completing its stroke. Make a prick-punch mark at any convenient place on the crosshead (see Fig. 2-1), insert one point of the tram in the mark and with the other point. make a scratch on the engine frame to locate a second prick-punch mark. The tram points should now measure the exact distance between the two marks and when applied shotikl be nearly paraled to the 
piston-rod, as shown in Fig. 23. In the same manner, a mark should be made at any convenient place on the frame near the crank-disc, a scratch made on the disc, (which should come across the face of the disc), and a light prickpunch mark made on the disc, so that the tram measures the exact distance between the marks, as shown in Fig. 22.

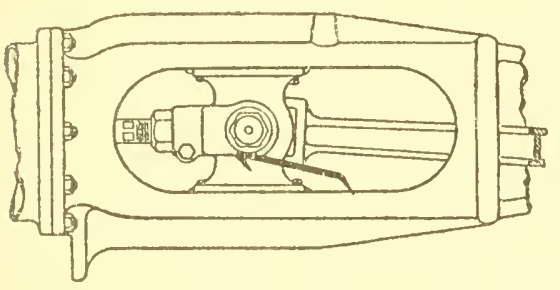

FIG. 24 . Next, turn the engine until the cross-head comes back to the same place, but with the crankpin on the other sicle of "the dead-center, holding the tram TRAM ON CROSS-HEAD. with one point in the mark on the frame, near the guides, and the other so that it will drop into the cross-head prick-punch mark when it comes to the right place. Next, place one leg of the tran in the other mark on the frame and make a scratch on the disc as before, to locate the second mark on the rim of the crank-disc. When this is done, find the mid-point between the two marks (which are temporary), on the disc, with a pair of dividers, mark it clearly, and then destroy the two original marks. The other dead-center is found in the same manner. Now when the crank-disc is turned around until the tram point drops into one of the marks on it, the engine will be on either of its dead-centers. With engines, on which the crank-disc is not easily reached, the prick-punch marks for the tram are usually located on the fly-iwheel rim. They were so placed on "Case" center-crank engines. 
In placing the engine on its dead-centers, in examining the valve setting. or in setting the valve, it should always be turned in the direction indicated by the reverse lever, that is, if the reverse lever is in the forward end of the quadrant, the engine should be turned "under," or in the direction in which it runs when threshing. If turned past the mark, it should be turned the opposite way and again brought to the mark, moving in the right direction. This elininates any error due to lost motion.

To Determine if the Valie Setting has been Disturbed. New engines have their valves set at the factory before being painted, so that broken paint often reveals the fact that someone has re-set the valve. Besides this indication, "Case" engines are provided with marks, by means of which, one can determine whether or not the valve setting has been disturbed since the engine left the factory and, if it has been disturbed, furnish the means to bring it back to the original setting without removing the steam chest cover. The eccontric hub and the shaft are marked, as with a sharp cold chisel, so that the marks meet when the eccentric is in its proper position. When one suspects that the eccentric has slipped from its original position, an examination of these marks will show whether it has or has not. If it has slipped, the trouble may be corrected by loosening the set-screws and rotating it around the shaft until the marks correspond. An eccentric is liable to slip when it becomes hot from running without oil and this tendency in such cases is sometimes 
strong enough to shear off the points of the set screws which secure the eccentric.

Piesides the marks on the eccentric, there are marks on the valve-stem and its stuffing-box, in order to make apparent any change in the length of the valve-rod or the eccentricrod. To use these marks, however, one should have one of the Company's valve-rod trams. This is shorter than the one used on the crank-disc and measures exactly four and threesixteenths inches between points. It is used as shown in Fig. 24. There are two marks on the valve-stem and they

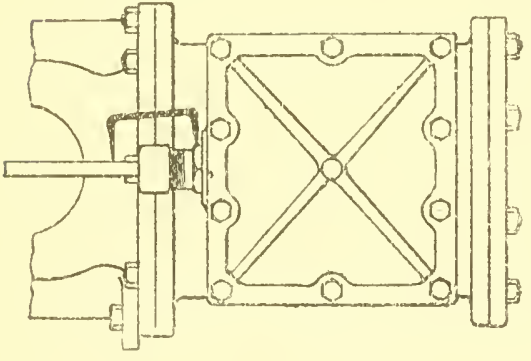

FIG. 25. TRAM ON VALVE-STEM. should be on top. When the reverse lever is at the rear end of the quadrant, (i. e., the road motion), and the engine is placed on one of its dead centers, the valve-rod tram should drop into one of the marks, and when the engine is placed on its other dead-center, the tram should drop into the other mark. If the tram points do not drop into the marks, the eccentric rooi should be adjusted as to length until they do or else the valve must be entirely re-set as explained below.

Setting the Valie on Engines with IVoolf Reverse. After having taken up all the lost motion on the valve-gear, mainbearings, crank-pin and cross-head pin and shoes, and being provided with the tram for placing the engine on its deadcenters, as explainerl, proceed to set the valve as follows: 
First. See that the "reach-rod" from the "reverse-lever" to the "block-guide" is of such length that the valve moves the same distance during a revolution of the fly-wheel in one direction as for a revolution in the opposite direction, with the reverse-lever in the end notch of the quadrant in both cases. The entire distance the valve moves, which is called the "valve travel," may be conveniently measured on the valve stem by the tram, as illustrated in Fig. 24. To do this hold one of the tram points in the punch-mark on the stuffing-box and, with the other, make scratches across the rod as the fly-wheel is slowly revolved. If the "valve travel" be more for one motion than for the other, it shows that the reach-rod is either too long or too short to give the proper angularity to the block-guide, which angularity determines the travel of the valve. This rod can be easily adjusted to the correct length by taking the pin out of the lever and turning the forked head of the rod until the required length is obtained. The jam-nut should then be tightened to prevent lost motion.

Second. See that the eccentric is in the proper position, which is, with it's point of greatest throw nearly opposite the engine crank-pin. The movement of the valve in throwing the lever from one end notch to the other end notch of the quadrant, with the engine on its lead-center, is called the "slip." When the eccentric is properly located, the slip will be the same for "head" dead-center as for "crank" deadcenter. The "slip" must not only be alike in amount, but 
must also be in the same direction as that in which the lever is moved, in both cases. If the "slip" be with the lever for one dead-center, and against it for the other, the eccentric is not in the correct position, and should be rotated slightly on the shaft, "mil the "slip" is in the same direction as that in which the lever is moved, for both dead-centers. If it be impossible to get this, the perlestal is not the right height, as explained in the following paragraph. In setting the eccentric, one set-screw will hold it in place temporarily.

Third. See that the pedestal is the correct height. The amount of "slip" indicates this, and if it be one-sixtcenth for both dead-centers, and in the same direction as that in which the lever is moved, the pedestal is the proper height. If the pedestal be too high, the "slip" of the valve will be more than one-sixteenth, and if too low, it will be less, or if very low, the valve stem will move in the opposite direction to that in which the reverse lever is moved. The pedestal may be raised, by placing "shims" of sheet-iron between it and the frame at the place where it is bolted, and lowered, by removing the shims. If there be none, the pedestal must be taken to a machine-shop and planed off in order to lower it.

Fourth. When you know that the reach-rod is the correct length; that the eccentric is in the proper position, and that the pedestal is the correct height, give the rive three-thirty-seconds of an inch "lead" on the crank-end for the threshing-motion. The "slip" of the valve, in throwing 
the lever over to the road motion, will reduce this lead by one-sixteenth, so that the leads will be nearly alike for the road-motion. The "lead" should be obtained by adjusting the length of the eccentric-rod, allowing the nuts on the valve-stem to remain undisturbed. If the nuts on valvestem be loosened, the "draw-block" is liable to be tilted so that the valve cannot leave its seat when necessary to let water out of cylinder.

It is best, after setting the valve, to go all over it again from the beginning, and if all be found correct, the eccentric may be set permanently by tightening both set-screws. These are counter-sunk into the shaft, and if necessary, the depressions may be changed by sliding the eccentric-hub to one side, (after having removed the eccentric-strap), and chipping them out with a round-nose chisel so that the deepest part is in the required position for the set-screw. The eccentric-hub and sinaft should be marked, (as is cione at the factory), with a cold-chisel, so that should the eccentric slip, the slippage can be discovered and the eccentric readily re-set.

In any style of valve-gear the "lead" is changed by rotating the eccentric around the shaft. It will be seen that the Woolf reverse, having but one eccentric cannot be adjusted to change the lead, because if the lead be increased for engine running "over," it will be decreased for engine rumning "under," and vice z'ersa. There is therefore but one position for the eccentric. This is determined at the factory, and on 
"Case" engines built since 1898 the main shaft is countersunk for the set screws.

Evon Cut-offs. The above is the method used in setting the valve on nine, twelve, fifteen, twenty and twenty-five horse-power "Case" traction engines at the factory, and brake and indicator tests show that these engines, with their valves so set, easily develop three times their rated horse-power, and are very economical. It will be seen that this method of setting the valve gives unequal "leads" for the threshing-motion, there being three-thirty-seconds of an inch on the crank-end and no lead on the head-end. The points of cut-off, however, will be "even." that is, alike on both ends, for both road and threshing-motions. Were it desirable to set the valve with equal "leads," it could be done by making the pedestal of such a height that there would be no "slip." In this case, the points of cut-off would not be even, and one end of the cylinder would do more work than the other. For this, and other reasons, this method is not recommended.

Setting the Valie on Compounds. The valve of the Woolf-compound cylinder is set in exactly the same manner as that of a simple engine, the part of valve covering lowpressure ports only, being considered.

Setting a Valve with Link Reverse. After having taken up all the lost motion, as explained, the first thing to do, in setting the valve on an engine equipped with the "link" reverse, is to find the correct length of the eccentric-rods. To do this, take off the steam-chest cover and place the reverse 
lever in the last notch at either end of the quadrant. Now, with a scratch-awl having a very fine point, make scratches on the valve seat, showing the extreme position of the valve at each end of its travel as the fly-wheel is rerolved. Measure from the marls to the outside edges of the steam ports, and, if there be any difference, divide it up by lengthening or shortening the eccentric-rod, that is for the time being, moving the valve. The length of the other rod is found in the same way, the reverse-lever being at the opposite end of the quadrant. If the engine be marked and you have the "tran" for placing it on the centers, as already explained, proceed to set the valve as follows: After the lengths of the eccentric-rods are correctly adjusted, according to the method already given, place the engine on one of its deadcenters, say, the head one, and set the reverse lever in the last notch at either end of the quadrant. The valve should now be in such a position that the port leading to the head end of the cylinder should show a "lead" equal to the thickness of an ordinary playing card. The anount of lead may be varied by rotating the eccentric hub around the shaft. Rotating it in the direction in which the engine is to run increases the lead and moring it in the opposite direction decreases the lead. When you liave obtained the desired lead, place the engine on the other dead center and see if the lead be the same. If it be not, the valve-stem should be lengthened or shortened, (by means of adjusting nuts), unti! it is the same. if, after dividing the lead, there be too 
mucl or too little, rolate the eccentric hub on the shaft, until the required lead is obtained at both ends. The valve is now set for the engine running either "over" or "under," according to the end of the quadrant at which the reverse lever was set. The reverse-lever may now be placed in the other end of the quadrant and the valve set for the other motion. This is done in the same manner, except that the dividing of the lead must now be cione on the eccentric-rod instead of the valve-stem, so that the first setting will not be disturbed. When this is done, try the other motion again, so that when you are through, you know that the lead is the same for both dead-centers for the engine running either over or under. The draw-block should be examined to instre its not being so tipped as to prevent the valve from raising from its seat when necessary to let water ont of the cylinder.

With the link reverse, the lead can be as much or as little as desired and need not be the same for both motions. However, lead equal to the thickness of a playing card will grive the best results for this class of engines. 


\section{CHAPTER VIII. \\ THE BOILER.}

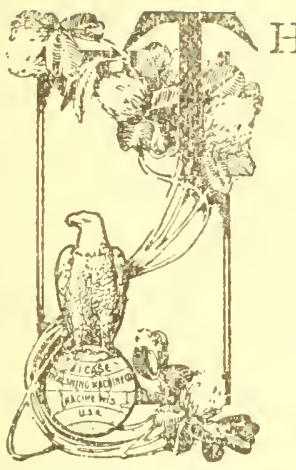

HE function of the boiler is to heat water sufficiently to change it into steam, for use in an engine, or for other purposes. The supply of water for the boiler has been treated under "The Feed Water" in Chapter II, and the management of the fire with various fuels under "Firing" in Chapter III. Temperature of Water and Steam in a Boiler. Although water boils in an open vessel at 212 degrees Fahrenheit, if it be confined, a pressure will be developed, which will prevent it from boiling until a higher temperature is reached. A certain relation exists between the pressure and temperature of the steam in a boiler and for any given pressure there is a corresponding temperature. Thus, for a pressure of 50 lbs., the temperature is 267 degrees, for ino lbs. pressure the the temperature is 337 degrees, and for 125 lbs. pressure, the temperature is 352 degrees. The temperature in the firebox is, of course, many times greater.

Boiler Fitings. The fittings necessary for the operation of a boiler, are the feeder, (for suppiying the water), glass gage and gage cocks, (for indicating the water level), a steam gage, (for indicating the pressure), a pop or safety 


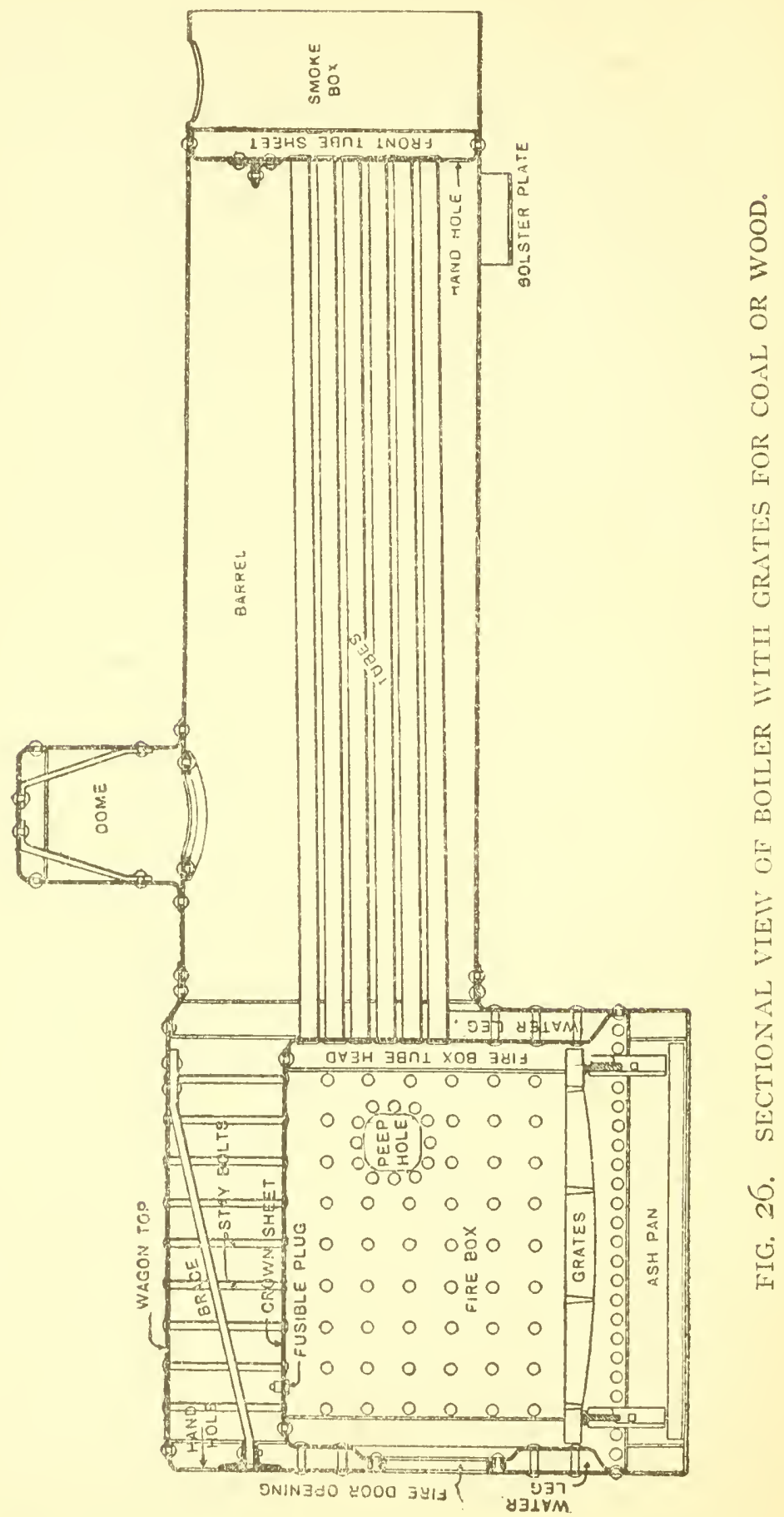


valve, (to prevent the pressure from reaching a dangerous height), and a "blow-off" valve, (for draining the boiler). A boiler is ustally fitted also with a whistle for signaling, and a blower for forcing the draft. The water feeders, water glass and gage cocks have been treated under the "Feed Wrater" in Chapter II.

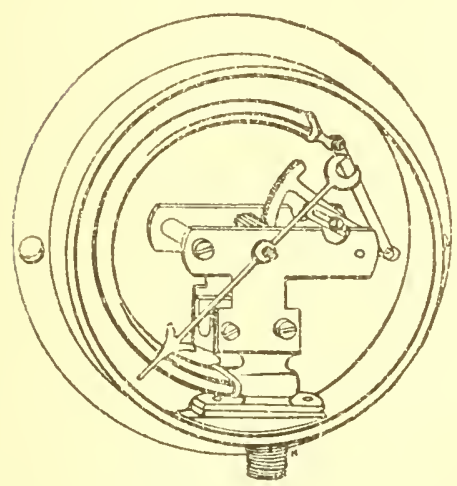

The Stcam Gage. The stean gage indicates the stean pressure in the boiler in pounds per square inch. The cut shows the interior of the gage used on Case engines. The curved tube or Bourdon spring has an oval cross section, and when exposed to pressure ITG. 27. INTERIOR OF G.IGE. from the inside, tends to straight(1) as a hose will do when under water pressure. The free end of the Bourton tube is connected to the pointer by means of a segment lever and pinion so that the pointer, which is on the same shaft as the pinion, revolves, indicating on the dia? the pressure on the inside of the tube, which is the same as that in the boiler. In order to prevent the temper of the tube from being injured by hot stean, a siphon, which condenses the steam and keeps the tube filled with water, is placed between the gage and the boiler. The sectional view of the siphon shows a loose cap over the pipe, which extends into the slobe chamber; this deflects the 


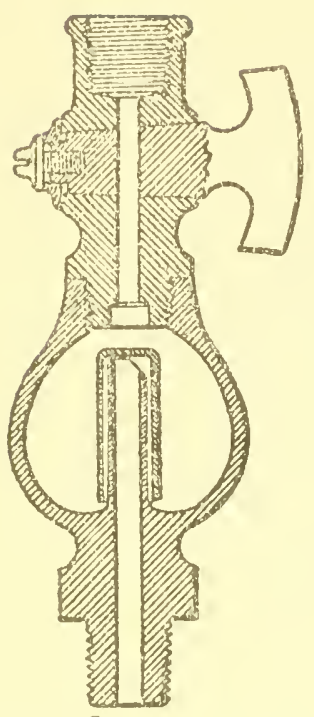

FIG. 28. SECTION OF SIPHON:

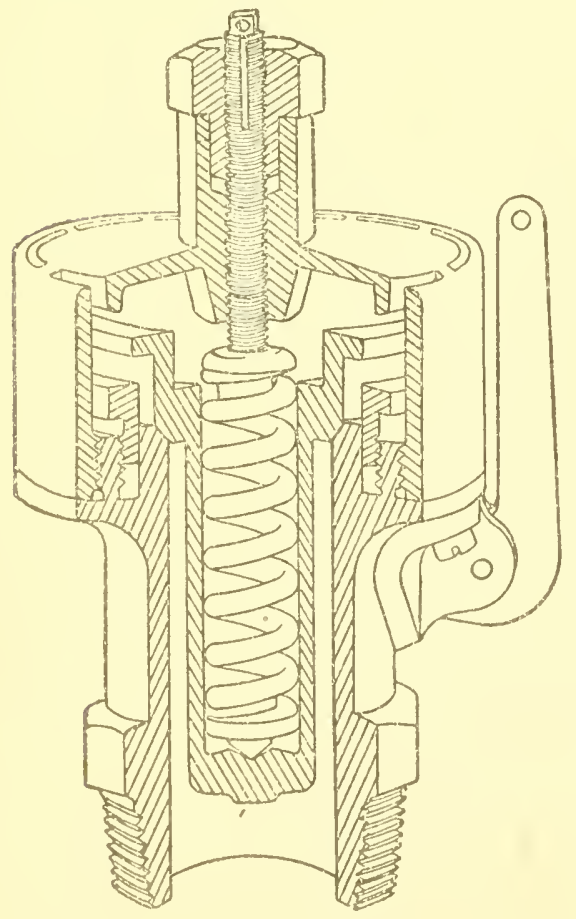

FIG. 29. open.

entering steam, to the bottom, where it condenses in the chamber, and thus effectually prevents any live steam from reaching the spring of the gage. The cap over the pipe falls when the pressure is removed, making a siphon, which is self-emptying, and thus all danger of bursting by frost is overcome. The cock should always be left

The Pop Safety Vali'e. The safety valve opens when the pressure reaches a certain point, allowing the excess steam to escape and closes when the pressure has been reduced a few pounds. The valves are usualiy set at the factory to blow off at. one hundred and thirty pounds. If a change of pressure be desired, unscrew the jam nut at the top and apply the key, provided for this purpose, to the pressure screw. For more pressure, screw down; for less, unscrew. After having obtained the desired pressure, SECTIONAL VIEN OF POP VALVE. screw the jam nut down tight 
on the pressure screw. To regulate the opening and closing action of the valve, take the pointed end of a file and apply it to the teeth of the regulator. If the valve closes with too much loss of boiler pressure, move the regulator to the right. This can be done when the valve is at the point of blowing off.

The Blozer. The blower consists simply of a pipe leading from the boiler to a nozzle in the smoke-stack. In the pipe is a valve for shutting off the steam. On traction engines, a rod is fitted to this valve, allowing it to be operated from the platform. The blower is intended for use only in raising steam, when the engine is not running. When the engine is rumning, its exhaust is discharged into the smoke-stack, creating what is known as "forced" draft, as distinguished from "natural" draft, which is due only to the height of the chimney. When an engine has been running and is temporarily shut down the blower should not be used unless the entire grate surface is covered with burning fuel. If the blower be used soon after shutting down and the grates are not entirely covered with burning fuel, cold air will pass throngh the dead places in the grates direct to the tubes, cooling them suddenly and rendering them liable to leak.

Foaming. When a boiler is "foaming," the water in the glass appears roily and the level changes rapidly, the glass appearing full one moment and nearly empty the next. Dirty water is usually the cause of foaming, alkali, or soap in any quantities being especially bad. No one should be allowed 
to wash in the tank, as even a small quantity of soap is liable to cause trouble. On account of the soap used in manufacture, new boilers are liable to foam until they are washed ont two or three times. It is difficult to tell exactly how much water there is in a foaming boiler. but it is probable that some of it is being drawn over with the steam, and therefore, the pump should feed more than the ustial amount. Do not run too long with a foaming boiler, but close the throttle occasionally to see how full the boiler is when the water settles. The remedy for foaning is to keep the boiler clean and to use clean water. Foaming often causes priming. Foaming and prining are more apt to occur with low than with high steam pressure.

Priming. When water is drawn over into the cylinder with the steam, the engine is said to "prime." A priming engine appears to be working very hard, exhausting heavily throwing water from the stack and often making a loud knocking or pounding noise in the cylinder. Priming may be catised by: $i$. Too much water in the boiler. 2. Too low steam pressure. 3. Engine working hard with the front of the boiler low. 4. Boiler working beyond its capacity. 5. Foaning. 6. Piston rings or valve leaking. 7. Valve improperly set.

In case the engine should begin to prime, the cylinder cocks should be opened and the throttle partially closed, so that the engine runs quite slowly, until dry steam comes from the cylinder cocks. Priming is liable to knock out a cylinder head. break the piston head. or do other serions 
damage to the engine. It always washes the oil from the cylinder and valve, thereby causing the latter to squeak. The lubricator or oil pump should be allowed to feed quite freely after priming, or serious injury to the valve-gear may result

Painting the Boiler. The greater part of the boiler can be kept black and looking well by rubbing with oily waste or rags. The front end of the boiler, around the smoke-box, and the smoke-stack require painting from tine to time to prevent them from beconning rusty and unsightly. For this, asphaltum or boiled linseed oil mixed with a little lamp black, is suitable. The entire boiler may aiso be painted with either of these when necessary.

Cleaning the Boilcr. No rule can be given as to the frequency with which a boiler should be washed out. In some localities it is necessary to clean it twice a week, while in others, where the water is aimost perfectly clean and pure, once in six weeks is sufficient. In emptying the boiler preparatory to cleaning, be sure that all of the fire is out, and that the steam pressure is below ten pounds before opening the blow-off valve. This is necessary, in order to prevent the mud from becoming baked on the tubes and sheets. See that the fire door, smoke-box door and drafts are all closed to prevent the boiler from cooling too quickly. To clean the boiler, remove the plugs or hand-hole plates in the water-leg and also the one at the bottom of the front tube-sheet. Wash the boiler thoroughly with a hose, using as much pressure as possible. Most of the sediment will be found around the "water-leg" and along the bottom of the barrel. 
Packing Hand Hole Plates. After the boiler has been cleaned, the hand-holes must be re-packed, for it seldom happens that a gasket can be used the second time. Gaskets, for re-packing, may be purchased, cut ready for use, or they may be cut from sheet rubber packing by the engineer. Other substances, such as sheet asbestos, card-board, straw-board, or rubber belting are sometimes used, but the most satisfactory material for this purpose is two-ply sheet rubber, which is about one-eighth of an inch thick. The gasket should be cut so as to fit closely around the flange on the plate, and should lie flat. The gasket for the bolt head may be made from the piece cut from the center of the larger gasket. Before the hand-hole plate is replaced, the nut should be oiled and screwed back and forth the whole length of the thread on the bolt, using a wrench if necessary, until it may be easily turned with the fingers. The inside of the boiler plate and the face of the hand-hole plate, where the packing touches, should be scraped as clean and smooth as possible. Care must be taken in inserting the plate, to prevent displacing the gasket. When the hand-hole plate is in place, the nut should not be screwed down too tightly, when the engine is cold, as the gasket may be injured so that it would not stand steam pressure. It is best to screw up the nut only moderately tight when cold, and turn it up a little more with a wrench when steam begins to show on the gage, and then a little more from time to time until the steam gage shows working pressure. In this way, the rubber has 
a chance to soften with the heat and adapt itself to the iron surfaces.

Cleaning the Tubes. The tubes should be cleaned at least once each day, whether in burning coal, wood or straw. The tube scraper is adjustable, and may be set out while in the tube by turning the rod to the right. Turning the rod to the left decreases the size of the scraper. Soot is a very poor conductor of heat, and even a thin coating of it affects the efficiency of the boiler to a considerable extent. It is therefore, essential to keep the scraper well set out, so that all the soot will be removed.

Expanding and Beading the Tubes. Leaky tubes should be fixed the first time the engine cools. When the steam no longer shows on the gage, remove the ash-pan bottom and grates; also the bricks, if the engine be a straw burner. If the leaks be only slight ones, they may be stopped by simply using a beading tool. To do this clean the end of the tube and the tube sheet and place the long or guiding end of the tool within the tube. Use a small hammer, and with light blows bead the tube all around, moving the tool slightly at each blow. The beading tool may be used when there is water in the boiler. but care must be taken to use only very light blows of the hammer or the concussion will be transmitted by the water and loosen other tubes. Having water iil the boiler when beading the tubes has the advantage of showing the leaks so that it may be known when the tube is tight. If the leaks be more serious, it will be necessary to 
use an cxpander. The expander reguires considerable care and some experience to use, and in the hands of an inexperienced or careless workman, may cause great damage to the boiler by distorting the flue sheet, or rolling the tubes thin and worthless. In 11 sing the roller expander, place the flange against the tube sheet and drive the pin in with a few light blows. Then turn it back and forth with a wrench until it loosens. Drive the pin in again, and repeat the operation several times. The roller expander may be used when there is water in the boiler. If a spring or plug expander be used, be stre that it is the right size, and is made to fit the thickness of the flue sheet in your boiler. This is very important. To use the spring expander, place it within the tube with the shoulder well up against the tube sheet. Drive in the taper pin with a few light blows and then jar it ont by striking it on the side. Repeat several times, turning the expancler a little each time, until it has made a complete tevolution. The spring expander cannot be used when there is water in the boiler, as the jar of the hammer-blows will be transmitted to the other tubes and loosen them. Use plenty of oil on either styie of expander, and carefully clean the end of the tube of soot and scale before inserting the tool. Care must be taken, in expanding the tubes, not to expand then so liard as to stretch or enlarge the hole in the tube sheet, and thereby loosen the adjoining tubes. When all of the leaky tubes have been cxpanded, they must be beaded down against the sheet with the beading tool. 
Danger of Using an Old Boiler. There is danger of a boiler exploding with plenty of water in it, if any part has corroded or been weakened so that a considerable portion of it is liable to give way at any time. The water in a steam boiler inder pressure, is explosive, and anything that reduces the pressure suddenly, will precipitate an cxplosion. Return flue boilers are especially danperous when old, on account of the large flue.

Testing a Boiler. To test an old boiler is not an easy matter. We advise making the "cold water test" as follows: Fill the boiler nearly full of water and build a fire to heat the water luke warm. When this is done, withdraw the fire, fill the boiler to the top of the dome and attach a small hand pump. The steam gage will register the pressure, which may be anything desired. The chill is taken off the water as the boiler is less liable to be strained when the iron is a little warm. The boiler may be tested with a hammer, but when coated with scale, this is not easy, even for an expert. The best way to test it is to go over the boiler with a straight-cdge, carefully noting how much the sheets are out of shape. This should be done first with no pressure, then repeating, increasing the pressure with the pump about twenty-five pounds at a time. On a locomotive boiler, the straight edge should be placed between the stay bolts. The parts exposed to the greatest heat should be examined par ticularly, as should also the bottom of the shell and along the riveted seams, where it is liable to be corroded. If there be any doubt about any part, or if the straight-edge 
shows that the sheets spring or bulge with the pressure, the only way to be sure is to drill a small hole and determine the thickness. If found to be safe, the hole may be made tight by tapping and screwing in a copper plug.

Another Mcthod. A boiler may be tested without using a pump. In this case the boiler is filled with water to the very top of the dome before the fire is built, and the expansion of the water, as it increases in temperature, gives the desired pressure for testing. The boiler may be filled by removing the whistle or the pop-valve and pouring the water through its pipe. The throttle and all of the openings from the boiler must be closed before the fire is built. Straw should be used as fuel, as a fire of it may be quickly checked. When other fuel, such as pine kindling wood is used, very little should be allowed in the fire-box, and the fire carefully watched. Enough dirt, sand or ashes should be at hand to check the fire at any instant. The pressure must be closely watched, and if it shows a tendency to rise too rapidly, or go too high, the fire must be covered. The pop-valve will open at the point at which it is set, in the same way as for steam pressure.

Amount of Pressure. An old boiler should not be tested at a greater pressure than one hundred and fifty pounds, as higher ones are apt to strain and weaken the boiler. When a boiler has been tested at one hundred and fifty pounds cold water pressure, it may be used at a working pressure of one hundred and twenty-five pounds. 


\section{CHAPTER IX.}

\section{THE TRACTION GEARING.}

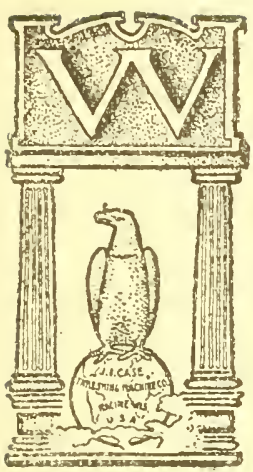

HEN the traction gearing is used only in moving the engine from place to place, very little attention need be given to it. When, however, the engine is used for plowing or for hauling freight, the gearing must receive careful attention in order to prevent the possibility of expensive repairs. The parts which require special attention on engines used for hauling heavy loads are the lower cannon bearing and the stud on which the intermediate gear runs. The pinions on the counter-shaft should mesh properly with the gears on the traction wheels. These may be set deeper into mesh on "Case" engines by adjusting the turn-buckles in the links, called "distance links," which connect the upper and lower cannon bearings. The springs which carry the weight of the boiler should not have too much leeway if the engine be used for heavy hauling.

Oiling the Camnon Bearings. A quantity of oil may be poured into the upper and lower cannon bearings, which will insure the lubrication of the axle and counter-shaft, since it can only work out at the ends. The oil boxes should be partly filled with wool or waste, and all other 
openings stopped by carefully fitteci pieces of wood, in order to prevent sand and other gritty substances from entering the cannon bearings.

Greasing the Gearing. The gearing should be kept well coated with axle grease. It is true that many men argue

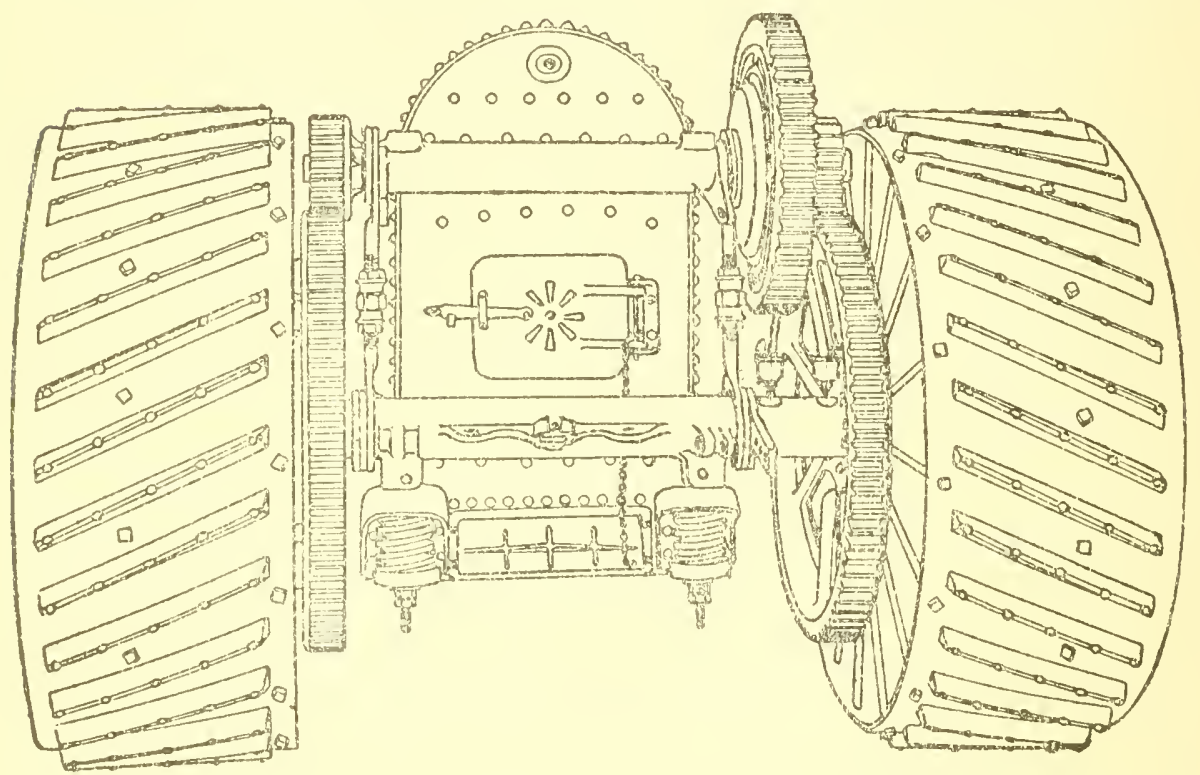

FIG. 3O. CUT SIIGWING CANNON BEARINGS AND GEARING.

that grease collects and holds sand which will cause cutting of gears. To prove the fallacy of this belief, however, it is only necessary to observe the gearing on engines which have been rmb by men of this opinion. In many cases, the gearing will be found nore badly worn than its use would warrant.

The Friction Cutch. The friction clutch is used to connect the engine to the traction gearing and wheels. By means of it, the engine may be made to travel as slowly as desired, while the engine proper is ruming at full speed. When the cluth is in partial engagement, the shoes, $(A)$, 
(Fig. 30), press lightly against the rim of the fly-wheel, transmitting only part of its motion to the gearing. But when in full engagement, the shoes press so hard against the rim of the fly-wheel that they prevent slipping, thus locking the flywheel and pinion, (C), together. The two shoes are hinged to the ends of the arm, (B). This arm has a long sleeve, which is loose upon the shaft, but at the end of which the pinion, (C), is firmly keyed. The sliding ring, (D), (Fig. $3 \mathrm{I})$, is loose upon the sleeve, and when moved toward the flywheel, straightens the toggle levers, thus pressing the shoes

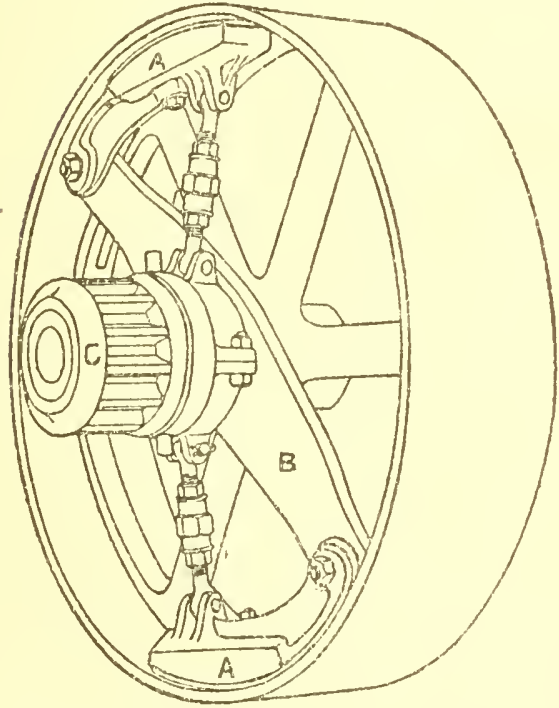

FIG. 3I. FRICTION CLUTCH. against the rim of the flywheel. The sliding ring is moved by means of the trunnion ring, $(\mathrm{E})$, which remains stationary, but allows the sliding ring to revolve within it. The trunnion ring is held to the sliding ring by means of the clamp ring, $(\mathrm{F})$.

Adjusting the $C l u t c h$. The wear on the shoes is taken up by means of the turn-buckles in the toggie levers. They should be so adjusted that the toggle levers will just pass the straight line when the clutch is in engagement, thus relieving the trumnion ring of all side friction; they should also be so adjusted as 
to produce equal tension on both shoes, or undue friction will be produced on the sliding ring making the lever hard to handle. A good way to adjust the turnbuckles is to apply a large wrench to them, when the clutch is in engagement, and lengthen the toggle levers until the shoes are pressed hard against the rim. In this manner, the shoes can be given equal and sufficient pressure and when the clutch is drawn out of engagement, the shoes will clear the rim. Of course, the jam-nuts must be loosened before adjusting and tightened afterwards. The inside end of the fly-wheel hub should touch the end of the clutch sleeve, or the sliding ring cannot carry the toggle levers beyond the straight line. The wooden shoes are easily replaced when worn out.

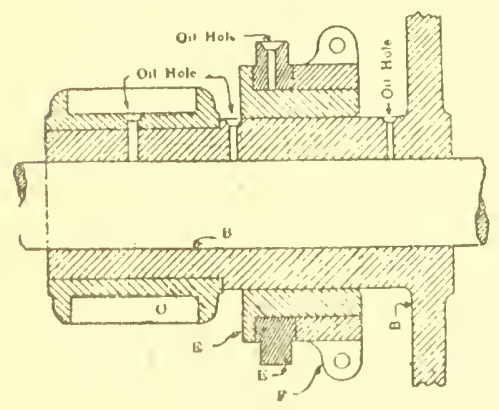

FIG. 32 .

SECTION OF CLUTCII-ARM AND RINGS.

Examine the clutch and see that it is properly adjusted before starting up or down a very steep hill. If it be in good order. it will not fail to do its work.

Oiling the Clutch. When the engine is traveling the entire clutch moves together with the exception of the trunnionring. This, then, should be oiled when the engine is on the road. When threshing, the clutch remains stationary, while the shaft revolves within it. The long sleeve should then be oiled and also the end of the fly-wheel hub where it comes in contact with the end of the sleeve. There are 
eight or nine oil-holes in the sleeve, three of which are drilled between the teeth of the pinion. There is also an oil-hole in the upper trunnion of the trunnion-ring.

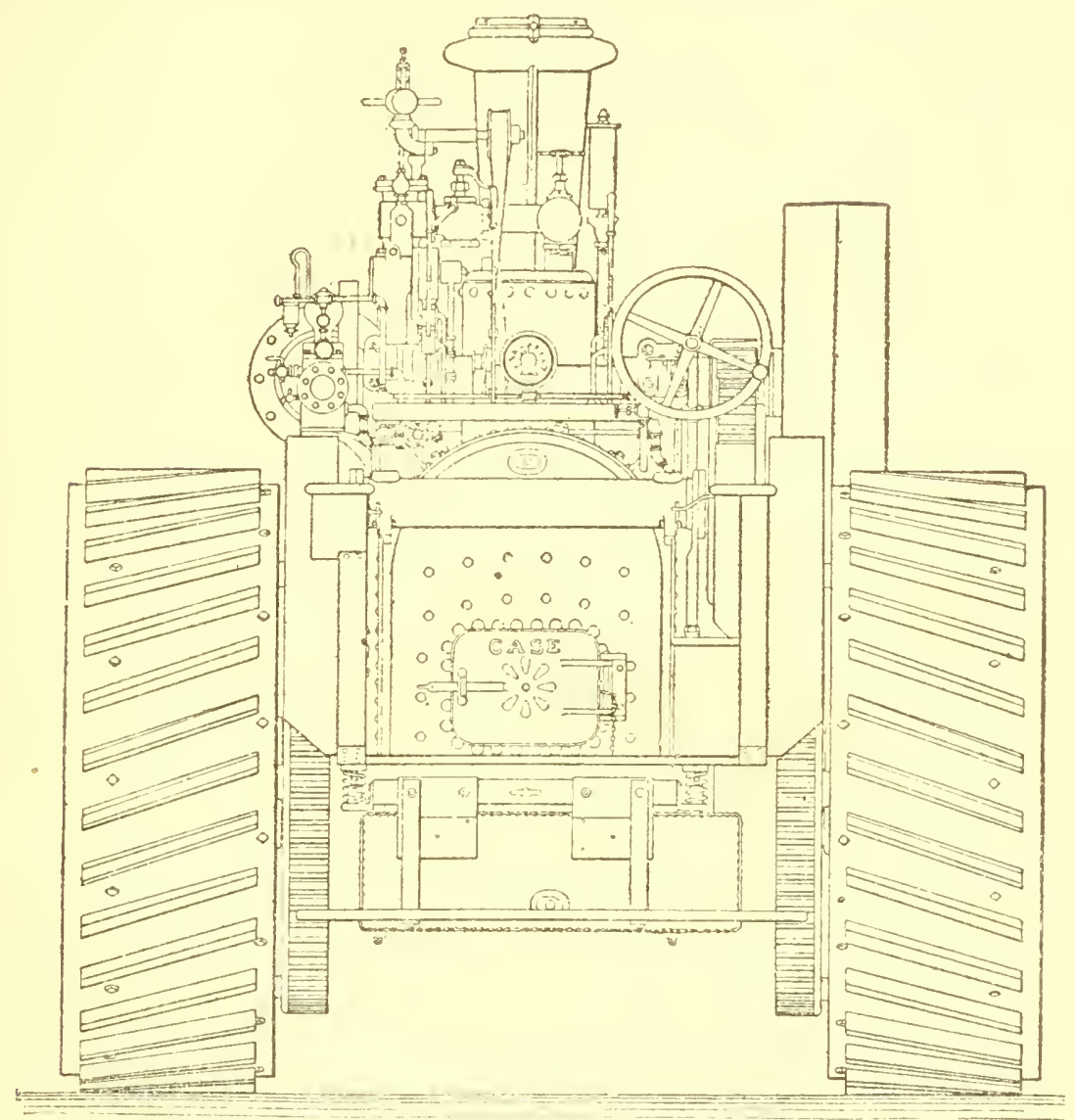

FIG. 33. REAR VIEW OF "CASE" TRACTION ENGINE.

The Differential Gear. In order to have both traction wheels pull, when the engine is traveling either forward or backward, and at the same time allow one wheel to travel further than the other in turning corners, the differential gear is necessary. It transmits the power from the intermediate gear to the two counter-shaft pinions, which mesh with the 
spur gears on the traction wheels. The four bevel pinions are carried by the center casting, and mesh with tivo bevel gears, one of which is cast in one piece with the right-hand counter-shaft pinion, (which is loose upon the shaft), and the other of which is keyed to the comnter-shaft and drives the left-hand counter-shaft pinion, (which is also keyed to the shaft). It will be seen that when the engine travels straight ahead, both counter-shaft pinions turn with the shaft and the whole differential revolves as one piece. In turning corners, however, the bevel pinions revolve, permitting one of the counter-shaft pinions to revolve faster than the other, thus allowing the traction wheels to accommodate themselves to the curve of the road. The differential spur wheel is a separate piece from the center casting, the power being transmitted from the rim to the conter casting through coil springs, which relieve the gearing of the shocks of starting and stopping the engine.

Locking the Differential. When both traction wheels have resistance, they pull equally, but if the engine be "jacked up" until one of them is off the ground and free to turn, then when the engine is started, the differential gear will allow the free traction wheel to revolve at twice its usual specd, while the traction wheel on the ground will scarcely pull at all. Revolving at twice its usual speed means that the frce traction wheel makes one revolution to nine of the fly-wheel, instead of, to the usual eighteen. Often, when one wheel is in a slippery place, it will spin around, while 
the other on solid ground remains still without pulling at all. To provide for such emergencies, the hub of the left traction wheel is made so that a pin can be inserted and both wheels locked to the axle. This, of course, makes both traction wheels revolve together, and prevents the differential gear from working. The engine must be steered straight when the lock-pin is used, or broken gearing is liable to result.
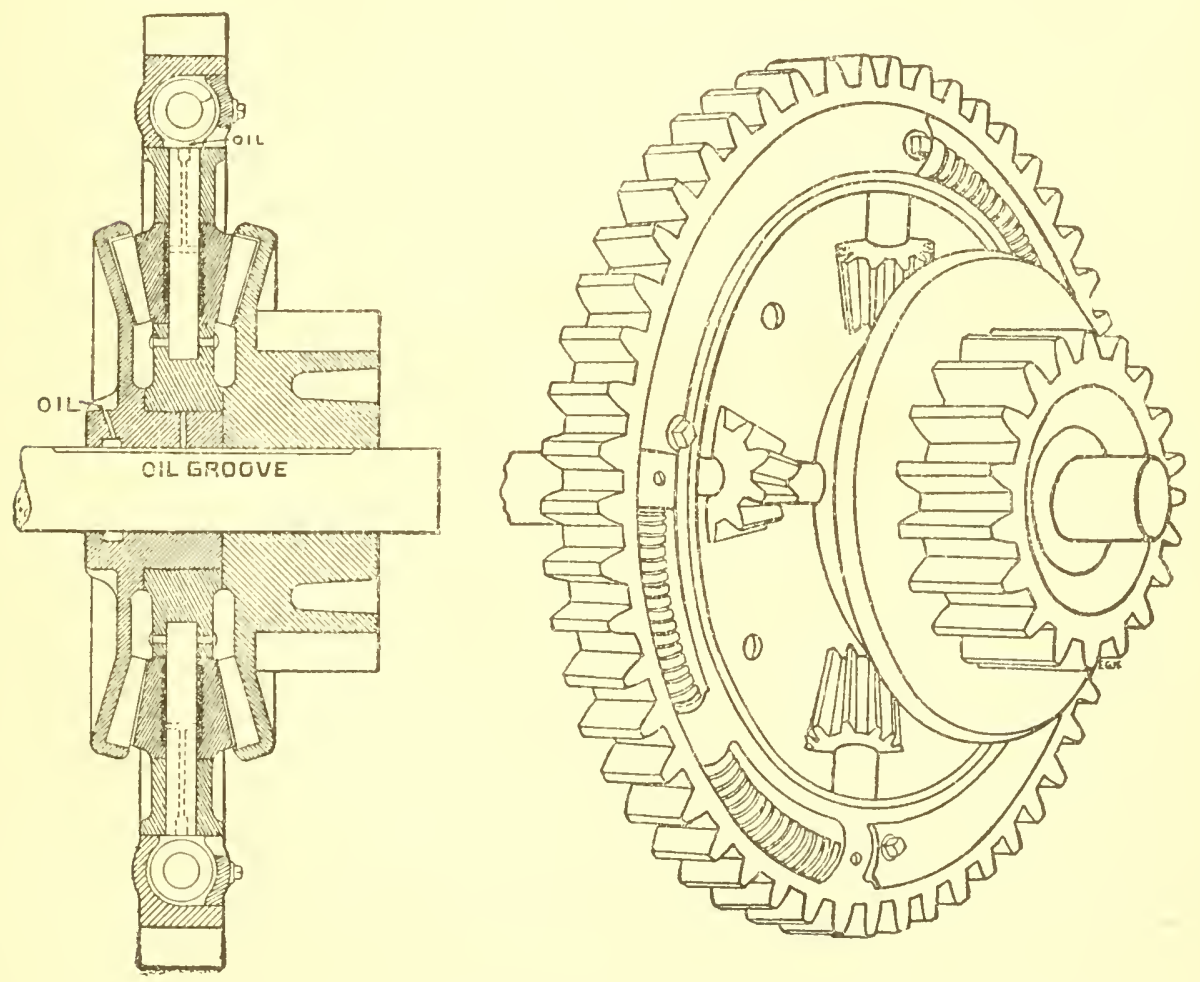

FIG. 34. THE DIFFERENTIAL GEAR, SHOWING SPRINGS

Oiting the Differential. The journals of the bevel-pin.ons in the differential and the hub of the left traction wheel should be oiled occasionally. The left-hand or inside bevel- 
gear turns upon the shaft, when the differential-gear works, and accordingly, it should be oiled occasionally through the hole provided for this purpose in its hub. The bevel-pinions also revolve about their shafts. An oil-hole is drilled through the center of each of these shafts, to provide for oiling them, as is shown in Fig. 32. The hub of the left traction wheel turns upon the axle in turning corners, and therefore should be oiled occasionally. This is done by removing the capscrews in the hub of the traction wheel. 


\section{CHAPTER X.}

WATER-TANKS.

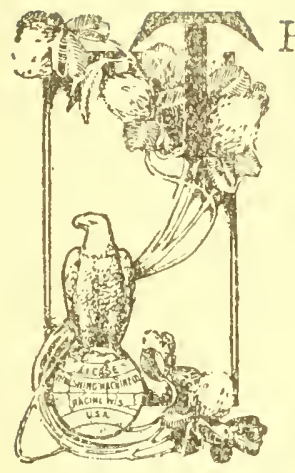

HE threshing outfit, to be complete, must be provided with first-class water-tanks. A leaky tank is very apt to cause clelay. One that is liable to break down may entirely cut off the water supply for a time. The axles are wet much of the time and therefore, rot very fast and are apt to break without warning. Waiting for water for any cause should not be tolerated by the man in charge of a threshing outfit, and one whose duty it is to haul water should never allow the rig to be idle for lack of it. In localities where the farms are small and water may be had near at hand, one nounted tank does very well, as the platform tank, (with which an engine is usually equipped), will furnish the water while the mounted tank is being refilled. In localities where the water must sometimes be hauled a mile or more, two mounted tanks are generally used, or if only one be used, three or four barrels should be provided to use in addition to the platform tank.

Engine Tenders. Within the last few years engine terders have come largely into use and they are very convenient, especially where most of the threshing is done around 
barns and it is necessary to back the engine more or less. The engine tender does what its name implies, that is, it keeps a supply of coal and water near at hand.

Tank Pumps. At least one tank with each outfit should have a tank pump, with a capacity of about two barrels a minute. The pump is of use not only in filling the tank, but also in rapidly transferring water from it to the platform tank, engine tender, or barrels. When equipped with a sprinkling hose, it is also useful in washing out the boiler.

Attaching "Case" Tender. Remove the tank from under the platform. Place the tender in position behind the engine and put in the draw-pin. Turn the front axle of the engine square, measuring on cacll side with a string or tape from the traction wheel of the engine. Place the tender axle square, measuring from the traction wheels in like manner. Now connect the steering chains. They pass from the tender axle, above the step, along the sides of the fire-box and pass over the reach-rod, crossed, the right chain going to the left end and the left chain to the right end of the front axle. An eye-bracket, ( $56 \mathrm{R})$, is placed on each side of the firebox, near the botton, through which the chains pass. To locate the holes for bolting these on, hold one of them in position, (with the bolt holes down), between the second and third rivet from the front, in the horizontal row of rivets along the sides, so that the center of the bolt holes will be four and three-eighths inches from the bottom of the sheet. Mark the holes through the casting and drill them 
with a nine-sixteenths inch drill. This will bring the heads of the one-half inch bolts inside of the ash pan. The chain brackets on the front axle of the engine are placed so that the chain is above the axle. The position of these brackets is given in the table below.

\begin{tabular}{|c|c|c|c|c|c|c|}
\hline $\begin{array}{c}\text { SIZE } \\
\text { ENGIKE }\end{array}$ & 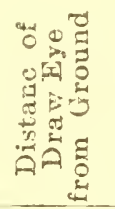 & 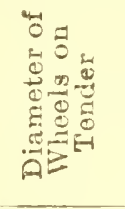 & 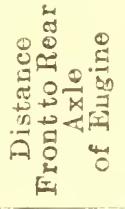 & 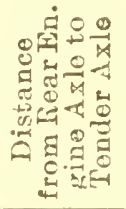 & 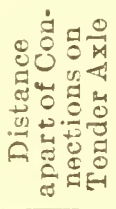 & 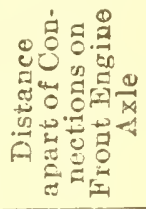 \\
\hline & Inches. & Inches. & Inches & Inches & Inches & Inches \\
\hline 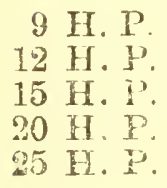 & $\begin{array}{l}251: 2 \\
29 \\
29 \\
32 \\
32\end{array}$ & $\begin{array}{l}30 \\
31 \\
31 \\
12 \\
42\end{array}$ & $\begin{array}{l}98 \\
113 \\
126 \\
1311 \% \\
1121 \%\end{array}$ & $\begin{array}{l}861 \% \\
87 \\
87 \\
87 \\
871 / 2\end{array}$ & $\begin{array}{l}37 \\
37 \\
37 \\
37 \\
37\end{array}$ & $\begin{array}{l}321 / 2 \\
281 / 2 \\
251 / 2 \\
24 \\
221 / 2\end{array}$ \\
\hline
\end{tabular}

The chains must not be allowed to get too loose. The wear may be taken up by means of the turn-buckles. If they are too taut, the engine will steer hard. When connected according to these directions, the tender will retain its alignment while following the engine backward Oi forward, around any curve.

Attaching to Other Engines. For engines of other make, to find the distance the chains should be apart on the front axle, first place the tender in position and place the front axle of the engine and the axle of the tender square. Then measure the distance of the tender axle from the rear axle of the engine and multiply this number by the distance in inches between the chain connections on the tender axle, 
(thirty-seven inches). Divide this product by the distance of the front axle of the engine from the rear axle of the engine. The numbers must be in inches in every case and the quotient so obtained will be the distance the chains should be apart on the front axle of the engine. If it be impossible to put them the required distance apart on the engine axle, assume some distance between the connections on the tender axle and figure it again, substituting the assumed distance. To find the diameter of the wheels for the tender, subtract eleven from the number of inches the engine draw-eye is from the ground and multiply the remainder by two; the product will be the required diameter, in inches, of the tender wheels. Three sizes of wheels are furnished, thirty inch, thirty-four inch and forty-two inch. The parts necessary to attach the tender to "Case" center-crank engines can also he furnished. 


\section{CHAPTER XI.}

\section{HORSE-POWERS.}

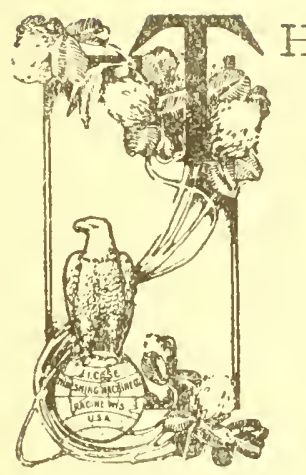

HE horse-power, which, at one time, was the principal means of driving threshingmachines, is still used to a considerable extent for this purpose. With a sufficient number of good, strong horses, this means of supplying the motive power for threshing is very satisfactory, and, owing to the fact that the investment involved in a horse-power outfit is considerably less than is required for a stean rig, it is probable that the horse-power will continue its usefulness in this industry for many years to come. The present style of metal-frame power is superior to the wood-frame because it is not subject to atmospheric conditions, which continually cause the swelling and shrinking of wood.

Starting a Nea Horse-Power. The first thing to do in preparing a new power for work is to carefully clean the cinders from the oil-boxes. Next, oil each of the bearings and thoroughly grease all the gearing, turning the power by hand until the entire wearing surface is well lubricated. A new power should be run at least half an hour before being coupled to the separator or other machine to be run. If the horses be nervous, because unused to the work, put a man 
with each team until they are accustomed to the noise and to traveling in a circle.

Setting a Horse-Pozer. A horse-power, to work properly, must be securely held in position. To do this, it is necessary to use at least four stakes, each of which should be about three feet long. The power should be set in alignment with the separator so that the tumbling-rods are as straight as possible. As it is almost impossible to secure the power so that it will not shift slightly when started, it is best to make allowance for this when setting. The line of rools canmot be straight horizontally, as one end must attach to the spur-pinion shaft of the power and the other to the bevel-gear shaft of the separator, while the second rod from the power must lie near the ground in order to allow the horses to walk over it. The angles in the line of rods necessary to meet these conditions are taken care of by the knuckles connecting them, but the angles should be carefully divided so that they are as slight as possible at each knuckle. When run at great angles, knuckles consume considerable power and cause excessive and unnecessary work on the part of the horses.

Iubrication of the Horse-Power. There are two bullpinion boxes, (an upper and lower), and two center-boxes at cach end, making eight boxes in all, to be oiled on the bull-pinion shafts. There are also two spur-pinion shaft boxes and the journals of the traverse-rollers to be oiled. All the gearing and the bottom and the top of the bull-wheel 
rim should be coated with good axle grease. When the grease becomes hard and caked with dirt, it should be cleaned off and fresh grease applied.

Connecting the Equalisers. The following cut shows a top view of a fourteen-horse power with "sweeps," braces

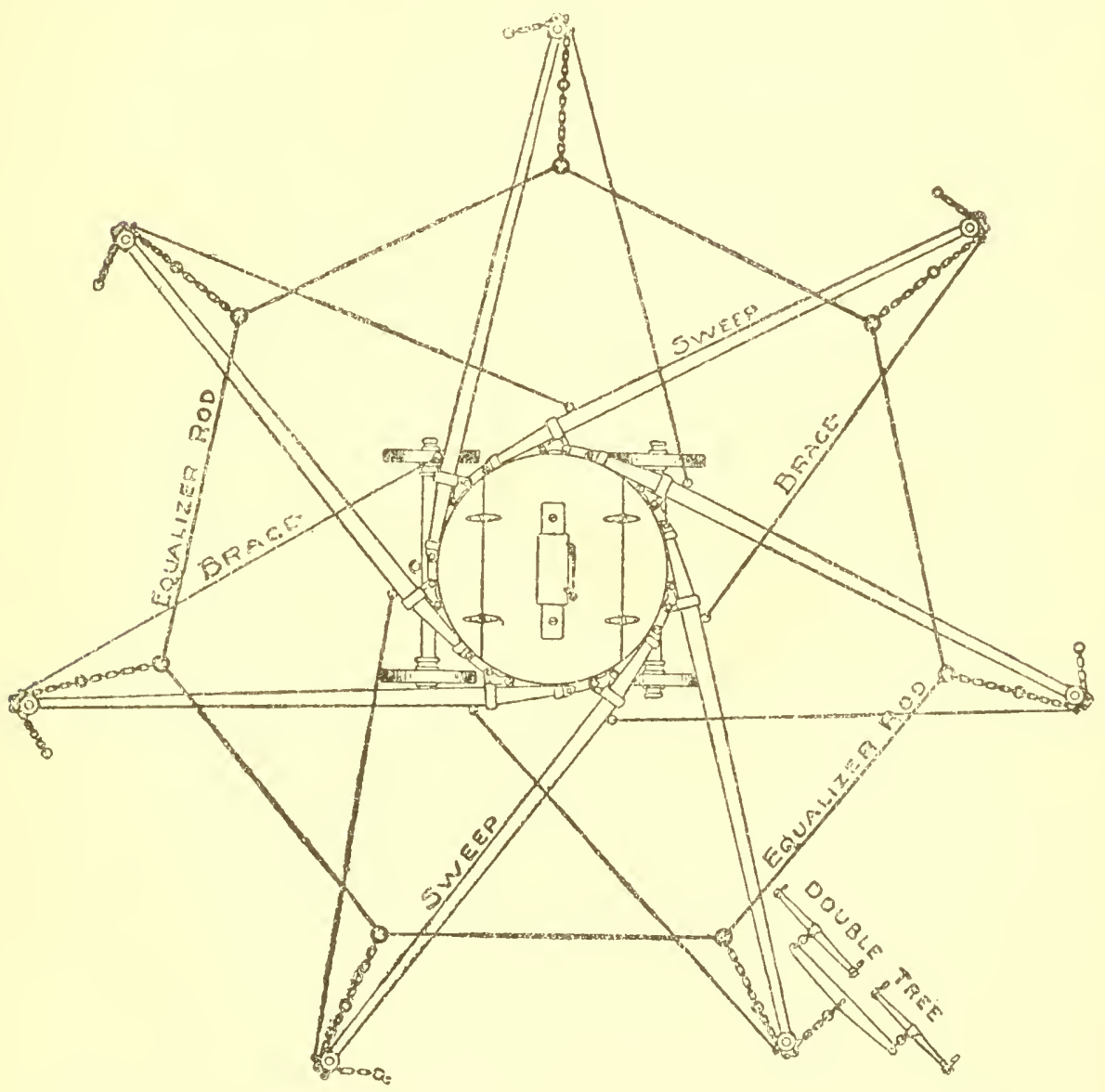

FIG. 35. TOP IIEW OF POWER IVITII SWEEPS AND EOUALIZER ATTACHED.

and equalizer-rods attached. In hooking the equalizer-rods, always hook the ends of two rods in the and ring of the 
chains. The ring near the center of each chain is merely a stop and the rods should never be hooked into it.

Speed of the Tumbling-Rods. The use of the sixteen$\operatorname{cog}$ pinion, which gives one-hundred and one revolutions of the tumbling-rods to one round of the horses, is recommended, and will ordinarily run the cylinder of a "Case" separator at the proper speed. The following table gives a complete list of spur-pinions for "Case" horse-powers, any of which may be obtained if desired.

\begin{tabular}{|c|c|c|c|c|c|c|}
\hline ஜ & 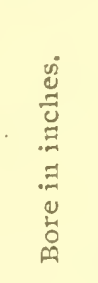 & 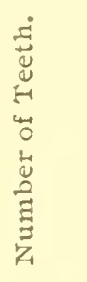 & 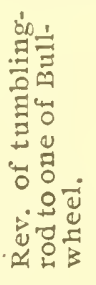 & 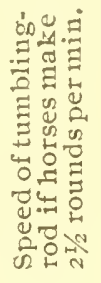 & 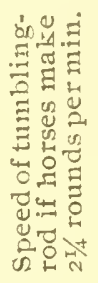 & 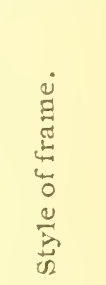 \\
\hline $41 / 8 W$ & $\mathrm{I}^{11} / 32$ & I 5 & 107 & 267 & $24 \mathrm{I}$ & Wood \\
\hline $4 \mathrm{~W}$ & $\mathrm{I}^{11 / 32}$ & 16 & IOI & $25^{2}$ & 227 & Wood \\
\hline $41 / 2 W$ & $I^{11 / 32}$ & I7 & 95 & 237 & 214 & Wood \\
\hline $9 \mathrm{~W}$ & $I^{11 / 32}$ & 18. & 90 & 225 & 202 & Wood \\
\hline $7 \mathrm{~W}$ & I11/32 & 20 & $8 I$ & 202 & I 82 & Wood \\
\hline $41 / 4 W$ & $1^{11 / 32}$ & $2 \mathrm{I}$ & 76 & 190 & I 7 I & Wood \\
\hline $8 W$ & $1^{11 / 32}$ & 22 & 73 & 182 & 164 & Wood \\
\hline A $212 W$ & $1 / 1 / 2$ & I 5 & 107 & 267 & $24 \mathrm{I}$ & Iro11 \\
\hline 2 I $2 W$ & $\mathrm{I} 1 / 2$ & 16 & IOI & 252 & 227 & Iron \\
\hline $2 \mathrm{I}_{3} \mathrm{~W}$ & I $1 / 2$ & 17 & 95 & 237 & 214 & Iron \\
\hline A9IV & $\mathrm{I} 1 / 2$ & I8 & 90 & 225 & $2 \mathrm{O} 2$ & Iron \\
\hline $\mathrm{A}_{7} \mathrm{~W}$ & $I \frac{1}{2}$ & 20 & SI & 202 & $\mathrm{I} S 2$ & Iron \\
\hline ASW & $I^{1 / 2}$ & 22 & 73 & 182 & I 64 & Iron \\
\hline
\end{tabular}

Scparator Sidc-Gear. A separator must be fitted with a side-gear, or a jack must be used, in order to be driven by means of a horse-power. A speed of 750 revolutions for the twenty-bar or I075 for the twelve-bar cylinder of "Case" separators fitted with a side-gear, requires a tumbling-rod 
speed of about 227 revolutions per minute. The required speed of the tumbling-rods is found, in each case, by multiplying the number of revolutions of the cylinder by the number of teeth on the cylinder-pinion and dividing the product by the number of teeth on the bevel-gear.

Jacks for Horse-Pozers. The device used to change the motion of the tumbling-rods into that of a pulley is called a "jack." The "Case" jack has a bevel-gear, (208T), with sixty teeth and a pinion, $(209 \mathrm{~T})$, with twenty-two teeth. The pulley, (206T), is sixteen inches in diameter and has a six-inch face.

Adjusting the Iron-Frame Horse-Power. It is very important that the bull-pinions should mesh properly with the bull-wheel. When the bull-pinion shafts are correctly set, the bull-wheel will not have more than one-sixteenth of an inch up and down play at any point. As the web between the upper and lower cogs of the bull-wheel varies in thickness, it is best to locate the thickest place and mark it. This part may be then turned between the bull-pinions and the shaft bearings adjusted so that the gears mesh as deeply as possible and at the same time allow the bull-wheel to pass freely between them. In building powers at the factory leather packing is placed between the box of the upper short bull-pinion shaft and the main frame It is the intention to shave down this leather packing from time to time as the bearings wear, thus allowing the bull-pinions to be kept in proper mesh by means of set screws. The box of the 
lower shott bull-pinion shaft has no leather between it and the main frame; however, it can be set deeper in gear at any time by turning its set-screw from below. The main spur-wheel shaft is not adjustable and the set screws bearing against its boxes are used only to prevent them from becoming loose in their slots. Adjustable slides are placed above and below the bull-wheel. Those below have setscrew adjustment, and should be adjusted, as they wear, so that the bull-wheel just clears the lower bull-pinions. The top slides prevent the up and down novement of the bullwheel, and should be set down as they wear. The traverserollers prevent the bull-wheel from crowding endwise on the bull-pinions. They should be set out by the key adjustment as they wear. The spur-pinion frame is secured by four five-eighths inch bolts in slotted holes. These allow adjustment of the pinion so that it may be made to mesh properly with the spur-wheel. When properly set, the pitch circles will touch and the spur-pinion shaft will be parallel with the spur-wheel shaft.

Cantion Conccrung the Bull-Pinion Boxes. The bullpinion boxes, $8 I 1 / 4 \mathrm{~W}$ and $8 I \mathrm{I} / 2 \mathrm{~W}$, have flanges which hook over the outside of the main frame, thus preventing them from crowding toward the center. When these boxes have been removed, care must be taken in replacing them to insure these flanges hooking over the outside of the frame, for if they be placed too far toward the center of the power, these flanges may come in contact with the box seat and prevent 
the bull-pinions from meshing as deeply as they should with the bull-wheel. To prevent their getting loose, the large set-screws are locked by means of small set-screws, which bear against their threads.

Removing the Shafts. To take out the spur-wheel shaft, remove the four bolts that secure the cross-pieces to the main frame, and lrop them, together with the spur-pinion frame, to the ground. Next remove the four bolts securing the bull-pinion boxes and those securing the center boxes, after which the spur-wheel shaft may be taken out without disturbing the gears keyed to it. The short bull-pinion shafts have trumnion-boxes at their inner ends, which permit movement sufficient to allow the shafts to be removed. It is necessary to remove the wood piece with slide attached, which is on the rear axle.

Reversing the Gearing. The bull-wheel may be turned over, the short shafts interchanged and the spur-wheel shaft reversed. (end for end). so that the teeth of all the gearing may be worn on both their faces.

Reverse Motion of Tumbling-Rods. The direction in which the tumbling-rods revolve may be reversed so that they turn in the same direction as that in which the horses walk, instead of turning, as usual, in the opposite direction. When reverse motion is necessary for driving machinery other than "Case" separators, proceed to attach the parts as follows: First, bore a one and one-half inch hole in rear axle, two and three-eighths inches from its top and five and 
one-half inches from the center of the bolt holding the casting, ${ } \delta_{4} \mathrm{~W}$ or $222 \mathrm{~W}$. Then bolt steady-bearing, $104 \mathrm{~W}$, on the inside of the axle with seven-sixteenths by four and three-fourths inch bolts. Next put the knuclile on the spurpinion shaft and connect it with the short rod, oI $25 \mathrm{~W}$, which passes through the casting, $104 \mathrm{~W}$, and through the hole in the axle.

Attaching Truck-Brake to Iron-Frame Horse-Power. Put the brake pipe under the main frame with casting 2 roW, face down and on the right-hand side. The pipe is located between the two five-eighths inch hooks and rear wheel, the short ends of the hooks coming outside of the iron frame. In order to prevent the nuts from working loose, the ends of the hooks may be riveted. When this is done, casting 32I W may be bolted on top of the flange of the main frame. A hole to receive it will be found on the front end of the power frame. Next insert the iron lever into its socket, 2IoW, and tighten the set-screws, which should not be tightened too much, or they will cause unnecessary strain on casting $2 \mathrm{IOW}$. Put the ratchet in casting $232 \mathrm{~W}$ with the hole down and with the notches turned towards the front. Then, put it in the notch that holds the brake from the wheels, and bolt it to the brake lever below. Place the brake-block casting, 208W, on the right end of the pipe and $209 \mathrm{~W}$ on the left; bring the blocks against the wheels and turn the set screws up tight; then loosen and remove, and with a file or cold chisel, flatten a place on the pipe for the 
set-screws. This will prevent the pipe from turning in these castings. The pipe is countersunk for the set-screws in $2 \mathrm{roW}$, these set-screws being tightened at the factory. The key with straps should be nailed to the driver's platform. This is used to prevent the brake from dropping onto the wheels when not wanted. The brake is applied by the foot. Do not press the ratchet down harder than necessary.

The Spur-Wheel and Bull-Pinion Shafts. The keyseats of these shafts are cut in line with each other and those in the bull-pinions and inside-pinions are cut with reference to one of their teeth so that when the pinions are keyed to the shaft, their teeth will be in line. It will be seen that if the shaft has been twisted so that the teeth of the pinions are even slightly out of line, the power cannot be made to run properly. A new spur-wheel shaft is the only remedy for such a condition.

Work Done by Horses. The sweeps of the twelve-horse power and smaller sizes are twelve feet and seven inches long, and their ends move in a circle the circumference of which is seventy-nine feet. The sweeps of the fourteenhorse power are fourteen feet long, and their ends move in a circle, the circumference of which is eighty-nine feet. Horses ordinarily travel around the seventy-nine foot circle two and one-half times a minute, and around the eighty-nine foot circle two and one-fourth times a minute, in either case covering about two and one-fourth miles per hour. The term "horse-power" (the standard measure of power) is defined 
as the power necessary to raise 33.000 pounds one foot per minute. A horse walks two hundred feet per minute in traveling around the eighty-nine foot circle two and onequarter times per minute so that to do work equal to one "horse-power" it is necessary for it to pull only one-hundred and sixty-five pounds, which is the quotient of 33.000 divided by 200. This quotient does not allow for the friction of the machine.

The Number of Horses. When desired for light work, the regular twelve-horse power with six sweeps may be used with only six horses by tying up equalizers on the empty sweeps and attaching teams to alternate sweeps, or by hitching a single horse to each sweep. In the same manner any of the other sizes of horse-powers may be used with half the usual number of horses. Since different numbers of sweeps are used the holes in the bull-wheel are marked with dots so that the brackets and end-supports for the sweeps may be easily placed in their proper positions. One of each of these castings should be first bolted to the holes with three lots near them for this set of holes is used with any number of levers. Bull-wheel $89 \mathrm{~W}$ has the dots at the side of the holes for twelve horses, inside of the holes for ten horses, and outside of the holes for eight horses. Bullwheel IoW has the dots at the sides of the holes for twelve horses, inside of the holes for ten horses and outside of the holes for fourteen horses. 


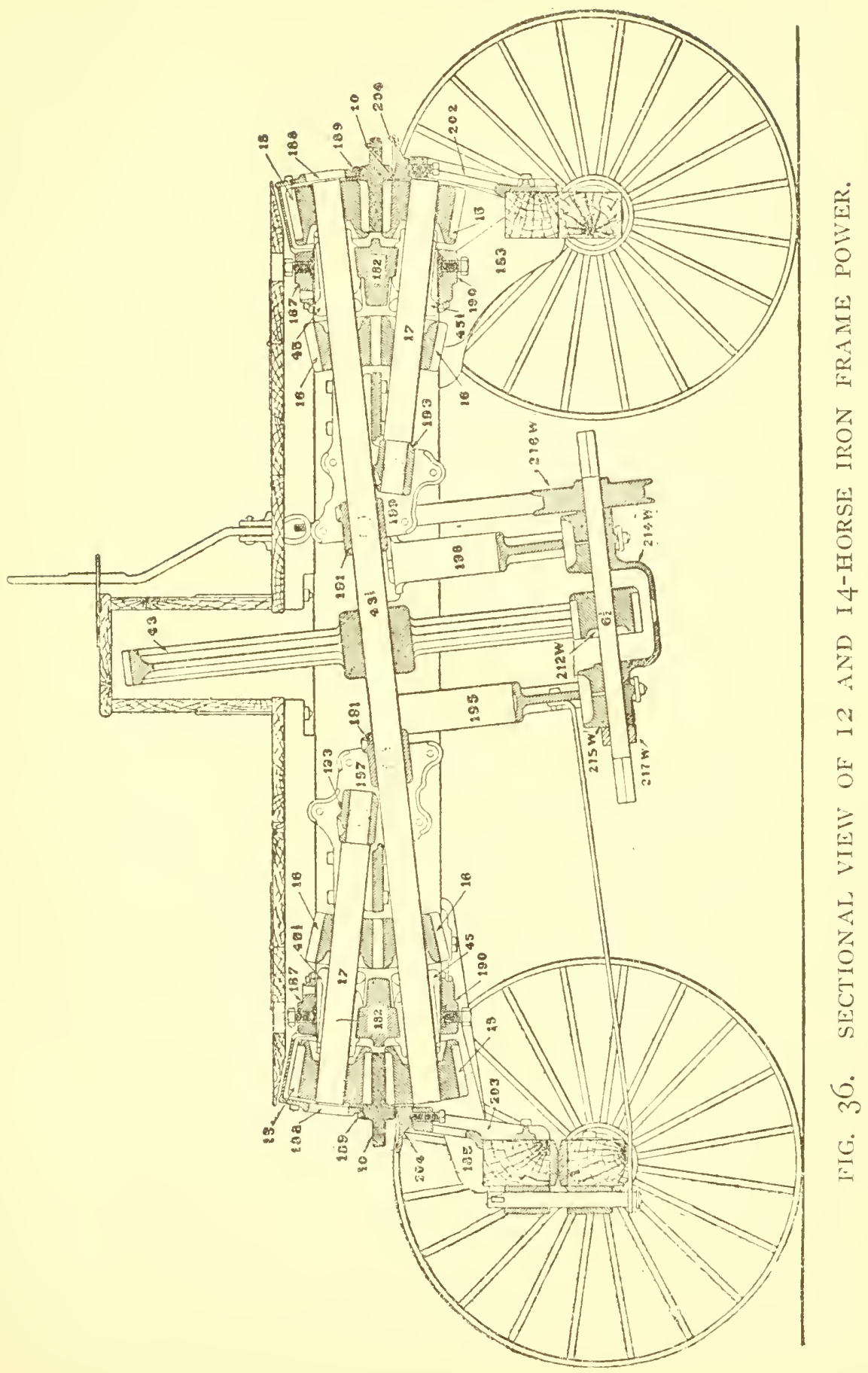


PARTS USED ON IRON AND WOOD FRAME POWERS.

\begin{tabular}{|c|c|c|c|c|c|}
\hline $\begin{array}{l}\text { S and } \\
\text { Iforse }\end{array}$ & so & $\begin{array}{r}12 \text { and } \\
\text { Horse } \mathrm{S}\end{array}$ & $\begin{array}{l}14 \\
\text { size. }\end{array}$ & $\begin{array}{c}\text { Iron or } \\
\text { Wood } \\
\text { Frames }\end{array}$ & NAMF, OF PART. \\
\hline & W & $41 / 2$ & W & Wood & Spur-pinion. \\
\hline 212 & IV & $2 \mathrm{I} 2$ & W & Iron & Spur-pinion. \\
\hline OI 22 & IV & OI 22 & $W$ & Both & Spur-pinion shaft. \\
\hline S9 & W & IO & $W$ & Both & Bull-wheel. \\
\hline 2 & W & 15 & W & Both & Bull-pinion. \\
\hline 90 & W & I6 & W & Both & Inside-pinion. \\
\hline Or 21 & W & OI 2 I & W & Both & Inside-pinion shaft. \\
\hline 3 & W & 43 & W & Both & Spur-wheel. \\
\hline OI 23 & W & OI 24 & W & Botl1 & Spur-wheel shaft. \\
\hline $811 / 4$ & W & 45 & W & Both & Half bull-pinion box. \\
\hline $8 \mathrm{I} / 2$ & W & $451 / 2$ & $W$ & Both & Other half bull-pinion box. \\
\hline 220 & W & IS2 & W & Iron & Cast frame for power. \\
\hline I 2 I & W & 183 & W & Iron & Rear-axle bracket, R. H. \\
\hline I 22 & IV & I85 & W & Iroll & Rear-axle bracket, I. II. \\
\hline 227 & $\mathrm{~V} V$ & I87 & W & Iroil & Top cap for bull-pinion box. \\
\hline 185 & IV & I 88 & WV & Iron & Top slide holder. \\
\hline rSg & W & IS9 & W & Iron & Top slide for bull-wheel, \\
\hline 190 & IV & I9) & W & Iroll & Botton cap for bull-pinion box. \\
\hline 225 & W & I9I & W & Iron & Center-box for spur-wheel shaft, R. II. \\
\hline 193 & W & 193 & W & Iron & Inside trunnion box for shaft. \\
\hline 218 & W & 2 IS & $\mathrm{WV}$ & Iron & Front support for spur-gear frame. \\
\hline 219 & WV & 2 I 9 & W & Iron & Rear support for spur-gear frame. \\
\hline I 97 & W & 197 & W & Iron & Support for short shaft, center-box, I. H. \\
\hline 199 & W & 199 & W & Iron & Support for short shaft, center-box, R. II . \\
\hline 229 & W & 202 & WV & Iron & Support for bull-wlieel slide, Rear. \\
\hline 230 & W & 203 & W & Iron & Support for bull-wheel slide, Iiront. \\
\hline 204 & W & 204 & WV & Iron & Slide under bull-wheel. \\
\hline 2 I 4 & W & 214 & W & Iron & Spur-gear frane. \\
\hline 215 & W & 215 & W & Iron & Cap for spur-gear frame. \\
\hline 216 & W & 2 I 6 & W & Iron & Brake-wheel. \\
\hline 2.17 & W & 217 & W & Iron & Collar on spur-pinion sliaft. \\
\hline 55 & W & I 2 & W & Wood & Back support. \\
\hline 56 & W & 13 & $W$ & Wood & Front Support. \\
\hline 19 & W & 19 & W & Wood & Support for center-box. \\
\hline 20 & W & 40 & W & Wood & Center-box for spur-wheel shaft. \\
\hline 48 & W & 48 & IV & Wood & Cap for spur-gear frame. \\
\hline 49 & W & 49 & IV & Wood & Back Stirrup for spur-gear frante. \\
\hline 50 & W & 50 & W & Wood & Front Stirrup for spur-gear frame. \\
\hline 52 & W & 52 & W & Wood & Spur-gear frame. \\
\hline 75 & W & 75 & W & Wood & Arch frame. \\
\hline $761 / 2$ & IV & 761 & W & Wood & Inside-box, inside-pinion shaft. \\
\hline 78 & W & 78 & W & Wood & Cap to hold bull-pinion box. \\
\hline 82 & IV & S2 & W & Wood & Slide under bull-wlieel. \\
\hline 103 & $\alpha$ & 103 & $x$ & Wood & sece \\
\hline
\end{tabular}


PART II. SEPARATORS. 


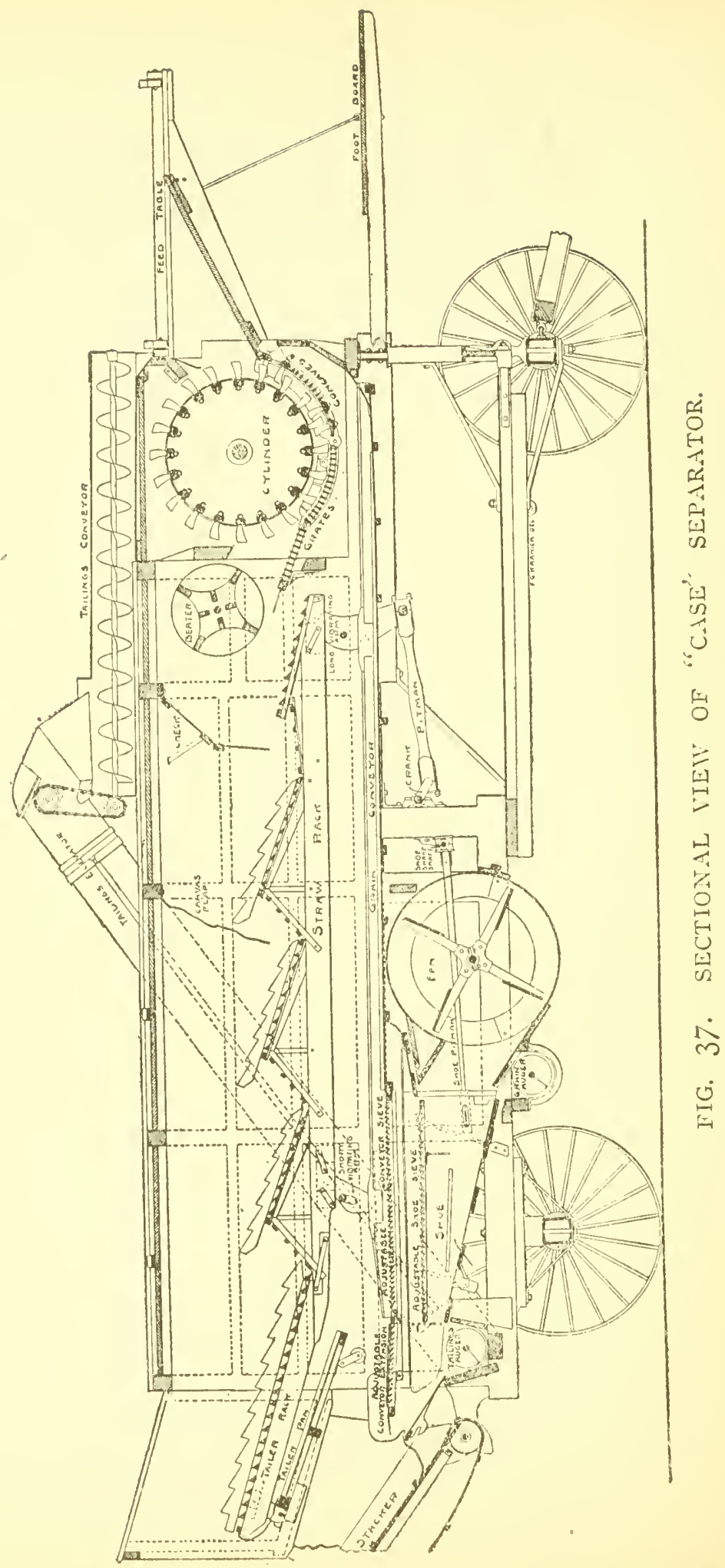


CHAPTER I.

\section{FITTING UP AND STARTING A NEIV SEPARATOR.}

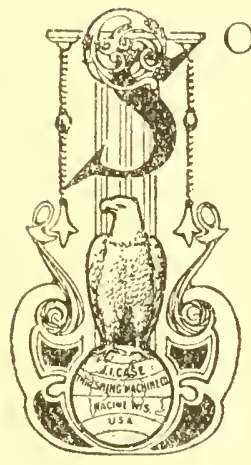

OME separators are shipped from the factory "set-up" with pulleys and all parts put on and all attachments in place. Others, for compactness, are shipped as they are stored, with tailings-elevator removed and tied on the deck, pulleys and other parts packed inside the machine, and the attachments "linock-down"that is, taken apart and small parts boxed. For ocean shipment, separators are taken apart so that all parts may be boxed.

Sctting Up. In setting up a dismantled separator, care slould be taken to see that all nuts and keys are properly tightened. The pulleys must be set in line to insure the belts rumning properly. The cuts showing belting arrangement will aid in placing the pulleys in their proper position. If the box of parts contains a list of its contents, the names and numbers will also help in determining the position of each. The crank-shaft which drives the straw-rack and conveyor should be put in with the long end to the right.

Starting a New Scparator. A new machine should be 
set up and run a couple of hours, before attempting to thresh any grain. Look into the machine on the straw rack, conveyor and fans, and then turn each shaft by hand a few revolutions to make sure there is nothing loose or misplaced in the machine, before putting on the belts.

Oiling. The oil boxes should be carefully cleaned of cinders and dirt that may have collected during shipment, and the paint removed from the oil holes. Screw down the plugs of the grease cups on beater, fan and crank boxes to the end of the threads, using a wrench. if necessary, to clean off the paint. Fill the grease cups on beater, fan and crank boxes with hard oil and fill oil ctips on cylinder boxes with a good lubricating oil. It is best to first place a small quantity of wool or cotton waste in the bottom of each oil-cup. Connect the separator with engine or other power, running only the cylinder for a time, and feeling of the boxes to ascertain whether they show any tendency to heat. While the cylinder is rumning, oil both ends of the crank pitmans, the four bearings of the rock shafts and the two of the tailer rock shaft if there be one. Take off the tightener pulley from its spindle, clean the oil chambers and oil the spindle before replacing it. Put on the belt driving beater and crank (see cut page 170), which will put the beater, straw rack and conveyor in notion. Next oil the shoe-pitman eccentrics and the bearings of the shoe shaft if there be one. "This shaft is driven from the fan on right sicle of machine ( see cut page I76). The fan belt, which runs over crank belt, but 
not under tightener (see cut page i70), and the shoe belt may be now run on. Oil the moving parts as they run, occasionally screwing down the grease plugs on crank- and fan-shaft boxes. The chain of the tailings elevator should be adjusted so that it has slack enough to turn freely, but not enough to allow it to kink or unhook. After oiling the upper boxes and both bearings of the tailings anger and the four of the tailings conveyor, run on the elevator belt, which drives from the crank, crossed, (see cut page I28). Oil the bearings of the grain auger and put on its belt. Where no grain elevator is used, this belt will so on either side of the machine, so that it may always be on the opposite side to that from which the grain is taken.

When all parts of the separator are in motion the bearings should be carefully watched to detect any tendency to heat, and this can best be done when the machine is running empty, for the operator can then give it his entire attention. The machine has been tested and left the factory in good rumning order, but dirt and grit of shipment by rail is liable to cause trouble and it is best to make sure that all the bearings are oiled. It is of great importance that these bearings be well oiled on the first run, as they are somewhat rough, and consequently require more oil and a longer time for it to spread over the journals. Oiling a shaft as it runs, allows the oil to work in and be distributed over the whole bearing surface.

When the machine has run for an hour or so and every- 
thing shown to be in good order, it is ready for threshing. After adjusting the concaves, check board, sieves and blinds, to suit the kind and condition of grain, according to the directions given elsewhere in this book, grain may be rum through the machine. 


\section{CHAPTER II.}

SETTING THE SEPARATOR.

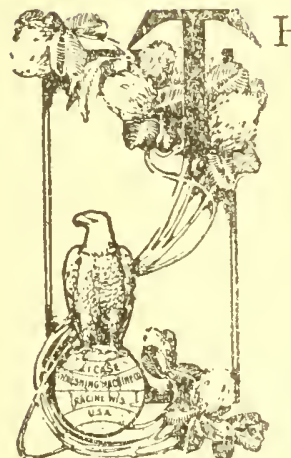

HE separator may do good work if the rear truck wheels be a few inches higher or lower than the front wheels, but it must always be level crossways. Use a spirit level of good length on the rear axle and on the sills. A little practice or calculation will enable one to determine how deep a hole to dig in front of the high wheel in order to bring the machine level when pulled into it. Knowing the axles of the separator to be about twelve feet apart, it is easy to calculate how much the front or rear wheels must be lowered to bring the machine level. For example, if a spirit level two feet* in length be used and when placed on the sill of machine its front end must be raised one-half inch to bring it level, then the rear wheels must be lowered six times as much, or three inches. to bring separator level. This method may also be used in determining the amount to lower one rear wheel to bring machine level crossways, which, as already stated, is more important than having it level lengthways. In this case, however, the amount is different for each size of separator.

* In this case the distance between axles (twelve feet), is just six times the length of the lever, (two feet). 
The hole or holes should be dug before the engine is mincoupled or the team mulnitched, so that if not level, machine may be pulled out, the holes changed and the machine backed into them. When the machine is high in front it can be quickly leveled, after engine or team has been removed, by cramping the front axle, digging in front of one wheel and behind the other, so that wheels will drop into the holes when pole is brought around square.

With geared machines "bolster-jacks" are used to keep the "side-gear" from twisting front end of machine out of level. The hind axle being level, place the bolster-jacks in position, and screw them up so as to level the front of machine. It is not necessary to have the front axle level, as the bolster-jacks will accommodate themselves to it.

Place a block in front of the right hind wheel to prevent the machine from heing drawn forward by the belt. This block shonld be earried with the machine, so as to be handy when needed.

When pulling the machine out of holes, starting it on soft ground or on a hill, cramp the team around to one side, and it will move the load with abont half the effort necessary to start straight ahead. Tn cramping the front axle, but one of the hind wheels starts at a time.

Setting acith Reference to the Wind. The thresherman cannot always choose the direction in which to set the machine, but when he can, he should select a position in which the wind will be blowing in the same general directions as 
that in which the straw is moving, and preferabis a little "quartering," as this keeps the men out of the dust more than when set straight with the wind. This position insures greater safety from fire in case woor or straw is used as fuel. 


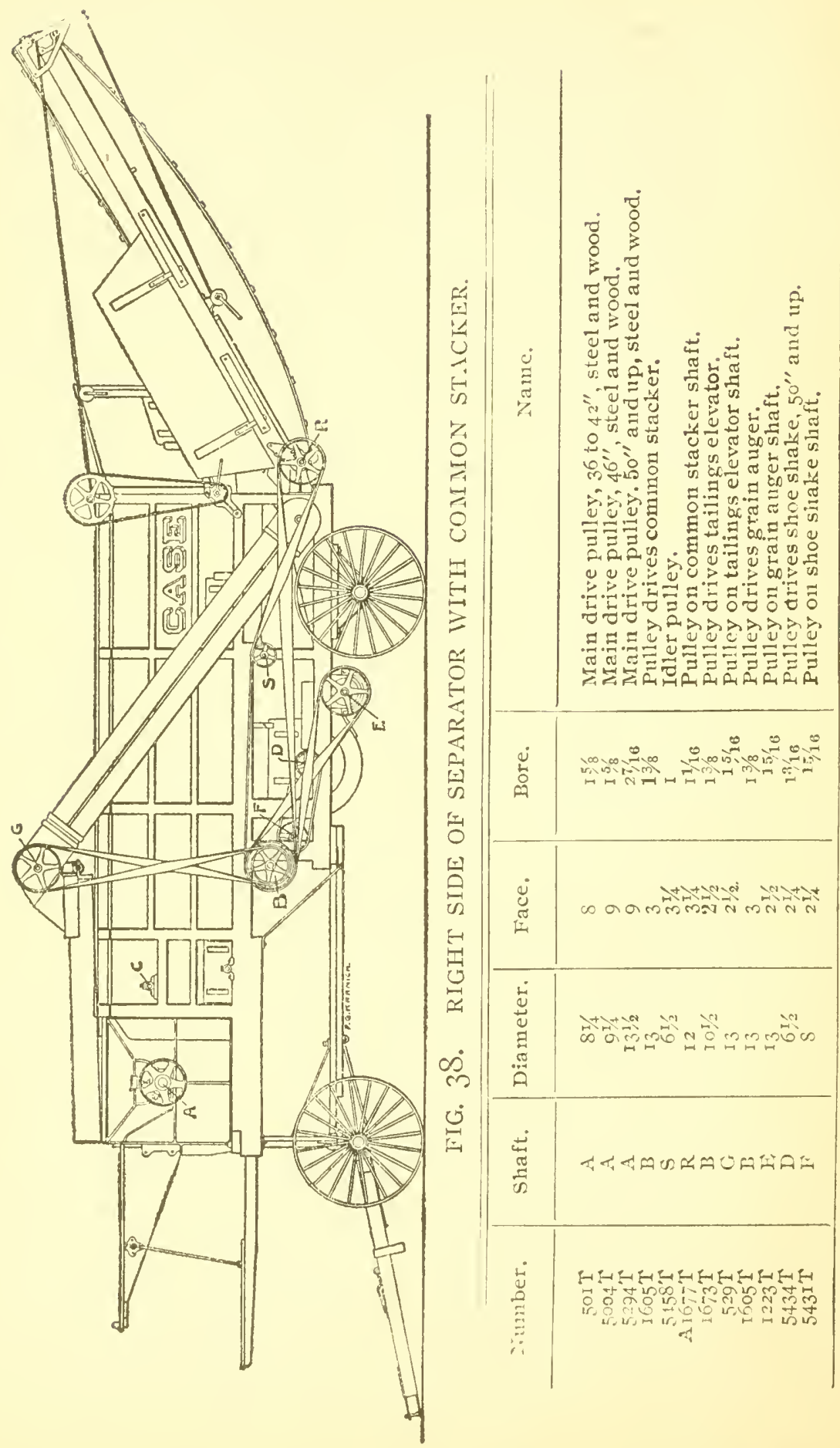




\section{CHAPTER IIT.}

\section{THE CYLINDER, CONCATES AND BEATER.}

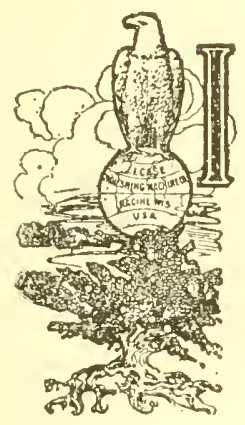

$\mathrm{T}$ is the function of the cylinder and concaves to loosen the kernels of grain from the straw on which they grew. The ends of the cylinder teeth travel about a mile a minute so that the grain in going through meets the concave teeth with considerable force. The concave teeth engage with the cylinder teeth in such a way that the grain heads camnot pass through without being broken and the kernels knocked out although the straw is in contact with the cylinder but a fraction of a second. If the teeth be in good condition and a sufficient number of rows of concave teeth be used to suit the work, practically all of the grain will be knocked out.

Cylinder Tecth. When the cylinder is new or newly refilled, care should be taken to keep the teeth tight until they become fitted to their holes and firmly seated. The cylinder should be gone over occasionally during the first week, and each tooth driven in hard with a heavy hammer and the nuts tightened. If this be done, ordinarily the teeth will give no further trouble, but if at any time they show a tendency to get loose, they should be carefully watched. At the factory the teeth are driven in and tightened with a long 
handled atger wrench and then driven in and tightened again, but they are liable to get loose the first few days unless special attention be paid then. If a tooth be allowed to remain loose for any length of time the hole will become so misshapen that the tooth cannot be kept tight thereafter. The teeth should be kept straight, not only so they will not strike, but also so that they will pass at equal distances from the concare teeth on both sides.

Cylinder speed. It is very iniportant that the cylinder run at the proper speed. If run too fast, there is danger of cracking the grain, and if run too slowly, it will not thresh clean. Then, too, the work of separation and cleaning is very much easier if the cylinder rums at the proper speed and is never allowed to get below it. The motion must be mniform if the best results be expected, for every time it is allowed to get much below or above the correct speed, the separator will waste grain. With the regular pulleys, the large 20-bar cylintler of the Case separator should run at 750 revolutions per mintute to give the proper speed to the other parts of the machine. The regular speed of the small or I2-bar cylinder is Io/5 revolutions per minute. In threshing tough rye or oats, the cylinder is subjected to more work, and often runs too slowly if attempt be made to maintain the normal speed, therefore, the cylinder should run faster than usual, say, Soo for the 20-bar and I 50 for the I2-bar, in order that the other parts of the machine may run up to their usual speed. Some grains and leommes require special 
cylinder speed for which a change in cylinder pulleys is usually made. These are given elsewhere in this book.

\section{MAIN CYLINDER PULLEIS.}

\begin{tabular}{|c|c|c|c|c|}
\hline Number. & Dianeter. & lace. & Dore. & MACHINI:. \\
\hline $\begin{array}{r}5564 \mathrm{~T} \\
76 \mathrm{I}^{\prime} \mathrm{T} \\
501 \mathrm{~T} \\
501 \mathrm{l} / 2 \mathrm{~T} \\
1367 \mathrm{~T} \\
861 \mathrm{~T} \\
5004 \mathrm{~T} \\
5005^{\prime} \mathrm{T} \\
5006 \mathrm{~T} \\
500 \mathrm{~T} \\
505 \mathrm{I} T \\
5052 \mathrm{~T} \\
5053^{\prime} \mathrm{T} \\
544 \mathrm{I} T \\
5367 \mathrm{~T} \\
5365^{\prime} \mathrm{T} \\
5294 \mathrm{~T} \\
\mathrm{~A} 5294 \mathrm{~T} \\
5440 \mathrm{~T} \\
5369^{\prime} \mathrm{T} \\
5372 \mathrm{~T}\end{array}$ & 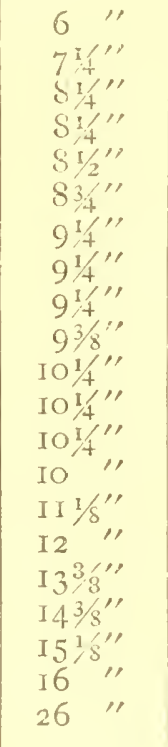 & 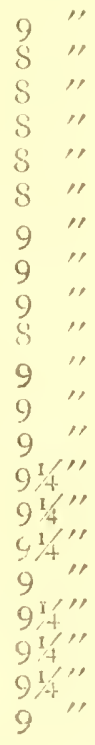 & 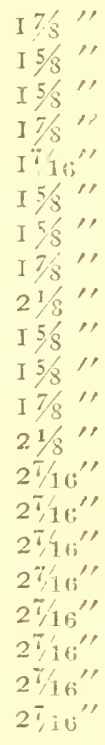 & $\begin{array}{l}\text { 12-Bar Wood. } \\
\text { 12-Bar Steel or Wool. } \\
\text { 12-Bar Steel or Wool. } \\
\text { 12-Bar Wood. } \\
\text { 12-Bar Wood. } \\
\text { 12-Bar Steel or Wood. } \\
\text { 12-Bar Steel or Wood. } \\
\text { 12-Bar Wood. } \\
\text { 12-Bar Wood. } \\
\text { 12-Bar Steel or Wood. } \\
\text { 12-Bar Steel or Wood. } \\
\text { 12-Bar Wood. } \\
\text { 12-Bar Wood. } \\
\text { 20-Bar Steel or Wood. } \\
\text { 20-Bar Steel or Wood. } \\
\text { 20-Bar Steel or Wood. } \\
\text { 20-Bar Steel or Wood. } \\
\text { 20-Bar Steel or Wood. } \\
\text { 20-Bar Steel or Wood. } \\
\text { 20-Bar Steel or Wood. } \\
\text { 20-Bar Stecl or Wood. }\end{array}$ \\
\hline
\end{tabular}

Ascrtaining Cylinder Spect. The best way to ascertain the speed is by means of a revolution counter, but if one be not at hand, the speed may be found by counting the number of times the main drive belt goes around in a minute. To do this, nutultiply the required speed of the cylinder by the circumference of the cylinder pulley in inches and divide by 12 to redice to feet. Dividing by the length of the belt in feet will give the required number of times belt should go around in a minute. For example: If cylincier be a 20 -bar, its speed should be 
750 and the regular pulley $5294 \mathrm{~T}$ for this is $13 \mathrm{~T} / 2$ inches in diameter or 42 inches in circumference. Multiplying 750 by 42 gives 31,500 inches as the product. Dividing this by 12 to reduce to feet gives 2625 feet per minute as the required travel of the belt. If this be I 20 feet long, dividing by 120 gives 22 (nearly) as the required number of rounds of the belt per minute. With a I 50 foot belt, the number of rounds will be nearly i8 or with 160 foot belt I7 (nearly) rounds. In the same manner, the required number of rounds can be figured for any cylinder speed, cylinder pulley or length of belt.

Cylinder Bores. The cylinder boxes are the most important bearings on a separator and they must receive a certain amount of attention or there will be trouble. All Case 20 bar cylinders are fitted with ball and socket boxes, which practically eliminate all possibility of their heating from improper alignment. The boxes are eight inches long, allowing a good bearing surface for these large cylinders and are fitted with oil cups which hold a sufficient quantity of oil to amply lubricate the bearings. The 12 bar cylinders of the steel separators also have ball and socket or "self-aligning" boxes. The chapter on "Lubrication and Hot Boxes" should be rearl with special reference to the cylinder boxes.

To Take "End Play" Out of the Cylinder. Loosen lower" half of housing of box by slacking the nuts which secure it, and slide it against hub of cylinder head. The holes in the ironsides are slotted to allow for this end adjustment and also 
to permit the moving of the cylinder in case the cylinder teeth do not come exactly between the concave teeth. Do not crowd cylinder box so hard against the cylinder head as to cause danger of heating. It is best to leave about I/6+ of an inch end play.

Tracking of Tecth. All regular Case 20 bar cylinders have five teeth which pass in the same space between the concave teeth, during one revolution, "five teeth tracking" as it is called. The I 2 bar cylinders have three teeth tracking. Some machines of other manufacture have two and some four teeth tracking, and some have irregular spacing, as. for example, three and six alternating. The effect of this latter arrangement is to take twice as much straw through some concave spaces as through others.

Cracking Grain. The cut on the following page is full size and shows the actual distance between the concave and cylinder teeth of our regular cylinder. It is shown to emphasize the importance of having the cylinder properly adjusted endwise and of keeping the teeth straight. Supposing all the teeth to be straight and that the cylinder be moved I/I6 of an inch to one end. Then instead of there being I/8 of an inch space between the cylinder and concave teeth on both sides, the cylinder teeth would be $3 /$ I 6 of an incl from the concave teeth on one side and only I/I6 of an inch from them on the other. This condition of affairs would allow the heads to slip through without being threshed on one side of the teeth and on the other would crack the grain and cut 


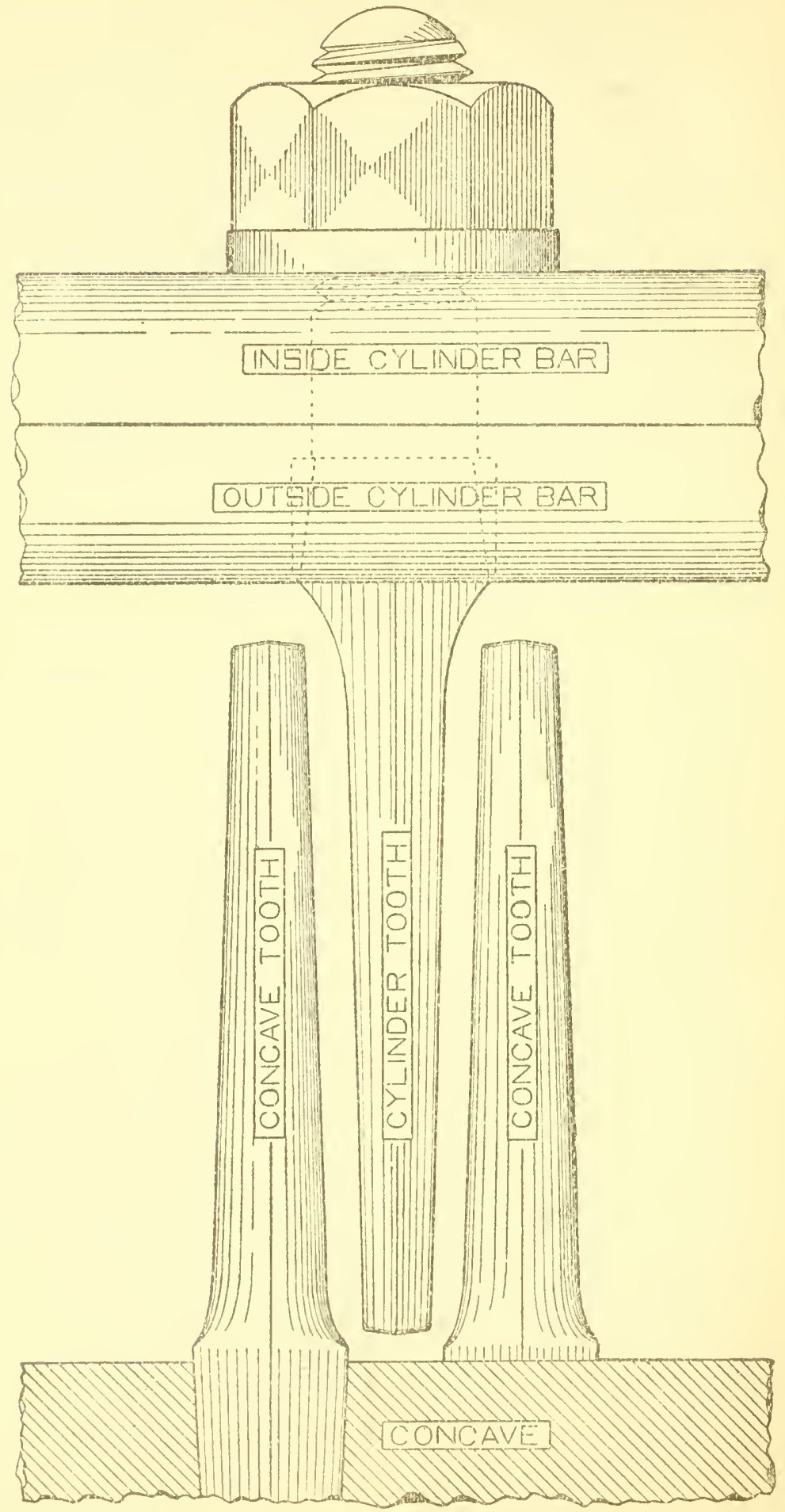

FIG. 39. CUT SIIOWING SPACE BETWEEN CYLINDER AND 
up the straw, thereby consuming much power, increasing the difficulties of separation and niaking the sieves handle a large amount of chaff. This same condition exists when all of the teeth are more or less bent. The cylinder may be moved endwise, as already explained, to give the proper spaces between the teeth, but the teeth must be liept straight. Special Cylinders, To do good work in rice a special cylinder and concave are required with a wider spacing of the teeth than the regular ones. This gives more clearance between the cylinder and concave teeth and, together with a reduced speed, prevents the cylinder from cracking the rice. A special cylinder and concaves are also made for threshing peas and beans. Either of these special cylinders may be put in any Case separator by making the complete change in cylinder, concaves and concave circles. Further information regarding threshing rice, peas, beans, etc., is given elsewhere in this book.

Balancing Cylinders. On account of the high speed at which cylinders run, they must be accurately balanced or they will not run smoothly. It is essential in balancing a cylinder that the weights used for this purpose be placed where the deficiency of weight exists. The shop practice is to rest the journals of a cylinder on level ways and put weights under center bands until the cylinder will stand at any point on the ways. The cylinder is then put in a frame having narrow, loosely fitting wooden boxes and run at about 1200 revolutions per minute. The parts of the jour- 
nals extending beyond the boxes are marked as it runs. These marks show the initiated at which end and at what point to drive the weights used in the final balancing. A cylinder may be balanced, though not as perfectly as is done at the factory, by resting it on ways made by placing two carpenter's squares on wooden horses. The squares should have blocks nailed on each side to keep them on edge, and should be carefully leveled both ways. Place the cylinder near the center of the ways and roll it gently. Mark with a piece of chalk the bar that is uppermost when it comes to rest. Repeat, and if cylinder stops in the same position three times in succession, drive a wedge under center band at the chalk mark. Rub off the marks and repeat until the cylinder comes to rest at any point. Care should be taken not to mar the journals in placing then on the ways.

The Concaves. All that has been said about keeping the cylinder teeth tight applies also to the concave teeth. They should be driven in and tightened as often as necessary, until they are firmly seated. In driving them in, it is necessary, however, to use some judgment, for as the concaves are of cast iron, they are liable to split if the teeth are driven in too hard.

Setting the Concai'es. The concaves should be adjusted to suit the kind and condition of grain. Four rows of teeth are usually required for wheat and barley, but for damp grain six rows will be necessary. Rye can usually be threshed with two rows, but the cylinder speed should be 
higher than for wheat. Oats when dry can generally be threshed with two rows of teeth, but flax and timothy will require six rows. Where four are used, they are most effective if one concave be placed clear hack and one in front with a blank in the center. In hand feeding, if the straw be dry and brittle, the cylinder can be given more "draw" by placing a blank in front. Always use as few teeth, and leave them as low as is possible and thresh clean. When more teeth than are required are used, or when they are left higher than is necessary, the straw will be cut up, and, besides using more power, the separation is made much more difficult, and the sieves are obliged to handle an unnecessarily large amount of chopped straw. It is better to use two rows set clear up, than four rows left low. Sometimes a row of teeth is taken out of a concave, making it possible to use one, three or five rows.

Special Concaz's. Some grains, as for example, Turkey wheat, are extremely difficult to thresh from the head, and if it be found that the regular six rows will not thresh clean, a three-row concave, filled with corrugated teeth, should be procured. This, with two regular concaves, will give seven rows of teeth. Should it be necessary, two, or even three, three-row concaves of corrugated teeth may be used. The three-row concaves of corrugated teeth are usually used for threshing alfalfa, but for clover, the special clover concaves are necessary. Information concerning them is given elsewhere in this book. 
Adjustment of Concaves. In the left side of the "ironsides," or cylinder side castings, of the wood I2 bar separator, there are thumbscrews, which press against the concave circle and take up the end play of the concaves. The steel and 20 bar wood machines have set screws in both ironsides. When it is desired to change the concaves, raise them up and drop them down a few times to jar out the dust and dirt which has become lodged between concave circles and ironsides, wedging them tight. With concaves in their lowest position, place a stick of wood, the tooth straightener, or anything else that may be handy, between concave and cylinder teeth and raise the concaves so that the teeth cannot pass. Then roll the cylinder backward, striking the concaves several times with the momentum of the cylinder if necessary, until they are jarred loose and come up with the cylinder, as it is rolled backward by hand. The thumb-screws mentioned above may be loosened if necessary. but if they be, it should be clone on one side only so as not to disturb the adjustment.

Caution. When the separator is belted to an engine one should make sure that the engineer has closed the throttle and opened the cylinder cocks before changing concaves, fixing teeth or otherwise handing the separator cylinder.

The Beater. In threshing very heavy, tough grain, if the straw be inclined to wrap the beater or if it tends to follow the cylinder around too far, the beater may be raised by taking out the blocks from between the beater boxes and the 
girt to which they are fastened on wood separators or by moving the girts to the upper holes on steel machines. There is also provision in the girts for moving the beater back to give more room between beater and cross-piece, but it is very seldom necessary to move it. The speed of the beater is four hundred revolutions per minute and as its bearings are provided with hard oil cups, a little attention will keep them in good running order.

The Grates. A large percentage of the grain is separated from the straw by the grates through which it is thrown with all the force acquired from the cylinder. The grate under the beater is adjustable and should usually be kept as high as possible for the separation is better when it is high. It should never be lowered unless absolutely necessary.

The Check Board should usually be kept quite low to prevent the grain from being thrown to the rear of the machine on top of the straw, where it might be carried ont of the machine without being separated. In damp grain and especially damp rye or oats the check board should be raised to allow the straw to pass freely through the machine, for if left down, it will retard the straw too much, and may cause the cylinder to wind. 


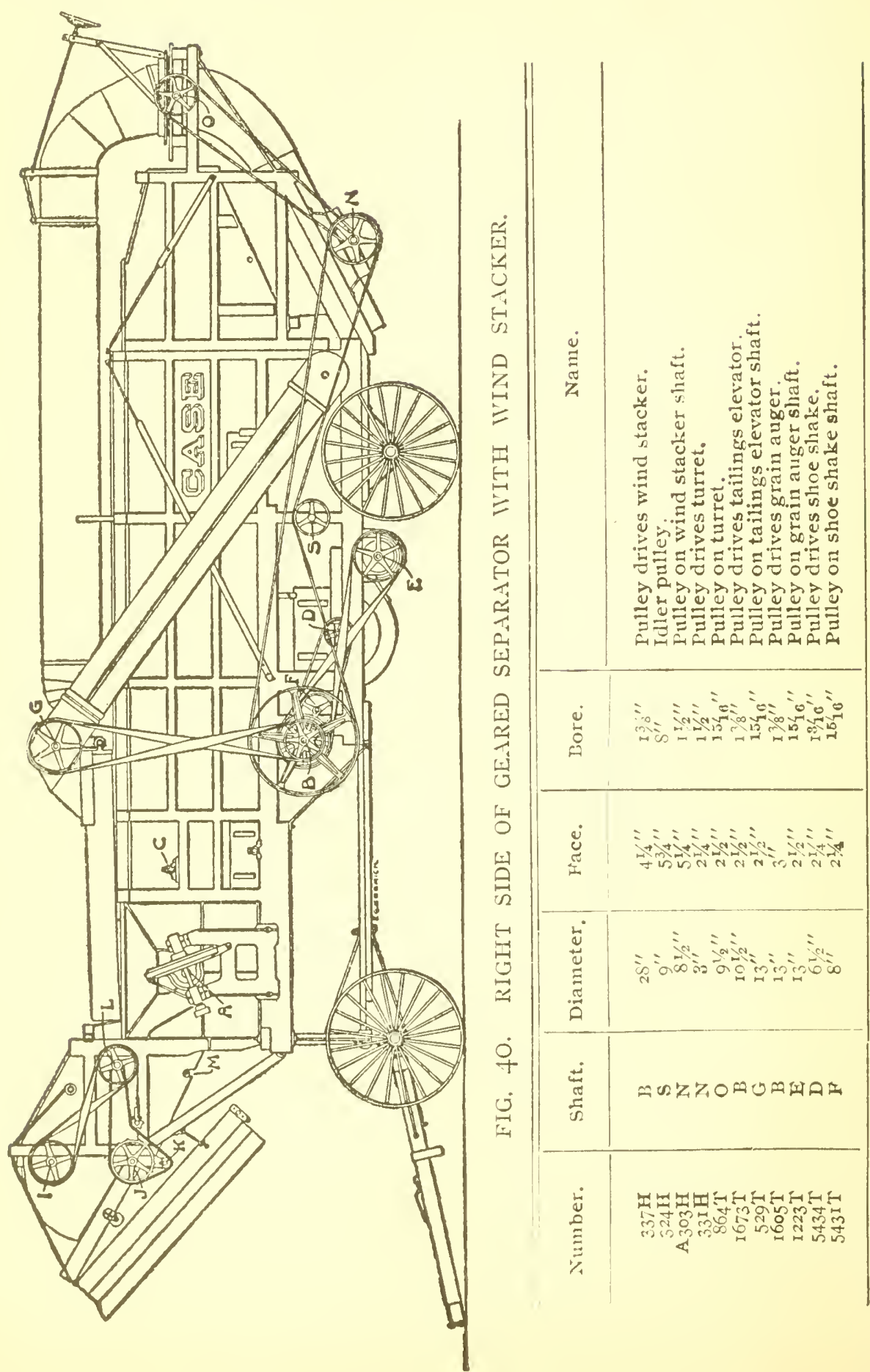




\section{CHAPTER IV.}

\section{THE STRAW-RACK AND CONVEYOR.}

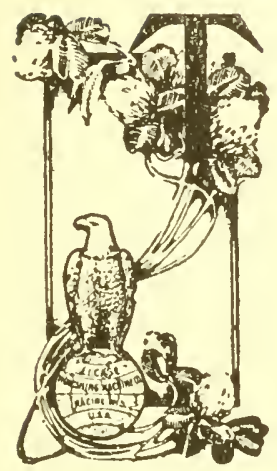

$\mathrm{HE}$ straw-rack and conveyor are both carried by studs on the rocker or "vibrating" arms, the straw-rack having a longer leverage than the conveyor, so that each counterbalances the other. They are more accurately balanced when the machine is in operation and both are loaded than when the machine is rumning empty. It is very difficult to separate grain from straw that is badly cut up, therefore care should be taken to use as few rows of concave teeth as will thresh clean from the heads.

Speed. The most important factor in producing good work by the straw-rack is the speed. To do good work, it must make 230 vibrations per minute. Its speed can best be determined by using a revolution-counter on the crank shaft. Some, although not all, persons can determine the speed by letting one of the pitmans or a key of one of the crank shaft pulleys strike one hand once every revolution, while holding a watch in the other hand and counting for a half or a full minute. The proper speed is as essential to good work by the conveyor sieve or "chaffer" as by the straw-rack; if too fast, grain will go over the sieve with the chaff, and if too slow the sieve will be overloaded.

The present style of straw-rack has riser supports, which 
prevent the risers from sagging in the middle. (See cut, page 120). Fish-backs are nailed to the straw-rack risers, two on the second riser (from the front), three on the third and four on the fourth. The straw-rack ordinarily does good work without the fish-backs, but in cases where the separation is very difficult, they will aid materially.

A Spccial Strarc-Rack called the "Oregon" straw-rack is made for use where the straw is badly cut up or so short owing to the grain being headed that most of it passes through the regular rack. Parts can be furnished for making an Oregon rack of the regular one.

Pounding. The crank-boxes and pitmans should be kept adjusted so that the machine does not make a knocking or pounding noise. The maple boxes on the straw-rack and conveyor are inexpensive and should be replaced when worn out. The pitmans shorten as they wear, and this, with the wear of the crank boxes, sometimes allows the rear vibrating arms to drop nearly to their dead-centers. This causes the machine to run hard, pound badly, and often breaks the vibrating arms. The rear vibrating arms may be prevented from clropping too low in three ways: first, if the frame be of wood, the crank boxes may be moved forward by putting leather between them and the post; second, by lengthening pitmans by putting leather over worn surface at ends or by getting new and longer pitmans; and third, by moving the rock-shaft boxes to the rear. This last method is the most difficult and should it be attempted, care must be taken to move all the boxes exactly the same distance. 


\section{CHAPTER T.}

\section{THE CLEANING APPARATUS.}

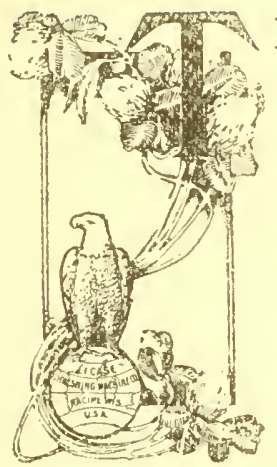

IE fan and sieves aided by the tailings auger and tailings elevator separate the grain from the chaff. It is in the handling of these, whicl constitute the "cleaning apparatus," more than any other part of the separator, that the skill of the opcrator or separator "tender," as he is istially called, shows itself and the local reputation of any particular machine is largely due to its record as a "cleaner."

The Fan Blinds. The position of the fan blinds regulates the amount of wind or "blast" that the fan produces. These should be adjusted to clean the grain without blowing it over and this adjustment can be made while the machine is running. Both upper and lower blinds should be partly open. The right hand blinds affect the left side of the sieve and vice versa; therefore, if grain is being blown over on one side, the blinds on the opposite side should be closed a little. Use as much wind as possible without blowing over grain. In windy weather it is necessary to close the blinds on the windward side of the machine more than those on the other side. The blast is retarded by the volume of chaff it is moving, hence heavy feeding, and a blast that is all right 
when the cylinder is kept full, will carry over grain when the machine runs empty. Steady feeding is therefore important on this account and the separator tender should let the pitchers understand that he cannot produce the best results without their aid, in keeping an even and continuous stream of grain going into the cylinder.

The Wind-Board is placed in the machine so that the blast from the fan will strike the conveyor sieve about half way back. The strongest part of the blast will then pass through the shoe sieve near the front end which gives it a cleaning capacity its entire length. If the wind board becomes bent or sagged so that it stands but little above the floor of the shoe, the grain will slide over it into the fan, and then be thrown clear out of the machine. To prevent the liability of this, belts or "traps" should not be kept in the fan drum. Fan. Specd. The speed of the fan for 12-bar separator should be about 470 and for the 20 -bar about 485 revolutions.

Sicaes. The function of all sieves is to assist the fan in separating the grain from the chaff and in preventing heads and other heavy objects larger in size than the grain from mingling with the clean grain. Sieves are distinguished from screens in that the grain being cleaned passes through them while it passes ozer a screen.

Adjustable Sier'es. To obviate the delay and trouble of changing sieves each time the machine threshes a different grain, adjustable sieves have been constructed in which the size of the openings may be changed to suit the kind of grain 
or seed. 'This adjustment may be made while the machine is running. All Case separators are now regularly fitted with an adjustable conveyor-sieve, commonly called the "chaffer," adjustable conveyor-extension and adjustable shoe-sieve. The latter should be placed in the shoe with the rear rod in the fourth hole and the front end high enough to leave only an inch between it and the heel board of the shoe.

The Conieyor-Extension or Chaffer-Extension carries the coarse chaff from the conveyor sieve to the stacker. The conveyor sieve sliould be so adjusted as to let all the good grain through because that which goes to the extension and drops through it is returned with the tailings to the cylinder. The conveyor-extension should be coarser than the conveyor sieve so as to allow all the unthreshed heads to pass through. If they pass over it they are lost. The present style of adjustable converor extension is hinged to the rear of the converor sieve and also fastened to the conveyor side-rails. By loosening the bolts which hold it to the side rails this extension may be lifted out of the way to get at shoe sieves.

Common Sieres is the name given to non-adjustable sieves and includes the lip, the round-hole, the oblong-hole and the woven-wire sieves.

Fig. 4I shows the nine positions or notches, in which a sieve may be placed at the fan end of the shoe, and they are numbered, beginning at the top. It also shows the six positions for the rod at the rear end and these are also numbered from the top. 
To Inscrt Common Sicues place a long rod in the bottom of slots, leaving muts loose. The rods at fan end of sieve are about $I \frac{I}{2}$ inches longer than those at rear end. In changing from one sieve to another it is not necessary to remove the rod at fan end. Slide in the sieve and put a short rod in the proper hole at rear. Adjust sieve to proper

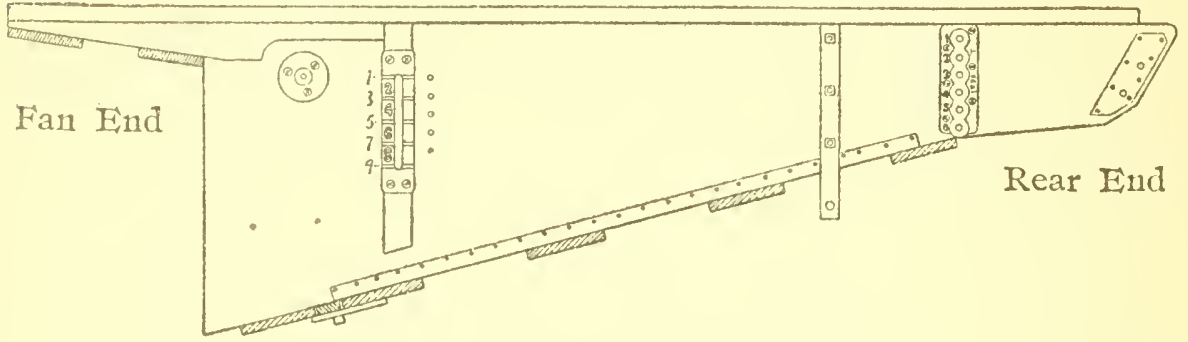

FIG. 4I. SHOE SIIOWING POSITIONS OF SIEVE RODS.

position at front end and tighien the nuts. If two sieves are to be used put the top one in first with rod in bottom of the slots. Raise it up to proper position, then put rod for lower sieve in the slots and slide it in below the other. The rod of upper sieve cannot be tightened until lower sieve is in place. Insert pins in the holes to hold it up while putting in lower sieve. Screw the nuts up quite tightly, but not so much as to cause the sieves to buckle. Twenty-penny wire nails may be used as pins in adjusting sieves.

List of Common Sicies. The following sieves are used for many other grains and seeds than those mentioned, but the few given may serve to identify and explain the nature of the sieves. 


\section{LIST OF COMMION SIETES.}

D. Conveyor sieve, $2 \mathrm{in}$. lip, shown below.

E. Conveyor or oat sieve, $1 \frac{1}{4} \mathrm{in}$. lip, shown below.

F. Oat sieve, $3 / 4$ in. lip, shown below.

G. Wheat sieve, 3/8 in. lip, shown below.

H Wheat sieve, $15 / 4$ in. round hole, shown on page 149.

I. Flax sieve, 5,32 in. rouad hole, shown on page 149 .

IK. Cheat screen, $1 / 16 \times 3 / 8$ in. oblong hole, shown on page 149.

L. Cheat screen, reg., 1/14x1/2 in. oblong hole, shown on page 149.

M. Timothy sieve, 1/16 in. round hole, shown on page 149.

N. Clover or alfalfa, $3 / 32$ in. round hole, shown on page 119.

O. Cockle screen, 1/8 in. round hole, shown on page 149.

P. Pea screen, $3 / 16 \times 3 / 4$ in. oblong hole, shown on page 149.

Q. Wheat sieve, $41 / 2 \times 41 / 2$ mesh wire, shown on page 149.

几. Clover sieve, $12 \times 12$ mesh wire, shown on page 149 .

T. Timothy sieve, $16 \times 16$ mesh wire, shown on page 149.

U. Orchard-grass sieve, $3 / 32 \times 1 / 2$ in. oblong hole, shown on p. 149 .

W. Pea screen, $16 \times 3 / 4$ in. mesh wire, shown on page 149 .

X. Screen, 1/20 in. round hole, shown on page 149.

I. Screen, 1/12 in. round hole, shown on page 149.
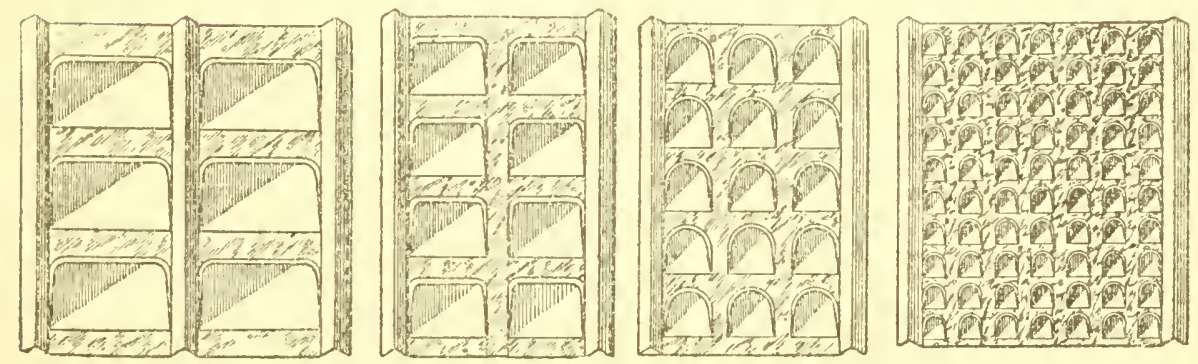

2" Lip Sieve "D" $\quad$ 1/1/2" Lip Sieve "E" 3/4" Lip Sieve "F" 3/8" Lip Sieve "G" FIG. 42. LIP SIEVES. (Reduced.) 
Screens. A screen removes particles smaller than the grain or, seed being threshed, such as weed seeds, sand, or other foreign matter which is usually valueless. Sometimes, however, a useful seed, such as timothy is screened out of one of the large grains, as oats. In general, for weed seeds that are approximately round, the round hole are better than the oblong hole screens. However, the latter are the only ones that will take out "cheat" which is often found in wheat. The screen lies in the bottom of the shoe and is held in place by hooks with thumb nuts which engage castings fastened on the frame of the screen. When a screen is used the removable strip in the bottom of the shoe is taken out to allow the screenings to fall on the ground. All screens are liable to become clogged and in this condition are an obstruction to the grain and wind. They should therefore be kept clean and only used when necessary. The list of screens is given on page 147 and they are illustrated on page I 49.

The Tailings Elciator returns to the cylinder for a second threshing the unthreshed heads and all trash, which is too coarse to fall through the sieves and too heavy to be blown out by the blast. It consists of an elevator with cups or flights carried on sprocket chain, into which the tailings are delivered by an auger (called the tailings auger), and a spout to carry the tailings from the end of the elevator to the cylinder. This spout has an auger on some separators and it is then called the "tailings conveyor." The tailings elevator is lriven from the crank-shaft with a crossed belt 
THE CLEANING APPARATUS.

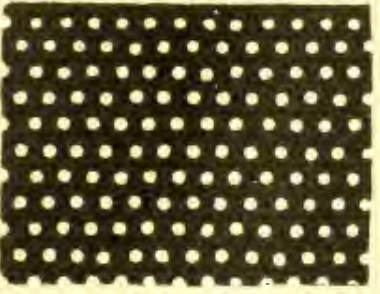

" Round Hole "X"

000000

$1000000 \mathrm{C}$

0000000

000000

0000000

$3000000 \mathrm{c}$

munmunge y้ "Round Hole "N"

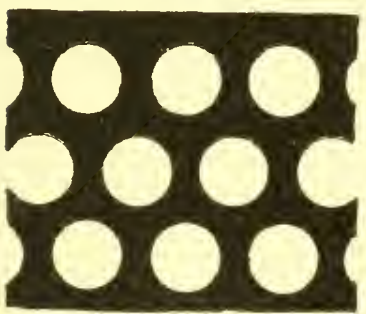

I" Round Hole "H"

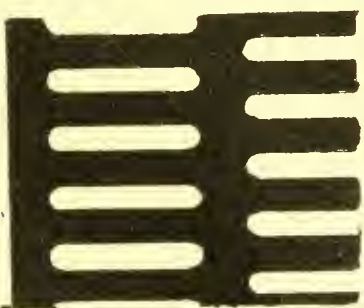

"If Oblong Hnle "U"

HHHHHH 74 H41474 H298404 7 7म НA サ

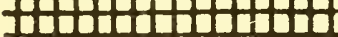

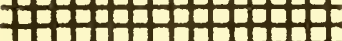
HAtAftAtAf

!fxl6 Mesh Wire " $T$ "

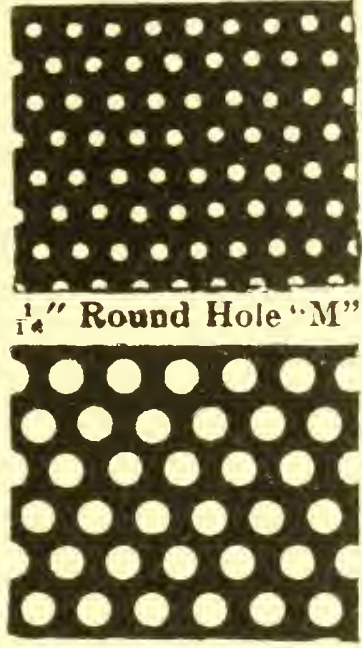

$f$ "Round Hule "O"

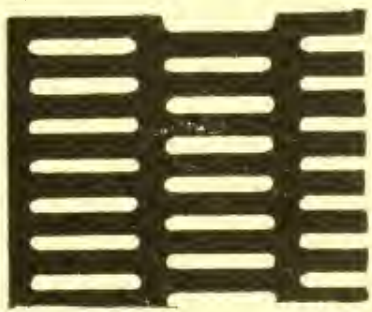

"x:" Oblong Hole "K"

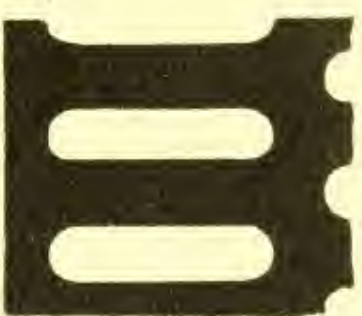

8. " "Oblong Hole "P"

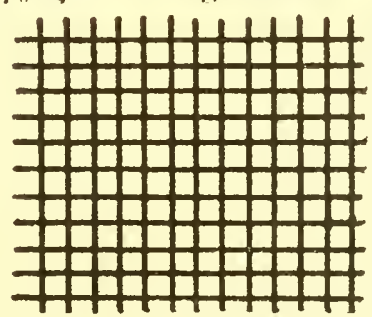

$12 \times 12$ Mesh Wire " $R$ "

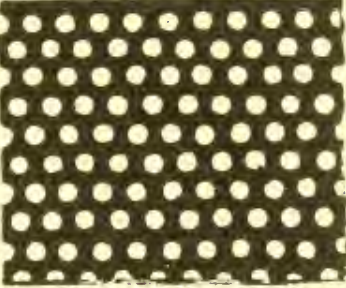

I"Z" Round Hole "Y"

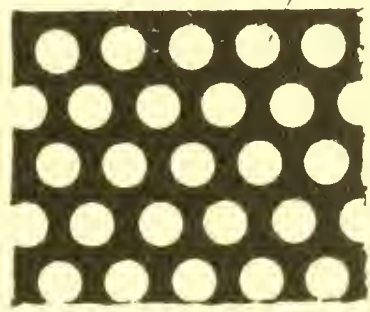

\&" Round Hole "I"

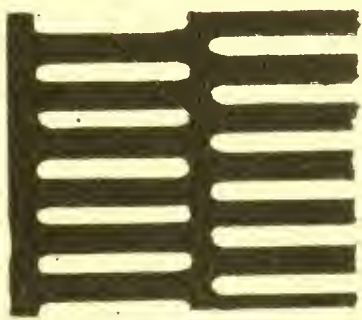

it $x$ " Oblong Hole "I,"

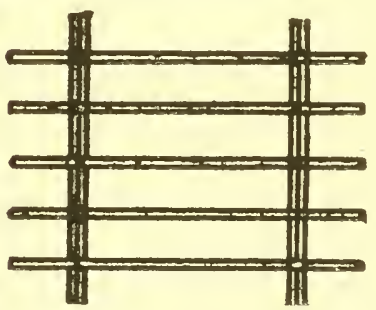

"xi" Mesh Wire "W"

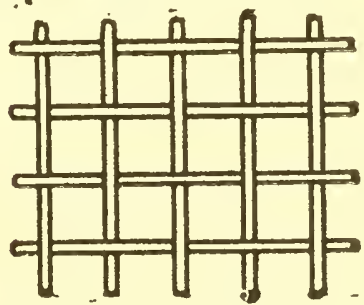

$4 \frac{1}{2} \times 1 \frac{1}{2}$ Mesh Wire "Q"

FIG. 43. SIEVES AND SCREENS, (Full Size.) 

so that the chain carries the tailings up the lower pipe. The speed of the drive shaft at top is 185 rcrolutions per minute and the upper and lower sprockets laving the same number of teeth, the tailings auger also runs at this speed.

Oiling Tailings Elevator. The boxes to be oiled on tailings elevator are the two of the shaft at the upper end, the one bolted to "boot" at lower cnd and its matc, which is at the other end of the auger on opposite side of separator. The tailings conveyor has two bearings for the small cross-shaft and one at each end of auger. These should be frequently oiled and the bevel gears kept greased.

Adjusting Chains of Tailings Elevator. The boxes at the upper end of the elevator have slotted holes to allow them to be moved for tightening the chain carrying the cups. Setscrews with long threads aid in adjusting the boxes and in holding them in placc. This chain should be kept tight cnough to prevent it from unhooking, but it should have slack enough to run freely. The short clain driving the tailings conveyor is tightened by lowering the brackets supporting it, the holes in which are slotted for this purpose.

To Put Chain in Tailings Elevator. Tie a weight to the end of rope and drop it down the lower part of elevator. Untie the weight and tie rope to end of chain, and while one man is pulling on the rope from above let another feed the chain in from below. When chain appears at the top, drop the rope down the upper part of the elevator, and when chain 
is started around the upper sprocket, pull the rope from below and feed it in as before to bring it to its proper place. Hook the cliain at botton, sce that it is on the sprocket, and tighten by means of adjusting screws at the top. Turn the pulley at top of elevator by hand until the chain has grone once around to insure its being free from kinks.

The Tailings are a good indication of the work the sieves are doing. They should be small in amount and contain no light chaff and very little plump grain. If too much good grain be returned with the tailings, ascertain if it comes ov'er the shoe sieve or through the conveyor extension. If it be passing over the shoe sieve, probably this sieve is overloaded with chaff, as is sometimes the case when the straw is badly cut up. To remedy this, the conveyor sieve should be partly closed to let less straw through. If, however, the good grain is going over the conveyor sieve and through the conveyor extension, the remedy is just the reverse, that is, the conveyor sieve should be opened. The adjustment in separators with lip sieves is made by bending the lips, but as a usual thing, they should be set at about a forty-five degree angle. Grain returned in the tailings is apt to be cracked by the cylinder, and when the tailings are heavy this is sometimes of importance. If very much chaff is returned it increases the difficulties of separation, and must be handled by the sieves again. In all cases have as few tailings as possible. 


\section{THRESHING WITH A REGULARLY EQUIPPED SEPARATOR.}

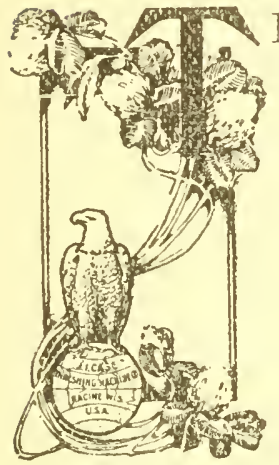

HIS chapter will deal with the threshing of those grains and seeds which may be successfully handled by a regularly equipped separator. It will include the threshing of wheat, rye, oats, barley, flax, timothy, buckwheat, millet and speltz or emmer. Those grains and seeds which cannot be threshed successfully without some change in, or addition to a regularly equipped separator will be treated separately in the following chapter.

Headed Grain. The bulk of the grain grown at the present time is cut by binders and is delivered to the threshing machine in bundles. There are localities, however, in which all, or nearly all, the grain is cut by headers and delivered to the separator loose. Bound grain is supposed to be fed to the cylinder, "heads first," and when so fed, the work of the cylinder is made easy as the straw holds the heads while the grain is being knocked out of them. This cannot be the case with headed grain, as ustrally but little straw is left on the heads, because, to keep the bulk small, the header is run to cut only low enough to get most of the heads. Other things being equal, headed grain is, then, 
harder to knock out of the heads than bound grain, but no trouble is experienced with the "Case" separator in headings, if the cylinder and concaves be in good condition. Most of the grain raised on the Pacific coast is headed, and a special feeder, known as the "Spokane Feeder," is used, ustally in connection with derrick-forks. In the more eastern headed grain districts, the mounted feeder carrier is used as an extension to the regular bundle feeder.

Threshing Wheat. Ordinarily, it is not difficult to do good work in threshing wheat with a separator which is in good condition. To get the best results, the cylinder, especially, should be in good repair and it should maintain a uniform speed. The speed should be fully up to the regulation, 750 revolutions for the twenty-bar cylinder or I075 revolutions for the twelve-bar cylincler. It is seldom that the ordinary varieties of wheat cannot be threshed with four rows of concave tecth. Before concluding that more are required, see that the teeth are in good condition, and that the cylinder fully maintains the given speed. It is generally admitted that four rows of concave teeth are more effective if a blank concave be placed between the filled concaves, and that the straw is less cut up if the filled concaves be placed together. but some good operators do not agree with the former statement. However, with this in mind, it will not be difficult for an operator to determine which arrangement is best suited to the particular conditions under which his machine is at work. Good operators judge by the work 
THRESHING WITH REGULARLY EQUIPPED SEI'ARATOR. I53

the machine is doing, what changes in the adjustment or arrangement of concaves or in the speed, will improve the work. For example, if the wheat be thoroughly knocked out of the heads and there be an excessive amount of chaff and chopped straw, it would be well to see if the kernels could still be threshed clean from the straw if the concaves were lowered a notch or two, or perhaps one filled concave replaced by a blank or else the speed lowered slightly. If any of these changes were made, the work of the machine as a whole would be improved, for separation and cleaning are made easier by reducing the amount of chopped straw.

The adjustable-chaffer, chaffer-extension and shoe-sieve can be best adjusted while the machine is rumning, the operator noting how much chaff each is handling, how the wheat is cleaned and the amount of tailings being returned, as explained in Chapter V. The adjustable shoe-sieve should be placed at, or very near, the top, at the fan end and in the fourth hole from the top at the rear end.

When the separator is equipped with common sieves, the two-inch lip sieve, D, should be used as a chaffer. Ordinarily, the three-eighths inch lip sieve, $G$, will do nice work as a shoe sieve, and it will remain clean with little or no attention. It should be placed in the second notch at the fan end and third hole at the rear,-from the top in both cases. When "white-caps," as kernels with chaff adhering to them are called, are numerous, the fifteen-sixty-fourths inch roundhole sieve, $\mathrm{H}$, is the best for removing them. It should be 
placed in the second notch and third or fourth hole. Sometimes these two sieves are used together and when so used, the former, $G$, sinould be placed in the first notch and third hole and the latter, $\mathrm{H}$, in the fifth or sixth notch and the fifth hole.

For a screen, either the one-fourteenth by one-half inch ublong hole, L, or the one-sixteenth by three-eighths inch, $\mathrm{K}$, is suitable, depending upon the size of the kernels of wheat. For cockle, the five-thirty-seconds inch round hole screen, $I$, is the right size.

Turkey Wheat. Some varieties of wheat, such as the "Turkcy," which is raised extensively in Oklahoma, is very difficult to knock ont of the heads and often six rows of concave teeth will not thresh it clean from the straw. In this case, one or more three-row concaves of corrugated teeth are necessary. For such grain, the cylinder speed should be kept fully up to the stated number of revolutions.

Threshing Rye. Rye is more easily knocked out of the heads than wheat, and nsually two rows of concave teeth are sufficient. When damp, the straw is tough and as it is long, it tends to wrap on the cylinder and beater. To prevent this, the cylinder should be run at a high speed-say 800 for the twenty-bar or II 50 for the twelve-bar. Tough rye straw is more liable to wrap if bruised by the cylinder, and therefore, in threshing damp rye, it is best to use not more than two rows of concave teeth and often these may be left quite low, as the high cylinder speed suggested above 
will ordinarily insure threshing it clean from the straw. The writer has seen a separator (not a "Case"), which could not handle damp rye with the usual concave teeth, because of wrapping, do very fair work when all the concave teeth were removed and a high cylinder speed depended upon for knocking the kernels from the straw. It is a common mistake to use too many concave teeth in threshing rye. Unless the straw be badly chopped up, this grain is easily separated and cleaned. The same sieves should be used as in threshing wheat, except that the round-hole sieve, $H$, for removing the white-caps from wheat is not necessary for rye.

Threshing Oats. Oats, when dry, are best threshed with two rows of concave teeth and, especially if the straw be short, with a cylinder speed somewhat lower than is required for wheat. When they are in this condition, it is easy to thresh them very fast and a machine of medium size often turns out as much as six or seven hundred bushels per hour. When damp, however, oat-straw is very tough and requires a speed of fully 750 for the twenty-bar or 1075 for the twelve-bar cylinder. The adjustable-chaffer and shoe-sieve should be set more open than for wheat. If the separator be equipped with common sieves, the two-inch lip-sieve, D, should be used as a chaffer and the threequarter inch lip-sieve, $F$, placed in the second notch and third hole in the shoe. If this sieve be found too fine, as is occasionally the case with large oats, and in fast threshing, the one and one-quarter inch lip-sieve, E, may be used. Any 
of the screens mentioned for wheat are suitable for oats. Since a bushel of oats weighs only a little more than half as much as a bushel of wheat, less wind must be used in cleaning. Oats that are poorly filled, and consequently very light, cannot be well cleaned without blowing over some apparently good kernels. Upon close examination, however, it will be found that very few of these are more than hulls, which contain no meat.

Threshing Barley. In certain localities, sometimes barley is in such condition that it is easily threshed. At other times, however, the "beards" are tough and difficult to knock off from the kernels. To successfully handle such grain, the cylinder- and concave-teeth should be in excellent order. Any teeth that are badly worn should be replaced by new ones. Six rows of concave-teeth may be required and the cylinder-speed should be kept up to fully 750 revolutions for the twenty-bar and I075 for the twelve-bar cylinder separators. In using these means to remove the beards, the straw being brittle, is apt to be badly cut up and, therefore, gives the cleaning apparatus a great deal of chaff to handle. The adjustable sieves should be set as in threshing wheat. By having the front end of the shoe-sieve high and the rear end low, the kernels with beards adhering to them will be carried to the tailings elevator and returned to the cylinder. Another advantage of placing the sieve in this position lies in the fact that when so placed, it lies across the path of the blast, thus forcing the wind through it. The wind, in 
passing through the sieve, will lift the chaff and enable the sieve to handle the large amount of chaff that comes to it in barley threshing. With brittle barley straw, the reguiar straw-rack sometimes shakes too much straw through to the conveyor. In this case, as in threshing "headings," the straw-rack should be converted into the Oregon style, mentioned heretofore. When the separator is fitted with common sieves, the two-inch lip. D, or the one and one-quarterinch lip, E, should be used as a chaffer and the threeeighths-inch lip-sieve, $\mathrm{G}$, in the second notch and fourth hole as a shoe-sieve. Any of the screens mentioned for wheat are suitable for barley.

Threshing Fla.r. The thresherman should devote some study to the peculiarities of flax if he wishes to do a nice job of threshing. Operators of some makes of separators have great difficulty in threshing flax on account of the straw being composed of tow, and therefore, having great tendency to wind on every revolving thing it encounters. The "Case" separator, having no rotary parts on which flax straw can wind, has always had an advantage in this respect. Flax is usually unbound, and on separators equipped with feeders, the pitchers are apt to throw it upon the feeder-carrier in large forkfuls. The straw, on the contrary, should be fed evenly to the cylinder, for if allowed to pass into the machine in large bunches, it will "slug" the motion down and prevent all parts of the separator from doing good work. When green or damp, it requires close work on the part of 
the cylinder and concave teeth to get the seed out.of the bolls. Usuaily six rows of concave teeth are required, and the speed must be liept fully up to the 750 for the twentybar or 1075 for the twelve-bar, but when dry and in good condition, it is best to run the cylinder at a little less than its normal speed to favor the shoe. Some very good samples of cleaned flax have been taken from separators fitted only with the adjustable sieves. Usually, however, it is necessary to place a sieve underneath the adjustable shoe-sieve to do first-class cleaning. For this purpose, the five-thirty-secondsinch round hole sieve, I, is the correct size. It should be placed in the seventh notch at the fan end and the fourth hole in the rear. This sieve should also be used in the same position in the shoe of machines fitted with common sieves. For an upper sieve, either of the wheat sieves may be used, but the three-eighths-inch lip sieve, G, is preferable to the fifteen-sixty-fourths-inch round hole sieve, H. For a chaffer, the three-quarter-inch lip-sieve, F, works the best of the common sieves. More wind can be used with two sieves in the shoe than with one.

Threshing Timothy. Although this seed when properly ripened and cured, is not hard to thresh, it is often in such condition as to render it very difficult for the separator tu handle. It is often cut and stacked when green or damp. When in this condition, the bundles are very solid and they must be properly fed or the cylinder and concave teeth may give trouble. The speed, too, must be fully up to the normal, 
750 for the twenty-bar or 1075 for the twelve-bar cylinder. Six rows of concave-teeth should always be used, as considerable rubbing is necessary to loosen the seed from the heads. When the seed is ripe and dry, the cylinder speed may be lowered considerably, and this should be done whenever possible, as a low speed favors the shoe in handling this small and rather light seed. Often when the seed is well ripened and allowed to stand in the field, especially if in shocks that are not capped, it will be badly shelled in handling so that the amount threshed will be considerably less than the actual yield would be, were it possible to save it all.

The adjustable-sieves should be set well closed for timiothy and a lower sieve must be used to get the seed clean. Either the one-sixteenth-inch round-hole sieve, M, or the sixteen by sixteen-mesh wire sieve, $T$, are suitable for timothy seed, and either may be used successfully, if placed in the seventh notch and fourth or fifth hole. When commonsieves are used, the three-quarter-inch lip-sieve, F, will be found to be the most suitable for a chaffer and the threeeighth-inch lip, G, is an excellent upper sieve for the shoe.

Threshing Buckwheat. This grain is easily knocked off the straw and one or two rows of concave-teeth are always sufficient. Very often when dry, it is best threshed with all the concave-teeth removed. Buckwheat straw is brittle and it is well to bear in mind that as with other grains, the work of separation and cleaning is easier when the work of the cylinder is not overdone. The speed should be low to pre- 
vent cracking the grain. The sieves should be set the same as for wheat. In localities in which sufficient buckwheat is grown to keep a separator threshing for several days at a time, excellent results can be obtained by changing the pulleys on the cylinder-shaft as for rice, thus making a low cylinder speed possible, while the balance of the machine maintains its normal motion.

Threshing Millet. This is the most easily threshed of the ordinary seeds. Usually the normal cylinder speed and four rows of concave-teeth are sufficient to knock out the seed. The adjustable-sieves will ordinarily clean it sufficiently. If the separator be fitted with common sieves, the three-quarter-inch lip-sieve, F, should be used as a chaffer, and either the three-eighths-inch lip-sieve, $G$, or the fifteensixty-fourths-inch round-hole sieve, $H$, used in the second notch and third hole in the shoe. When a lower sieve is desired with either the adjustable- or common-sieves, the one-eighth-inch round-hole-sieve, $\mathrm{O}$, or the five-thirtyseconds-inch round-hole sieve, I, is suitable. Either should be placed in the seventh notch and fifth hole.

Threshing Spelts or Emmer. This grain is easily threshed and if the directions for threshing oats be followed, no difficulty will be experienced. 


\section{CHAPTER VII.}

\section{THRESHING IVITH A SPECIALLY EQUIPPED SEPARATOR.}

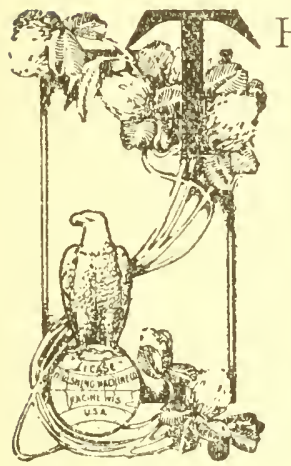

HIS chapter will deal with those crops, the threshing of which requires a change in, or an addition to, a regularly equipped separator. It will include the threshing of peas, beans, rice, clover, alfalfa, orchard-grass, Kafir and Indian-corn and peanuts.

Threshing Peas. To prevent cracking the peas, it is necessary to run the cylinder at a very much lower speed than is required for threshing grain. To obtain the best results, the twelve-bar cylinder should ordinarily be run at from 400 to 450 revolutions per minute, but when the peas are thoroughly ripened and dry, a lower speed will be better, 300 revolutions being sufficient, at times. Ordinarily the twenty-bar cylinder should be run 290 revolutions per minute, but this speed may also be lessened to nearly 200 revolutions when the condition of the pods permit. To secure this low cylinder speed and retain the normal motion of the other parts of the machine and of the engine, it is necessary to change the pulleys on the cylinder shaft.

The number of concave rows may be two, four or six, as the condition require. The cylinder must be run at a 
certain slow speed as already stated, and when so speeded, more concave teeth are required than if it were allowed to run faster However, since the cylinder speed must be low, a sufficient number of concave teeth should be used to knock the peas out of the pods. For "blanks", when less than six rows of concave teeth are used, hardwood boards cut to the right length and width and fitted to the concavecircles are preferable to the regular iron-blanks. Since peas are apt to be cracked by the corners on the iron-blank-concaves or grates, the grates inder the beater are sometimes covered with sheet-iron. This should be done where trouble from cracking is experienced.

In general, the adjustable chaffer and shoe sieve should - be set only slightly more open for the common field peas or for stock-peas than for wheat. If the separator be fitted with common-sieves, the one and one-quarter-inch lip, E, or the two-inch lip, D, should be used as a chaffer, and the three-eighths-inch lip, G, should be placed in the second notch and third hole in the shoe. For a screen, the threesixteenths by three-quarter-inch oblong hole, $\mathrm{P}$, is best, althongh the fifteen-sixty-fourths round-hole wheat sieve, IT, works very well in field or "Whip-poor-will" stockpeas.

If trouble be experienced because the peas strike the floor of the shoe and bound over into the fan, it can be prevented by covering the front part of the chaffer to a distance of twelve or fourteen inches with sheet-iron. If there 
THRESHING WITH SPECIALLY EQUIPPED SEPARATOR. 163

be much sand or dirt to be screened out, applying the same remedy will cause the peas to be dropped farther rearward and allow the dirt more chance to get through the screen. Returning peas to the cylinder with the tailings is apt to crack them, and therefore, the cleaned peas will contain fewer split ones if the tailings be kept separate. This may be done by opening the bottom of the tailings-elevator and allowing them to run on the ground. Afterwards they may be run through the machine while "cleaning up."

Throshing Bcans. All that has been said above, in regard to threshing peas, applies equally well to threshing the ordinary white navy beans, and also the larger varieties, except, that for the latter, if common sieves be used, the three-quarter-inch lip, F, should be used in place of the three-eighths-inch lip sieve, G, in the shoe.

Threshing Soy Bcans. Soy beans are difficult to knock ont of the pods, and are so hard that they are not easily cracked. Therefore, they can best be threshed with a separator adjusted and speeded as for wheat.

Special Cylinders for Peas and Beans. There are localities in which a separator may be kept constantly threshing peas or beans for several days or even weeks at a time. For such machines, it is often advisable to obtain a special cylinder with the teeth spaced for this work. When so equipped, a "Case" separator will do better work than it would do with the regular cylinder. In fact, its work is then equal to that of the machines designed especially for hulling 
beans, while its capacity is much greater. In changing to the special cylinder, it is necessary to procure the special concaves and concave-circles, as well as the cylinder.

Threshing Rice. This grain is difficult to thresh clean from the heads without cracking or hulling the kernels. The teeth in a regular cylinder are spaced too closely for ordinary rice threshing, although good work is sometimes done when the teeth have become somewhat worn and are consequently thinner than when new. The "Case" rice thresher has the proper spacing of teeth to thresh this grain out of the heads without cracking more than a small percentage. What is said in Chapter III in regard to the proper endwise adjustment of the cylinder and the necessity of keeping the teeth straight applies particularly to rice threshing. In reading that chapter with reference to rice, however, it should be borm in mind that a difference exists, from the fact that the space between the concave and cylinder teeth is about three-sixteenths of an inch in the rice machine instead of about an eighth of an inch, as it is in the regular. When the rice is in good condition, thr amount hulled and broken should not exceed five per cent., but when the grain is "sun-cracked", the percentage may be somewhat larger. The condition of the grain will determine the number and position of the concave teeth, two, four or six rows being used as required.

Besides requiring a special spacing of the cylinder and concave teeth, the cylinder speed must be lower for rice. 
TIRESIING WITH SPECIALLY EQUIPPED SEPARATOR. I65

than for ordinary grain. The twelve-bar cylinder-speed for rice should be 900 revolutions per minute and in order to give the proper speed to the other parts of the separator, it is necessary to have the special pulleys on the cylinder shaft. These are sufficiently larger than the regular pulleys to allow the cylinder to run at the desired low speed, while maintaining normal speed of the other parts of the separator. In the same manner, the twenty-bar cylinder speed for rice should be from 575 to 600 revolutions, and to obtain this, a corresponding change in all the pulleys on the cylinder shaft must be made. More rice is apt to be cracked the first few days a new separator runs, than will be afterwards, when the cylinder teeth have become worn smooth.

For rice the adjustable chaffer and shoe-sieve should be set in the same position and with about the same opening as for oats. Rice is considerably heavier, however, and will stand the extra amount of wind required to blow out its heavy chaff. When common sieves are used the chaffer should be the two-inch lip. D. The three-quarter-inch lipsieve, F. placed in the second notch and third hole gives excellent results as a shoe-sieve. For a screen, the onefourteenth by one-half-inch oblong-hole, $L$, is best, ordinarily. When the rice is so small that this screen lets too much through, the one-sixteenth by three-eighths-inch oblong-hole, $\mathrm{K}$, may be used.

Hulling Clover. The process of removing clover seed 
from the heads or tops of the plant is usually called "hulling;" instead of "threshing." A special attachment is made for "Case" separators, for use in hulling clover. This attachment consists of four narrow three-row concaves filled with corrugated teeth, one special blank concave and special sieves. All twelve rows of teeth should be used and the blank placed in front. If the seed be not threshed clean from the heads at the regular speed, with the twelve rows of teeth set clear up, run the cylinder a little faster. While doing this, the belts driving beater, crank and fan may be left a little loose so they will not drive these parts too fast. Clover must be very dry to be well threshed by any machine and when threshing from the field is usually not in condition to be hulled before ten or eleven o'clock in the morning. From three to six bushels per hour is fair work with a medium size separator in dry clover of an average yield. The machines built especially for hulling clover have only about half the capacity of the "Case" separator.

Good cleaning has been done with the adjustable-sieves alone, but ordinarily, it will be found much easier to produce clean seed if a sieve be used in the shoe below the adjustabie one. For this purpose, the three-thirty-secondsinch round-hole sieve, $N$, or the twelve by twelve mesh woven-wire-sieve, $\mathrm{R}$, is the correct size. Either should be placed in the seventh notch and eighth hole. The adjusiable shoe-sieve should be placed in the second notch and third hole. When common sieves are used, the three-quar- 
THRESHING WITH SPECIALLY EQUHPPLD SEPARATOR. IO7

ter-inch lip, F, makes a suitable cliaffer, and the threeeighths-inch lip-sieve, $\mathrm{A}$, is the best as an upper-sieve in the shoe. The latter should be placed in the first notch and first hole and the lower shoe-sieve should be of the same size and placed in the same position as given for adjustablesieves. Three sieves have been used in the siroe for clover, but few operators can make three sieves do better than two. The "Case" recleaner is sometimes used in hulling clover and when fitted with the proper sieves, it will thoroughly clean very weedy seed.

Threshing Alfalfa or Lucerne. The same rules which govern the hulling of clover apply in a seneral way to the threshing of alfalfa, although it is easier to rub the latter out of its pods than the fommer out of its heads. The clover concaves are sometimes used, but more often one or more of the regular three-row concaves filled with corrugated teeth are all that is required. The sieves may be the same and set in the same way as for clover. Often a weed known as dodder or love-vine, grows with alfalfa and its seeds are usially enough smaller than the alfalfa seed to allow the greater part of them to be removed by screening. The most suitable screen for this purpose is the one-twentieth-inch round-hole, $\mathrm{X}$.

Threshing Orchard-Grass. In threshing this grass, the cylinder should be run at its regular speed, and six rows of concave teeth, set well up, should be used. Good work has been done with the adjustable sieves alone, but as a rule, 
the seed can be cleaned better by using the three-thirtyseconds by one-half-inch oblong-hole special sieve, U, underneath the adjustable shoc-sieve. It should be placed in the seventh or eighth notch and sixth hole. The adjustable shoesieve should be placed in the second notch and third hole. If common-sieves be used, place the one and one-quarter-inch lip sieve, $\mathrm{E}$, in the conveyor. Use the three-quarter-inch lip sieve, F, as an upper sieve in the shoe placed in the first notch and third hole. Use the three-thirty-seconds by one-half-inch special orchard-grass sieve, $U$, below, placing it in the same position as when used with the adjustable one. But little wind is required, and if the grass be reasonably free from weeds, the lower blinds may be entirely closeci and the upper ones opened a little. If the grass be clamp or dirty, slightly open the lower ones also. From twelve-hundred to fiftcen-hundred bushels of orchard-grass have been threshed in a day with a medium sized machine.

Thrcshing Kafi-Corn. The three principal varieties of Kafir-corn-the white, the red and the black-hulled white, (African-millet), are known by various names, such as "redtop" or "sumac-cane", "milo-naize", "black-amber-cane". "guinea-corn", etc. Any of these may be successfully threshed with a "Case" separator. When the machine is kept continually threshing crops of this sort, it is best to use the "Texas" straw-rack, which is made especially for this work. The general directions for wheat may be followed in regard to the cylinder and concaves, speed and cleaning apparatus. 
THRESHING WITH SPECIALLY EQUIPPED SEPARATOR. I69

Threshing Indian-Corn or Mainc. The threshing of Indian-com is very hard on a separator and the use of a good machine for this purpose is therefore not recommended. Some threshermen use a separator which has been discarded for use in regular grain threshing and this arrangement is not objectionable. As the corn is shelled by the machine it must be drier than is necessary for a huskershredder, or the shelled corn will heat and spoil. Usually the cylinder is run at its normal speed and two rows of concave-teeth are used. Often concave-teeth are forged so as to be sharpened on the front edge or else shortened to lessen the amount of power required to drive the cylinder. The fish-backs may be removed from the straw-rack and the risers lowered so that the rack is flat, similar to the special "Texas" rack used for Kafir-corn.

Threshing Pcanuts. Although a great part of the peanut crop has always been removed from the vines by hand, machines are being used more and more each year for this work. The "Case" separator, when fitted with special parts, works very satisfactorily, and the separation is more complete with it, than with the machines built especially for hulling peanuts. 
SCIENCE OI: SUCCESSFUL THRESHING.

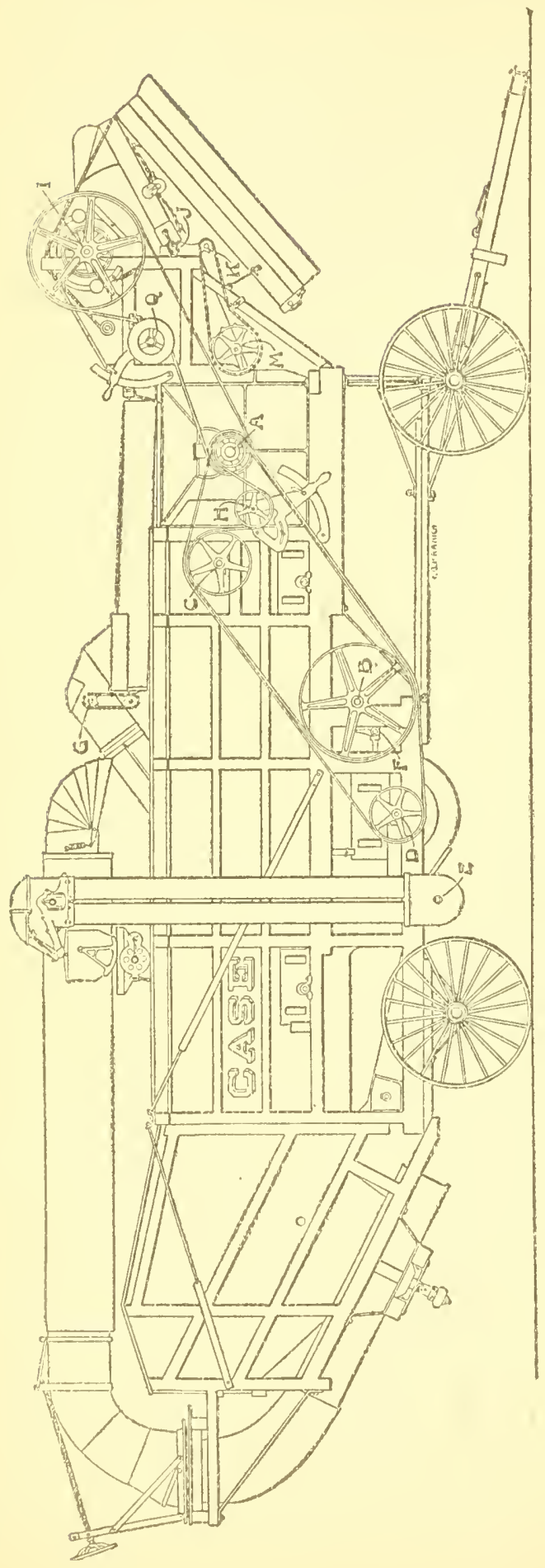

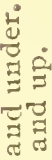

i。

हंड्य

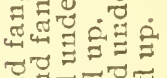

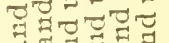

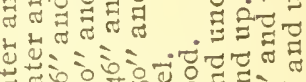

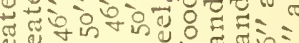

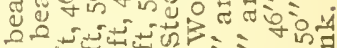

ด1

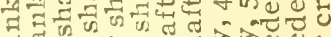

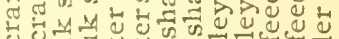

on

य 450 .

․․

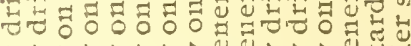

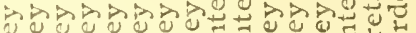

(2)

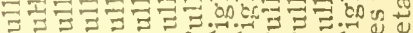

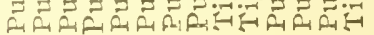
至

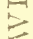

$\Leftrightarrow \quad$ i

0 to

西

$\vec{u}$

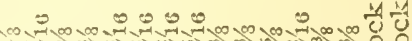

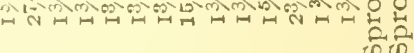

ב

at

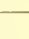

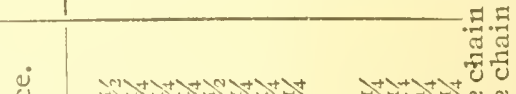

4

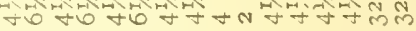

完兄

[긴

글

苟

究焉

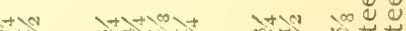

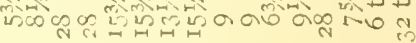

Fi

묄 穴

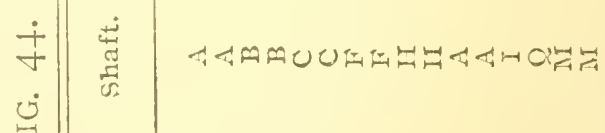

F 


\section{CHAPTER VIII.}

\section{FEEDING THE SEPARATOR.}

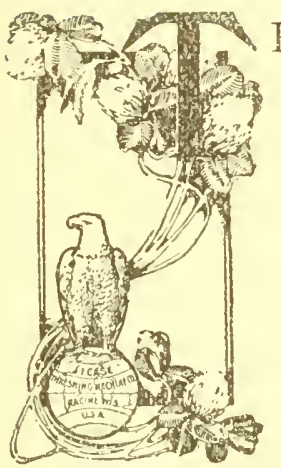

HE importance of having a separator properly fed was generally realized more fully in the old days when all machines were fed by hand and the power was furnished by horses, than at present. Then it was evident that some men could feed more grain to a threshing cylinder in a given period, at the same time letting the horses do their work easier, than others less skilled in the art of feeding. To-day, as in the past. to get the best results from a separator, it must be fed so that the cylinder maintains a uniform speed.

Feeding by Hand. To become a good hand feeder, considerable experience and practice are required. A good feeder tips his bundles well 11p against the cylinder cap. turning flat bundles up on edge, and always holding them from the under-side so that the cylinder may take from the top. But a slight movement is necessary to spread a bundle, and in fast threshing, feeding from both sides, each bundle should be fed almost entirely on its own side, keeping the cylinder full its entire width and having each bundie in position before the last of the preceding bundle has passed into the cylinder. A good feeder will keep the straw-carrier 
evenly covered with straw, and will watch the stacker, tailings and grain elevators and know the moment anything goes wrong.

Self-Feeders. A separator equipped with a feeding attachment may be spoken of as a "self-feeder," but properly speaking, the attachment itself is a "feeder," not a "selffeeder," becanse it feeds the separator, but does not feed itself.

Attaching the Fecder. Remove feed tables, hopper-arms and foot-board, if they be on the machine. A wagon placed in front of the separator will afford a convenient means of supporting feeder head while bolting it in place. When the head is bolted in position, the "notched bottom" and "retarder bottom" may be put in place. The plate of the latter must rest on top of the concave so that no ledge is formed. Any man who has tried feeding a cylinder by hand when the feed board had slipped off the concave, will understand the importance of this. The carrier is held by the notches provided for it on the head, by pins. Slack for hooking the sprocket chains of the rake may be obtained by partly folding the carrier. When all pulleys, including the tightener and govemor, are fastened in place, all the bearings are oiled and the governor adjusted according to the directions given below, the feeder is ready to run.

After attaching a feeder, it is well to try the cylinder for end-play, for it may be that the ironsides supporting cylinder boxes have becn sprung enough to cause too much end-play 
or else press the boxes so hard against the hubs of the cylinder heads as to cause heating.

Folding Feeder Carrier. The carrier is folded out of the way for transportation. The center-board must be removed and the sprocket-chains of the rake hooked up before folding.

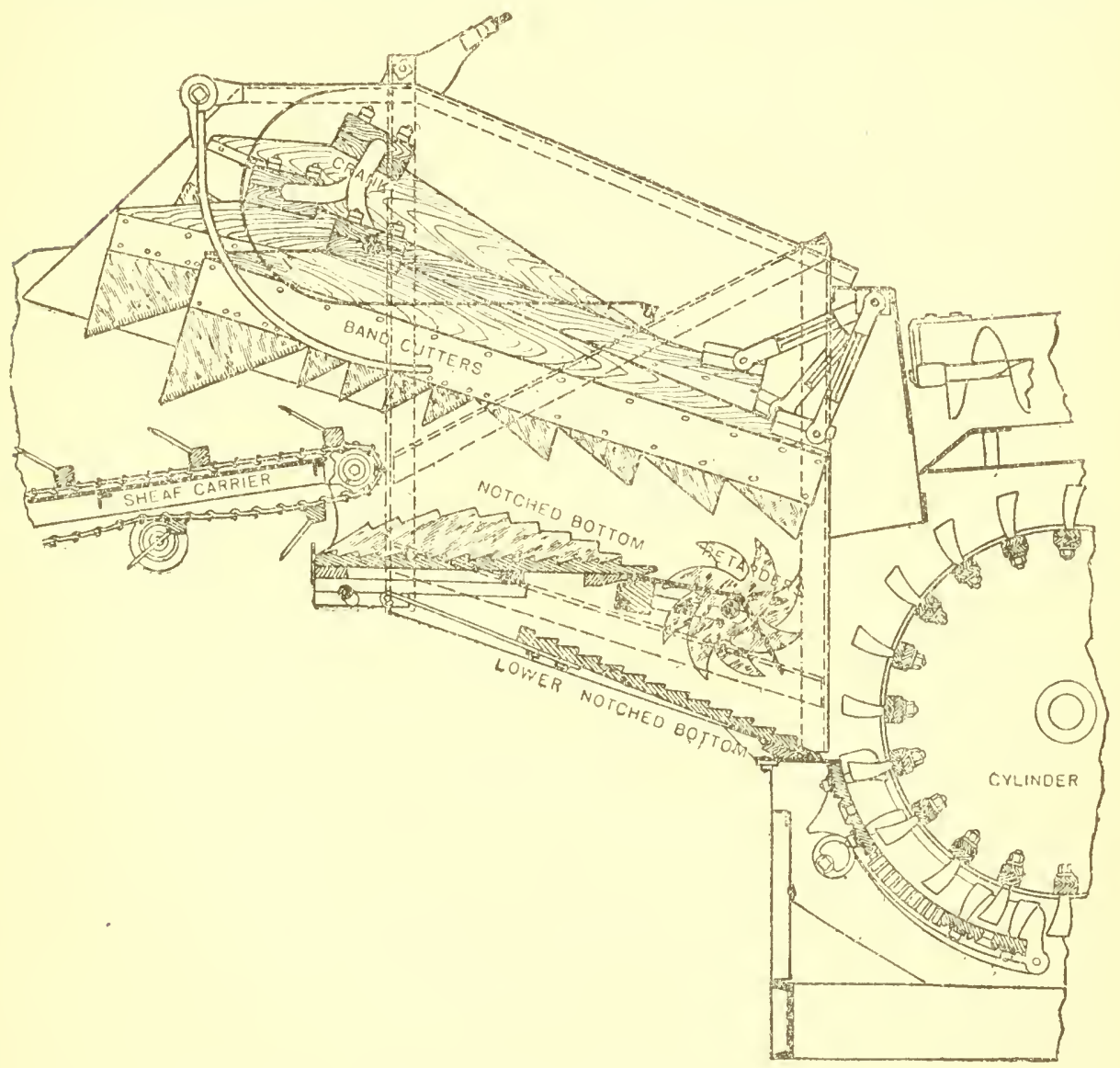

FIG. 45. SECTIONAL VIEW OF "CASE" FEEDER.

Oiling. The places to be oiled are the cranks, the two large crank boxes, the two small crank boxes, two carrier shaft ioxes, shaft at outer end of carrier, two wood boxes of hopper-bottom, tightener-pulley stud and the stud on 
which the idler pulley runs. The friction band of governor should not be oiled after it becomes smooth.

The Gorernor drives the feeder by means of a friction band, which is clamped over a friction pulley, by means of the centrifugal action of the weights. The spring tension on these weights should be such that the feeder will not start until cylinder is very near its normal speed. In starting a new feeder any paint that may be on the inside of friction band and on the face of the friction pulley should be carefully removed and the surface of both scoured with emerycloth or fine sand-paper until smooth and bright. A very little oil may be used the first few days, but when once properly adjusted, it will not require any further lubrication. The best adjustment of the governor will be found to be as follows: First adjust the friction band so that the weight arms may be pulled out about half way by hand. Then set the weights about one-half inch from the ends of the arms and give the spring but little tension when the weights are in and the band is loose. The final adjustment of the spring can best be made by trying it and setting it to suit the speed. Wrench $5548 \mathrm{~T}$ will be found convenient in adjusting the spring.

Specd. IVith the regular cylinder speed of 750 revolutions for the 20 bar and Io75 revolutions of the I 2 bar cylinders the knife-arm crank of the feerler will make 258 revolutions per mintute. The retarder blarles should be driven from the carrier-rake drive shaft and when so driven, will 
make 27 turns per minnte, with the belt driving stud shaft on the inner pulleys or 33 turns with belt on outer pulleys. As a change in the speed of carrier-rake is sometimes desirable, special sprockets have been provided which give a range of speed as shown in the following table.

\begin{tabular}{|c|c|c|c|c|c|c|c|c|c|}
\hline \multirow{2}{*}{ 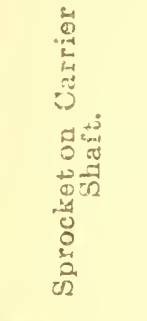 } & \multirow{2}{*}{ 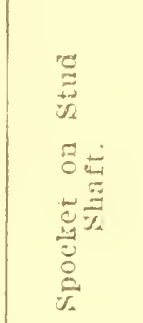 } & \multicolumn{4}{|c|}{$\begin{array}{l}\text { Slow. (Relt on Inner } \\
\text { Pulleys). }\end{array}$} & \multicolumn{3}{|c|}{ Fast, $\begin{array}{l}\text { (Peit on Onter } \\
\text { l'ulleys). }\end{array}$} & \multirow{2}{*}{ 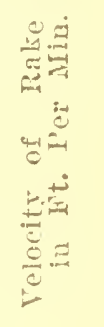 } \\
\hline & & 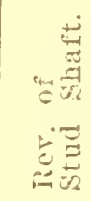 & 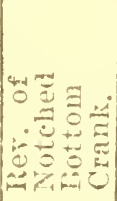 & 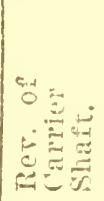 & 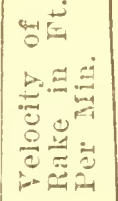 & 离 & 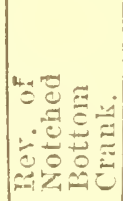 & 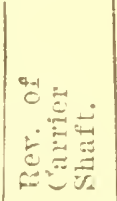 & \\
\hline $\begin{array}{r}5324 \mathrm{~T} \\
5324 \mathrm{~T} \\
\mathrm{~A} 53.24 \mathrm{~T} \\
\mathrm{~A} 5321 \mathrm{~T} \\
36 \mathrm{H}\end{array}$ & $\begin{array}{r}5417 \mathrm{~T} \\
45447 \mathrm{~T} \\
5447 \mathrm{~T} \\
\mathrm{A5447T} \\
45417 \mathrm{~T}\end{array}$ & $\begin{array}{l}230 \\
263 \\
230 \\
263 \\
263\end{array}$ & $\begin{array}{l}230 \\
201 \\
230 \\
261 \\
264\end{array}$ & $\begin{array}{l}67 \\
76 \\
80 \\
92 \\
92\end{array}$ & $\begin{array}{c}51.45 \\
61.75 \\
65 . \\
74.75 \\
71.75\end{array}$ & $\begin{array}{l}290 \\
331 \\
290 \\
331 \\
331\end{array}$ & $\begin{array}{l}290 \\
330 \\
290 \\
330 \\
330\end{array}$ & $\begin{array}{r}81 \\
96 \\
101 \\
116 \\
116\end{array}$ & $\begin{array}{l}68.25 \\
78 . \\
82 . \\
94.25 \\
94.25\end{array}$ \\
\hline
\end{tabular}

Note: Sprockets 5324T (24 teeth), and $5447^{\mathrm{T}}$ (7 teeth), are regular, and $A_{5324} \mathrm{~T}$ (20 teeth), and $\mathrm{A}_{5447 \mathrm{~T}}$ (8 teeth), are special. The number of revolutions per minute is given in each case. The above has reference to feeders previous to 1907 . On feeders built in 1907 and later, having the straw governor, sprocket $36 \mathrm{FS}$ is regular. 
I76 SCIENCE OF SUCCESSFUL THRESHING.

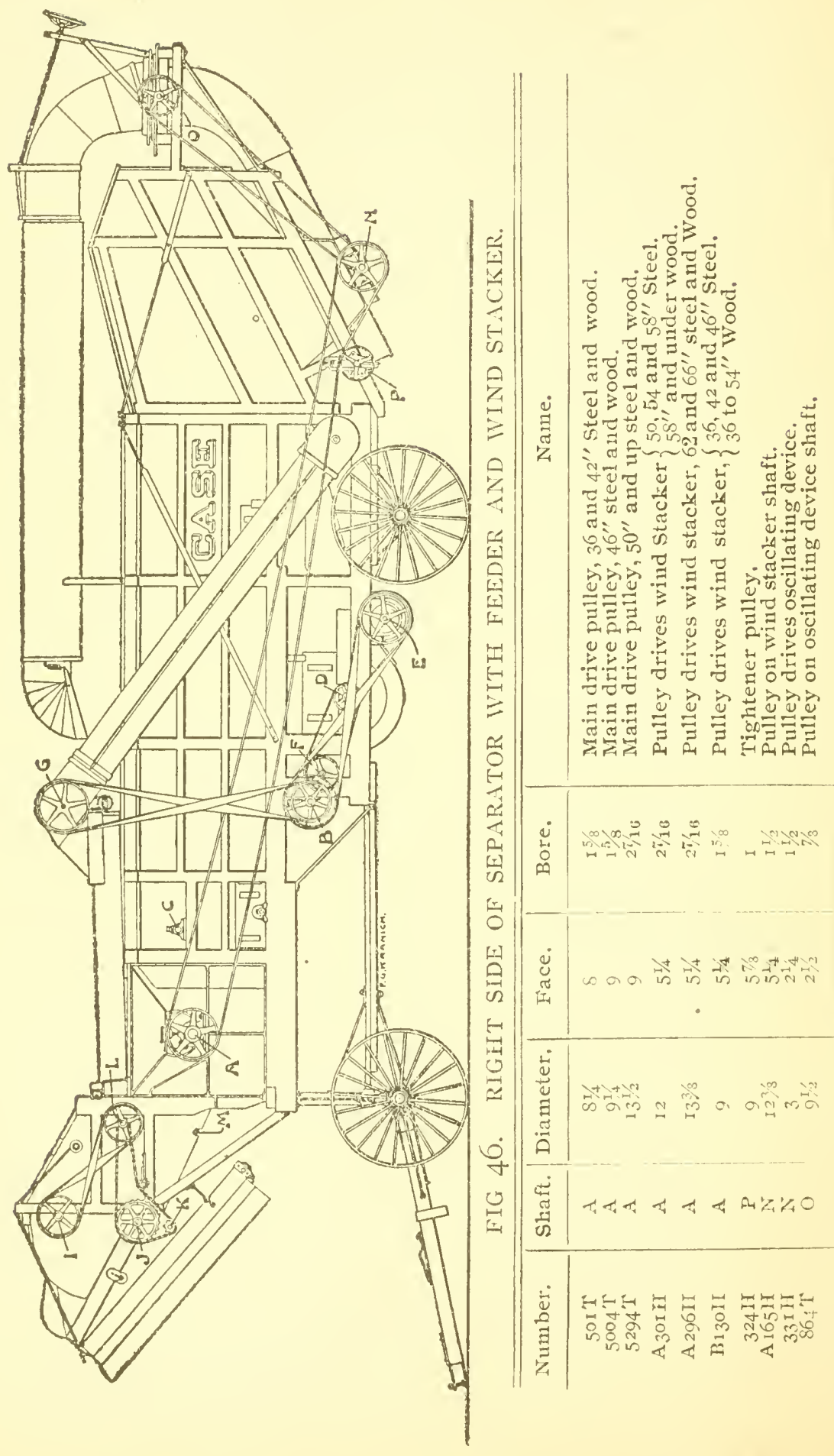




\section{CHAPTER IX.}

\section{THE STRAW STACKERS.}

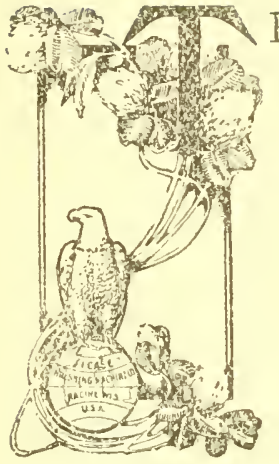

HE demands of the farmers in various localities for a means of handling straw, especially suited to their particular needs, has led to the designing and building of several different devices for this purpose.

Common Stackers. This is the name given to the plain straw carriers which do not swing. Ordinarily they are attached to the separator and are hoisted and lowered by means of a rope and windlass. The short lengths are usually in one section, but the longer ones are jointed so they may be folded for transportation. Being pivoted to the separator at a point near the ground, a common stacker is level when its end is not more than three feet from the ground. Therefore, the straw will be dropped nearer and nearer to the separator as the stacker is elevated. This tendency of the end of the stacker to draw away from the stack must be allowed for in locating the stack, which must be placed sufficiently under the stacker so that when elevated, the straw will be dropped well onto the stack. Parts may be obtained for converting any "Case" common stacker into a "side-stacker" for delivering the straw into the side mows in barn threshing. When so used the end of the straw-carrier rests on the ground. 
The Attached Stacker. This is the name given to the automatically swinging stacker which is attached to the separator. The present styie has an upright-section, to the upper end of which the carrier is attached. This brings the pivot-point about ten feet from the ground, and since the carrier is this distance from the ground when level, its outer end does not perceptibly draw away from the stack as it is elevated.

Operating the Attached-Stacker. The carrier of this stacker may be made to swing automatically, and, as is the case with other self-swinging stackers, the length of swing depends upon the position of the trip-pins. Many stack builders prefer to swing the carrier by hand from the stack. This may be done by disengaging the driving apparatus. The carrier of this stacker should always be folded so as to rest on the deck of the separator, before the machine is moved from place to place.

Oiling the Attached-Stacker. All of the gearing should be frequently greased, especially the bevel-gears and the worm-gears. The upright bearing is oiled through the center of the shaft. All the other shaft bearings are provided with oil-cups which should be partly filled with a little wool or cotton-waste.

Independent Stackers. This is the name given to swinging stackers which are mounted on trucks separately from those of the separator. The independent stacker was quite universally popular at one time. Of late years the wind 
stacker and other swinging stackers have replaced it very generally. These later stackers, from the first, were more popular with the threshermen because no time is lost in setting and aligning them. The independent stacker requires a complete common stacker, usually an eighteen-foot, to deliver the straw onto it. The carrier supports are arranged to move the carrier towards the stack as it is elevated so the path of the end of the carrier approxinates closely a vertical line.

Putting together the Independent-Stacker. The frame and platform should be first mounted on the trucks. The long section of the carrier may be then placed in position and its radial supports and hoisting ropes attached. These ropes should be kept the same length so that the carrier will hang level. The short section of the carrier together with the ropes and reel-shaft for folding it may be next put on. Wher the carrier-rake, the slicles for supporting it and the side-boards are put on, the stacker will be complete. The hood is attached to the end of the common stacker in such a manner as to prevent the wind from scattering the straw as it drops onto the independent-stacker.

Setting ihe Independent-Stacker. Holes should be dug or blocking placed under the truck-wheels until the frame is level, both cross-wise and length-wise. This is necessary, as otherwise an excessive amount of power is required to swing it toward the higher side of the frame. The stacker must also be placed in alignment with the separator in order 
to have the belt run properly on the pulleys. To prevent the belt from drawing the staclier ahead, at least one of the truckwheels inust be blocked. The block for this purpose should be carried with the machine so that it will not be necessary to hunt one each time the stacker is set.

Operating the Independont-Stacker. The length of swing is governed by trip-pins and will be readily understood. Before leaving the machine with a stack part way up, it is best to lower the carrier until it rests on the stack, so that in case a wind springs up, the stacker will not be in danger of being upset. The carrier should be folded and lowered until it rests on its supports before inoving from place to place. No special instructions are necessary in respect to lubrication, except, perhaps, to call attention to the fact that the bearings of the rake-drive-shaft boxes should be frequently oiled.

The IVind Stacker has steadily increased in poptularity until to-day there are more of them sold than of all the various other varieties of stackers combined. The wind stacker was extremely popular with the threshermen from the first, because of its freedom from "trappy" features, the absence of dust and litter about the separator equipped with it, and the ease with which the chute is swung around on the deck of separator for transportation.

Operating the ITind Stacker. To make the chute swing automatically, the two inch belt must be put on to drive the turret and if the clutch, which is operated by a rod handle 
from the foot-board, be engaged, the turret will slowly rerolve, carrying the chute with it. It may be made to go in the opposite direction at any time by throwing the reverse lever over by hand or it may be stopped by throwing the other clutch out by means of the rod. Rivets are used as trip

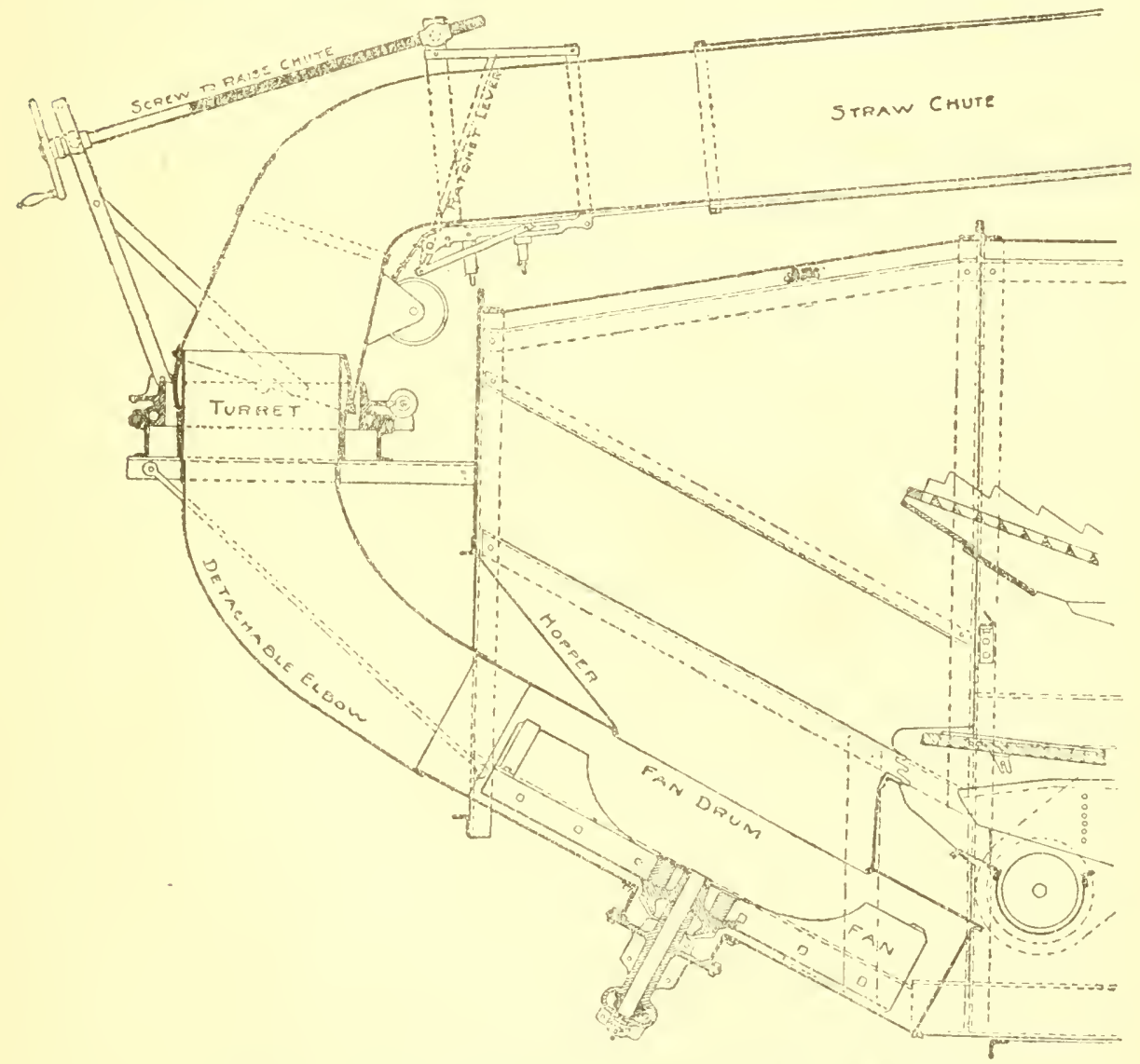

FIG. 4\%. SECTIONAL VIEW OF TIND STACKER.

pins and these will calise stacker to reverse its swing automatically, any desired length of swing being obtained by placing the trip pins in the different holes in the man-turning worm-wheel. Care nutust be taken to see that these trip 
pins are removed before trying to swing the chute by means of the hand-wheel for if left in, a broken reverse lever may be the restilt. When a setting is nearly finisherl, the trip pins should be removed so that the chute may be turned on top of the machine as soon as the engine belt is thrown off. The machine should nover be moved until the chute rests in its support. If it be not desired to use the automatic movement, the two-inch belt may be left off.

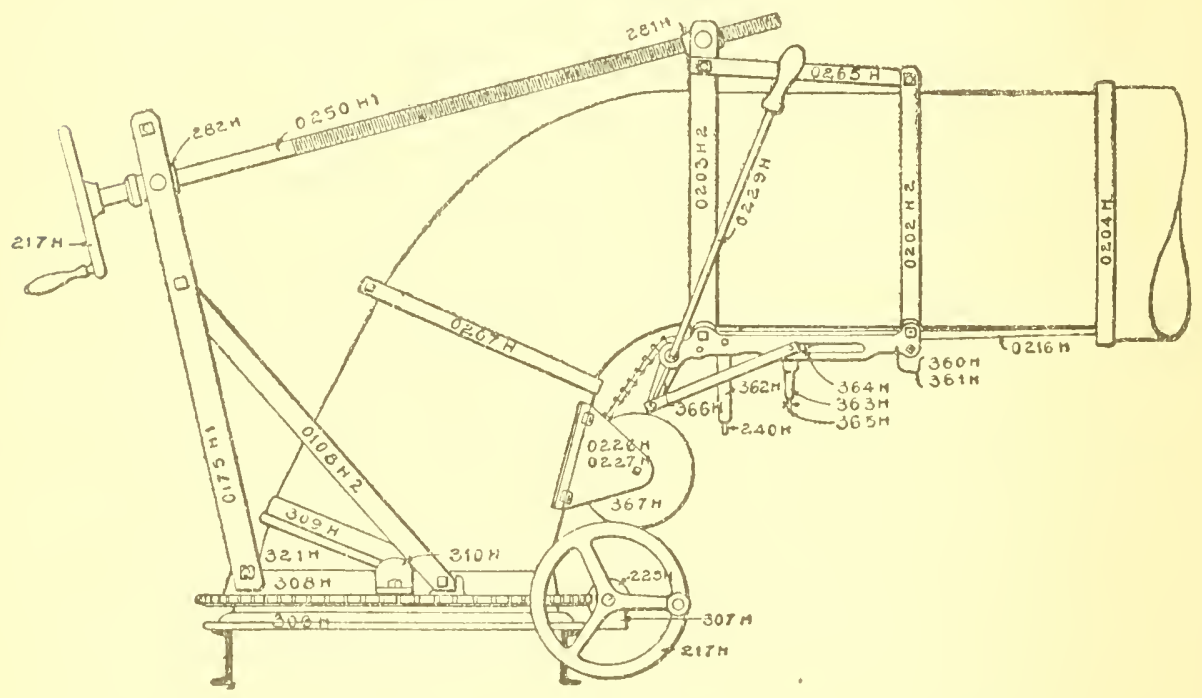

FIG. 48. TELESCOPING DEVICE FOR STRAIV-CIIUTE.

If the stacker drive belt does not run on the center of the stacker pulley, it may be made to do so by inserting a little cardboard under the idler-pulley bracket. If the belt has been running too far out (or away from the machine), on the pulley, put the cardboard under the front part of the bracket, and if the belt runs too far in on the pulley, put the cardboard under the rear part of the bracket. Underlaying 
the bracket above or below so as to raise the outer or the inner edge of the idler pulley, will not change the position of the belt on the pulley to any extent. It must be put under the front or rear part to accomplish the desired result, as this will divert the course of the belt slightly on its way to the pulley.

Stack Building acith Wind Stacker. Where it is desirable to stack the straw so as to preserve it, the wind stacker must be handled by a competent man. In starting the stack, bring the chute about level, extend it to its full length, raise the hood slightly, and build the back of the stack first. Alwavs keep the farther side of the stack highest. Make the stack bottom at least one-third smaller than would be done were it built by hand, and allow the straw chute to oscillate. It is very important that the farther side of the stack be kept highest, as it furnishes a hack wall to stop the force of the straw. A good rule to follow is: "Always throw the straw onto the stack and not over it." Tn topping out, allow the straw to strike the top and glance over it: in this way the farther side of the stack will be filled out and the straw will be prevented from rolling down or going over too far. When the straw chute is at the corner of the stack, raise and lower hood quickly, thereby distributing the straw and binding the corner.

Lubricating the Wind Stacker. Keep the bearings of the fan and jack shafts well lubricated with hard oil. The bevelgears must be kept well greased. All the bearings and worm gears of the automatic device for swinging the straw chute should be oiled. 
Speed of Stacker Fan. Ordinarily, with the twenty-bar cylinder running at $75^{\circ}$ revolutions, a twelve-inch cylinder pulley $\left(\mathrm{A}_{3} \mathrm{iH}\right)$, should be used on separators up to and including the 58 inch size. This gives a fan speed of 650 revolutions per minute. On separators with 62 or 66 inch rears, a larger pulley (A296H, thirteen and one-half inches), should be used, which gives a fan speed of 720 revolutions per minute. With the twelve-bar cylinder running at its normal speed of 1075 revolutions, the eight and one-half inch pulley (AızolI), will give the fan a speed of 665 revolutions per minute. It is desirable to keep the speed of the wind-stacker fan as low as possible, not only because it makes good stack building easier, but also because it requires less power to run. On page $5 \mathrm{I} 6$ of "Kent's Pocket-Book" an example is given of a fan which took $.25 \mathrm{H}$. P. to drive at a speed of 6oo. The same fan required .70 H. P., or nearly three times as much when the speed was increased to 800 .

Combination-Stackers. The combination-stacker has been made because of the demand for a stacker that would give the thresherman all the advantages of the simplicity and freedom from litter of the wind-stacker, and, at the same time, give the farmer, who desires to have his straw stacked by men placed on the stack, a stacker which delivers the straw onto the stack by means of an ordinary carrier and carrier-rake.

Attaching the Combination-Stacker. Up to the point of putting on the turret, this stacker is attached in the same 
manner as the wind-stacker. The turret, however, which has the mechanism for driving the rake, in addition to the parts used on the wind-stacker, is attached eight inches higher than that of the wind-stacker, in order to bring the carrier sufficiently high to swing clear of the deck of the separator. Holes are provided in the posts of the frame for attaching the turret in the positions required by either the combination- or wind-stacker. After the turret is in place, and the two sections of the carrier bolted together, the carrier may be attached. This is conveniently done by placing it in position upon the deck of the separator, as for transportation. The hoisting cables, sprockets, chain. handwheels for operating and the carrier-rake may now be put on. The presser-strips are hinged to the hinged-screen at one cnd, their outer end being carried by leather straps.

Operating the Combination-Stacker. This stacker receives its swing novement in the same manner as the windstacker. The trip-pins which determine the length of the swing must be removed before attempting to swing it by means of the hand-wheel. The hoisting mechanism is selflocking so the carrier cannot fall. The presser-strips hold the straw against the carrier-rake, thereby making it possible to elevate the carrier to an angle of about forty-five degrees. The carrie: should always be swung onto the deck of the separator before moving the machine from place to place. Stack-builders, who are unfamiliar with this stacker, should be cautioned against starting the stack too far under the car- 
rier as it does not pull away from the stack until elevated to a considerable height.

Oiling the Combination-Stacker. The bearings of the jack- and upright-shafts are fitted with compression-cups for hard-oil. These may be turned up as often as necessary to give sufficient lubrication. The bevel-gears driving the fan should be greased. The turret mechanism driving the carrier-rake should be oiled occasionally. The intermediategear-ring, and the two small pinions meshing with it, should be greased. 


\section{CHAPTER X.}

\section{THE GRAIN IANDLERS.}

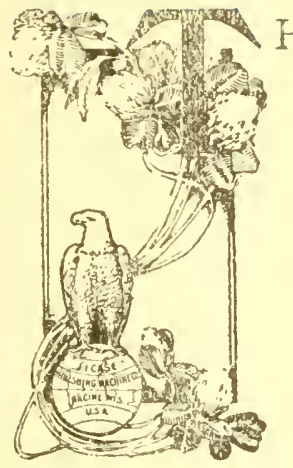

HE devices used to take the grain from the grain auger and deliver it into sacks or wagons, as the case might be, are called "grain handlers." These are made in six styles, some of which, in addition to elevating the grain, weigh it and automatically record the number of bushels threshed.

The weight of a given quantity of grain varies according to the kind and quality. Although almost universally sold by the bushel, the number of bushels is determined by weight so that the grain is actually sold by the pound. For example, if the price of wheat be one dollar per bushel, one dollar will purchase sixty pounds of wheat. Sixty pounds of heavy wheat will not fill a bushel measure, but this weight of light wheat will more than fill the measure. In the days when there were no grain handlers, and the grain from the separator was delivered into half-bushel or bushel measures, it was usually customary to give "big measure." By this method, were a farmer to sell all of his grain, he would receive pay for a greater number of bushels than he paid the thresherman for, for threshing it. This custom of giv- 
ing "big measure" in threshing, uncioubtediy grew out of the fact that it was necessary to heap the measure in order to make the light grain "hold out." Since the measuring was done by someone who looked out for the interests of the farmer rather than those of the thresherman, the measures were usually heaped with all that they would hold, and in some cases, even tamped in order to make them hold more. This, of course, was unfair to the thresherman. The thresherman should insist on pay for every bushel by weight, as he would do, were he selling the grain. When engaging the threshing, he should tell the farmer of his intention to do this, and then, if the former price were too high, it might be adjusted accordingly. Since the weighing attachments accurately weigh and automatically record the number of bushels threshed, all fair minded men must admit that the use of one insures a record of the amount threshed that is fair to both thresherman and farmer. The prejudice against weighers "that has, in some cases, existed because of the custom of giving "big measure" has graduaily disappeared until they have come into almost universal use. Their accuracy was at first often doubted, but in many cases the weigher's record of a certain amount of grain has been compared with the weight of the same grain on standard scales and found to correspond very closely.

The Number One Weigher consists of an elevator permanently attached to the left side of the separator, the weighing apparatus, and a conveyor across the deck of 
the separator. The cross-conveyor is of sufficient height to deliver the grain into a wagon box on either side of the

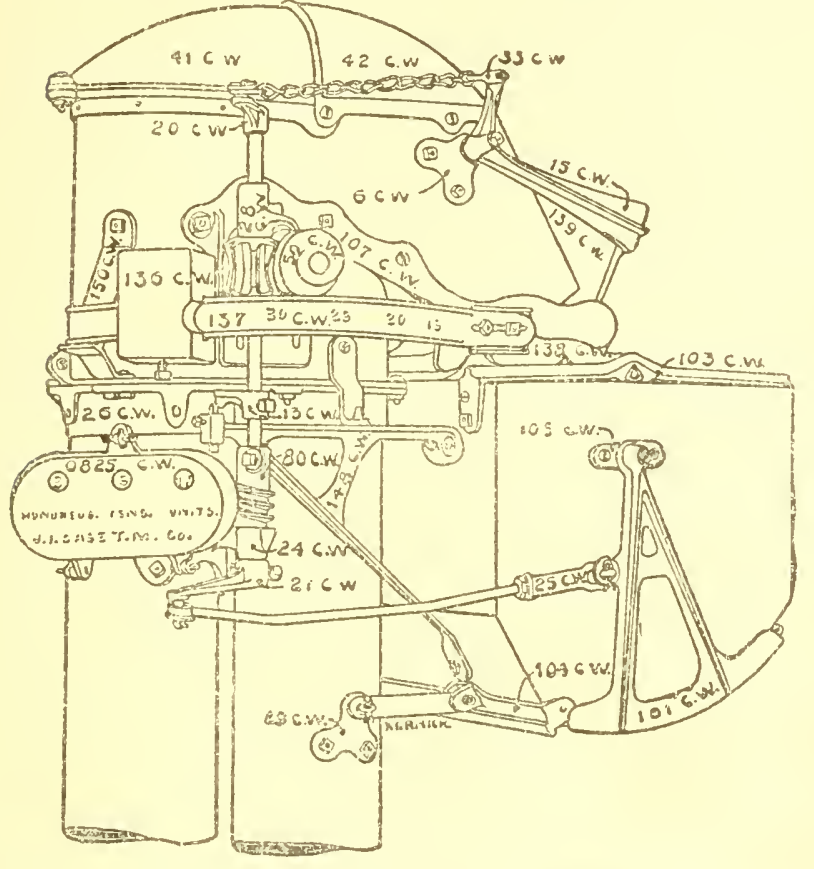

FIG. 49. IIEAD OF CASE WEIGHER. $\mathrm{mach}$ in e. The purchaser of a $\mathrm{Number} \mathrm{One}$ weigher is given the choice of two plain spouts for delivering the grain in bulk into wagon boxes, or of the bagging attachment for delivering the grain inta sacks.

(This bagging attachment has twin-spouts to allow putting on the empty sack before removing the full one). The Number-One weigher requires no folding for moving on the road, and is no higher than any other part of the separator. For these reasons it is largely used in localities in which the threshing is done principally in and around barns. It is one of the most popular of the grain handlers.

The Number Treo Weigher is also called the "Dakota style weigher". The elevator is so high that the grain is sufficiently elevated to be delivered by the long spout on either side of the machine. In this way the cross conveyor is dispensed with. As the spout is long, it will hold con- 
sidcrable grain so that the exchange of sacks may be made even in fast threshing, without danger of choking the elevator by obstructing its delivery. The grain may be delivered in bulk into wagons driven along side the separator as the end of the spout is a sufficient distance from the separator to make it unnecessary to back the wagon up to the machine. Where grain is to be sacked, an empty stationary wagon may be used to sack in, thus avoiding the necessity of lifting the sacks of grain into the wayon which hauls them away. The long spout is provided with hooks to hold the sacks. The Number Two weigher is used very generally in the localities where the threshing is done in the open field. It is the only suitable grain-handler for use in connection with portable-bins, such as are quite generally used in the northwest: The spont is long enough to deliver the grain into these bins and the weighing apparatus automatically records the number of bushels threshed.

The Number Three Weighing-Bagger. This attachment is intended for use in putting the grain into sacks on the ground and it can only be used on the left-hand side of the separator. It has the same weighing mechanism as the Number One and Number Two Weighers.

The Number Four Bagger. This grain-handler does not weigh the threshed grain, but is used simply to elevate it to a sufficient height to run into sacks. In order to keep the men sacking always on the windward or clean side of the separator, it is often desirable to change the basger from 
one side to the other. In doing this, it is also necessary to change the drive to the other side as the belt driving must alvays be on the side opposite the elevator. The direction in which the anger runs must also be reversed and this is accomplished hy rumning the drive-belt crossed, when the elevator is on the left-hand sicle of the separator and straight, when the bagger is on the right-liand side. On separators fitted with common stacicers, when the elevator is on the right-hand side, pulley No. I223T should be used on the grain auger, and pulley No. 529T on the top of the tailings elevator; when tine elevator is on the l-ft-hand side, pulley No. 529T should be used on the grain-auger and pulley No. I223T on the tailings elevator.

The Number Fir'c Loadcr. This attachment serves the same general purpose as the Number Two Weigher, except that it does not weigh the grain.

The Number Sir Loader is similar to the Number One Weigher, but has no weighing mechanism. For those who desire to sack on the ground it may be used in place of the Number Four. The delivery of the grain may be changed from one side of the separator to the other by simply throwing a lever. It may be used to run the grain into a wagon box in bulk or into sacks in wagons as desired, as was explained for the Number One Weigher.

Attaching Grain-Handlers. All of the "Case" grainhandlers, except the Number Four, require a left-hand grain anger. When it is desired to attach one of these elevators 
to separators built previous to the year of I899, which were fitted with the right-hand grain angers, it is necessary to replace the old auger by a left-hand one, or the attachment will not work. The Number Four Bagger is ordinarily used with a left-hand grain auger, but it may be used with 1 ighthand as well. To do this, it is necessary to remove the chain, and unbolt and reverse either the head or the boot.

Cantion Regarding the Sprocket-Chain. The chain in the elevators of all the grain-handlers must be kept properly adjusted. Since they are driven from the bottom, when the chain is too loose, it does not hug the sprocket properly and wears umnecessarily. On the other hand the chain should not be so tight as to be in tension, for this causes unnecessary friction and the consequent wear on the chain and shafts. As the chain wears, the hook of each link may be closed by hanmering its point, while its back rests on the horn of an anvil or similar projection. In this way the chain may be kept free from danger of unhooking until worn so that it fails from weakness. When necessary to shorten the chain, always remove two links at a time so that an odd number, three or five, of plain links remains between the cups or "flights," as they are called. This is necessary because the lower sprocket has teeth engaging only alternate links of the chain and the links with flights attached must skip the teeth.

Calculating a Quantity of Grain. Where a weigher is not user, the amount of grain in a wagon-box, portable bin or in any rectangular receptacle, may be calculated as fol- 
lows: Determine the length, width and height in inches, multiply them together and divide the product by 2I 50 , the number of cubic-inches in a bushel. The quotient will be the number of bushels. Where the depth is not uniform, several measurements should be taken and their average used. For example, the usual wagon-box is thirty-six inches wide, one hundred and twenty-four inches long and sixteen inches deep. Therefore, when level full, it holds, (36xi24x I6) divided by 2I50, equals 33.22 bushels. This equals 2.07 bushels for each inch in depth. In the same manner, the forty-inch wagon-box will hoid (40xI24xi6) divided by 2150, equals 36.91 bushels, or 2.37 bushels for each inch in depth. This method of calculating the quantity of grain gives the correct result only when the grain is standard weight, and when lighter or heavier, correction should be made accordingly. The weight per bushel of grain and sceds is given on the following page. 
Weight Per Bushel of Grain. The following table gives the number of pounds per bushel required by law or custom in the sale of grain or seeds in the several states.

\begin{tabular}{|c|c|c|c|c|c|c|c|c|c|c|c|}
\hline & 悹 & 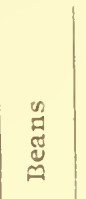 & 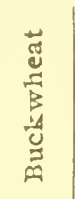 & $\begin{array}{l}\dot{u} \\
\overrightarrow{0} \\
\dot{0}\end{array}$ & 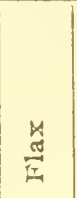 & 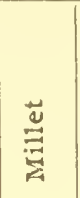 & $\begin{array}{l}\stackrel{\text { }}{\text { ஸ̊ }} \\
0\end{array}$ & ڤั & $\begin{array}{l}\text { D. } \\
0 \\
0 \\
0 \\
\stackrel{0}{0} \\
\frac{\pi}{0}\end{array}$ & 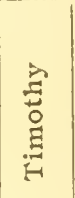 & 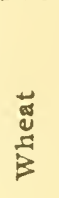 \\
\hline Arkansas ......... & 48 & 60 & 52 & 60 & ... & $\ldots$ & $\ldots$. & 56 & 56 & 45 & 60 \\
\hline California........ & 50 & $\cdots$ & 40 & $\cdots \cdot$ & $\ldots$ & $\ldots$ & 32 & 54 & 52 & $\ldots$ & O \\
\hline Connecticut. ...... & $\ldots$ & $\ldots$ & 45 & $\ldots$ & $\ldots$ & $\ldots$ & 32 & 56 & 56 & $\cdots$ & 56 \\
\hline Dist. Columbia.... & 47 & 62 & 48 & 60 & $\ldots$ & $\cdots$ & 32 & 56 & 56 & 45 & 50 \\
\hline Georgia.......... & 40 & $\ldots$ & $\ldots$ & 60 & $\cdots$ & $\ldots$ & 35 & 56 & 56 & 45 & O \\
\hline 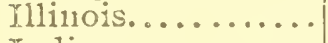 & 48 & 60 & 52 & 60 & 56 & 45 & 32 & 56 & 56 & $\cdots$ & o \\
\hline Indiana.......... & 48 & 60 & 50 & 60 & $\cdots$ & $\ldots$ & 32 & 56 & 56 & 45 & 60 \\
\hline 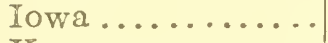 & 48 & 60 & 52 & 60 & 56 & 48 & 32 & 56 & 56 & 45 & ( \\
\hline Kansas .......... & 50 & 60 & 50 & ... & $\cdots$ & $\cdots$ & 32 & 56 & 56 & 45 & So \\
\hline Kentucky ......... & 48 & 60 & 52 & 60 & 56 & $\cdots$ & 32 & 56 & 56 & 45 & O \\
\hline Louisiana ........ & 32 & $\cdots$ & $\cdots$ & $\ldots$ & $\ldots$ & $\ldots$ & 32 & $\cdots$ & 56 & $\cdots$ & 60 \\
\hline Maine ........... & 48 & 64 & 48 & & & ... & 30 & ... & 56 & ... & 10 \\
\hline Manitoba........... & 48 & $\cdots$ & 48 & 60 & 56 & 34 & 34 & 56 & 56 & $\cdots$ & o \\
\hline Maryland......... & 48 & 64 & 48 & $\cdots$ & $\ldots$ & $\cdots$ & 32 & 56 & 56 & 45 & 0 \\
\hline Massachusetts..... & 48 & 48 & $\cdots$ & $\cdots$ & & $\cdots$ & 32 & 56 & 56 & $\cdots$ & \\
\hline Michigan ......... & 48 & $\ldots$ & 48 & 60 & 56 & & 32 & 56 & 56 & 45 & $\mathrm{O}$ \\
\hline Minnesota......... & 48 & 60 & 42 & 60 & $\ldots$ & $4^{8}$ & 32 & 56 & 56 & $\cdots$ & $\mathrm{O}$ \\
\hline Missouri.......... & 48 & 60 & 52 & 60 & 56 & 50 & 32 & 56 & 56 & 45 & 0 \\
\hline Nebraska......... & 43 & 60 & 52 & 60 & $\ldots$ & $\ldots$ & 34 & 56 & 56 & 45 & \\
\hline New York........ & 48 & 62 & 48 & 60 & & $\cdots$ & 32 & 56 & 58 & 44 & O \\
\hline New Jersey....... & 48 & $\ddot{m}$ & 50 & 64 & ... & $\ldots$ & 30 & 56 & 56 & $\cdots$ & io \\
\hline New Hampshire .. & $\cdots$ & 60 & $\cdots$ & $\cdots$ & $\cdots$ & $\cdots$ & 30 & 56 & 56 & $\cdots$ & o \\
\hline North Carolina.... & 48 & $\ldots$ & 50 & 64 & & $\ldots$ & 30 & 56 & 54 & $\cdots$ & \\
\hline North Dakota..... & 48 & & 42 & 60 & .56 & & 32 & 56 & 56 & $\cdots$ & 60 \\
\hline 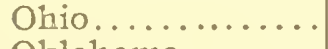 & 48 & 60 & 50 & 60 & & $\ldots$ & 32 & 50 & 56 & 45 & \\
\hline Oklahoma ........ & 48 & $\ldots$ & 42 & 60 & 56 & $\cdots$ & 32 & 56 & 56 & $\cdots$ & \\
\hline Oregon............ & 46 & & 42 & 60 & & & 36 & 56 & 56 & $\ldots$ & \\
\hline Pennsylvania ..... & 47 & $\cdots$ & 48 & 62 & & $\cdots$ & 30 & 56 & 56 & $\cdots$ & \\
\hline South Dakota.... & 48 & $\cdots$ & 52 & 60 & 56 & 50 & 32 & 56 & 56 & $\cdots$ & 60 \\
\hline South Carolina... & 48 & 60 & 56 & 60 & & $\ldots$ & 33 & 56 & 56 & $\cdots$ & \\
\hline Vermont.......... & 48 & 64 & 48 & & 60 & & 32 & 56 & 56 & 42 & \\
\hline Virginia .......... & 48 & 60 & 48 & 64 & $\ldots$ & $\cdots$ & 32 & 56 & 56 & 45 & 60 \\
\hline West Virginia..... & 48 & 60 & 52 & 60 & $\cdots$ & $\cdots$ & 32 & 56 & 56 & 45 & \\
\hline TVisconsin ........ & 48 & & 48 & 60 & & & 32 & 56 & 56 & $\cdots$ & \\
\hline
\end{tabular}




\section{CHAPTER NI.}

\section{LUBRICATION AND CARE OF THE SEPARA'TOR.}

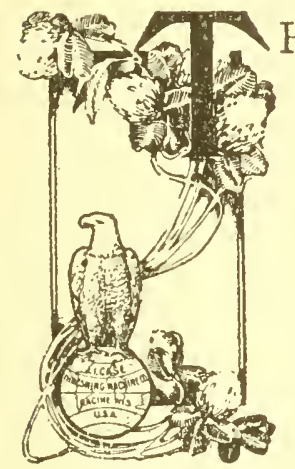

HE life of the machine depends largely upon the thoroughness of its lubrication. A light oil with good wearing qualities should be used. Thin oil is surer to reach the place it is intended to lubricate than thick, heavy oil.

A journal is more apt to be continually lubricated when a small amount of oil is applied frequently than when a great deal is used at longer intervals. Many of the oil boxes on the machine, as for example those on the rock shafts, may be partly filled with wool or cotton waste. Either will keep out dirt and make them hold oil longer. This wool or waste should be renewed at the beginning of each season and more frequently in localities in which there is sand. Use a nail or soft wire to clean out oil holes, for if a piece of steel be used when shaft is running, it is liable to "score" and injure the journal.

Hot Bcarings. The causes of hot bearings are: I-Insufficient lubrication because of too little or too poor oil or hole being stopped up; 2-Dirt or grit on the journal; 3Box too tight; 4-Belt too tight; 5-Box not in line with shaft; 6-Collar or pulley too tight against end of box; 7Journal rough or shaft sprung. In case a box heats, cool 
with water, clean the oil holes carefully, oil liberally and if it gets hot again, stop and remove the cap, clean the bearing carefully and be sure the oil holes and grooves are open before replacing it. Also be careful to leave the paper liners undisturbed. If the babbitt has adhered to the shaft, because of overheating, scrape every particle of it from the shaft with a knife. If the journal has been cut and is consequently rough because of the formation of ridges, smooth it carefully with a fine file and wipe it thoroughly so that no filings remain. Oil it well before replacing cap. Because of the expansion due to heating, it sometimes happens that a shaft that is cutting becomes fast in its box so that it will not turn. If the box be in one piece so there is no cap to remove, after cooling with water, kerosene may be applied to loosen it. In very windy weather the right cylinder box requires especial attention as the constant swaying of the main-belt causes an extra amount of friction on this bearing.

Greasing the Trucks. This book would be incomplete without a word of warning concerning the damage, frequently caused by neglect, to the skeins and hubs of the trucks of an outfit. To make the lubrication of truck-wheels convenient, in some cases, the hubs are provided with oilholes which are closed with plugs. It has been found, however, that this means of lubricating cannot be relied upon, as the holes are sure to become clogged, and unless great care is taken in cleaning them, very little or no oil will reach that part of the axle which needs it most. All truck-wheels 
should frequently be removed and the skein cleaned of all caked grease and dirt. The skein should then be well coated with axle-grease, especially near the large end which has the greatest wear. It is well to spread some machine-oil over the axle-grease. The separator truck-wheels especially should have frequent attention, as the dust and chaff of threshing quickly dries the grease or oil. A good operator will not permit the skeins and hubs of the machinery in his care to be injured for want of proper lubrication.

The Care of a Separator. With good care a separator should last eight or ten years, and there are many Case machines that have been in use twice that length of time. When the threshing season is finished, the machine should be thoroughly cleaned and housed in a dry place. Dirt that has been allowed to remain on the machine during the winter, holds moisture, ruins varnish and paint, rots the wood and rusts the sieves and other iron parts. The appearance of a machine usually tells a truer tale of its condition than the number of years it has been run. The separator should be given a coat of good coach varnish at least once in two years. Before applying the varnish, the paint should be thoroughly cleaned and all grease and oil removed with benzine.

Before the beginning of each threshing season, the separator should be carefully overhauled, worn cylinder teeth being removed and all broken slats in the straw-rack or stacker-rakes being replaced. Any boxes that are worn 
should be taken up or rebabbitted if necessary. The wooden boxes on the straw-rack, conveyor and shoe eccentrics can easily and cheaply be replaced when worn out. All nuts that are loose should be tightened and any bolts that may have been lost, replaced. In tightening a nut it should always be turned, square with the piece on which it rests. If this be habitually done, not only does the machine look better, but it serves to make the loosening of a nut apparent.

Canc'as-Coz'cr. If a canvas be used to cover the separator nights and when not running during the threshing season, its appearance will amply repay the extra trouble and expense, in addition to prolonging its usefulness.

In Laying up the Machine see that the bolster is blocked up by bolster-jacks or other means so as to hold the frame square. This is especially necessary if the separator has a side-gear, if the main-belt remains on the reel, or, if for other reasons, one side is heavier than the other.

Remoring the Beater. The beater can be taken out of the machine without removing the shaft or pulley. This may be done on wood-frame machines by removing the pieces of siding and the bolts holding bearings and blocks and lifting the beater straight up. On steel machines the girt and circular piece of sheet-steel on the left-hand side are removed and the beater taken out through the hole thus created.

To Remore Rock-Shafts. The rock-shafts are enlarged at one end so that when the set-screws are loosened, they may be readily removed. The front rock-shaft is straight 
and can be taken out at the left side of the machine by simply loosening the set-screws in the vibrating-arms. Tha rear rock-shaft is bent and is taken out by loosening the set-screws and moving it to the right until it comes out of the ieft-arm. It may then be removed by sliding it towards the left side of the machine.

To Remoic the Stran'-Rack. Take off the tailor-ract, pan and rock-shaft, if these parts be on the machine. Take off the four straw-rack boxes, the bolts of which can be easily reached with a socket-wrench through the holes for vibrating-arms. The rack can then be taken out through the rear of the machine. On separators fitted with windstackers, it is necessary to remove the rear board.

To Remorc the Concevor. If the straw-rack be already out, simply nnbolt the four boxes. The bolts of the front ones have their nuts below and those of the rear ones can be reached while sitting in the shoe. To remove the conveyor without taking out the straw-rack, disconnect the latter from the rear rock-shaft, raise it as high as possible and secure it in this position. The conveyor can then be taken out.

To Remor' the Shoe. The shoe can be taken out without removing the straw-rack or conveyor. Take out the rear rock-shaft, raise the straw-rack and conveyor as high as the deck will allow and secure them in this position. Disconnect the four wood hangers and pitmans and the shoe, may then be taken out. 
To Reach the Fan. The lower part of fan housing is readily removed when it is necessary to reach the fan for repairs or other purposes. Take out the bolts through the end segments and those at the joint on the front side of the drum. 


\section{CHAPTER XII. \\ THE BELTING OF A SEPARATOR.}

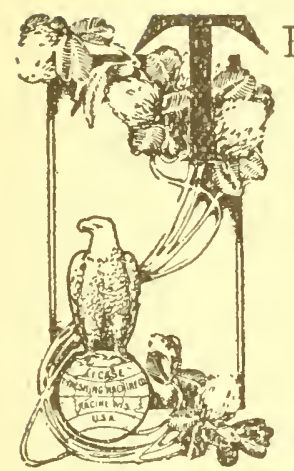

HE Belting of the separator should be carefully looked after, as the working of the machine depends in a large measure upon the condition of the belts. The pulleys must be in line, to insure the belt rumning on them to its full width. Where the shafts are parallel a belt will always run to the tightest place or where the pulleys are largest. For this reason, all pulleys on the separator are made larger in the middle "crowning" as it is called, so belts will tend to run in the center.

The separator tender should look over the belts once each day and re-lace any on which the lacing has become worn. This will prevent the necessity of stopping to repair a belt when the machine should be running. Some threshermen, realizing the expense of delays, carry an extra set, so that in case anything happens to any belt in use, the extra one may be put on and the work immediately continued. If it starts to rain while threshing, the separator should be stopped at once, and the belts, especially the leather ones, put under cover before they get wet. The machine will run only a few minutes in the rain before the belts begin to slip 
and come off, and it is best to stop in time and leep them in good condition to start again.

Leathor Belts. All leather belts should be run hair side to the pulley. Some years ago mechanics and engineers disagreed as to which side of the leather should be next to the pulley, but it has been shown that belts last longer and transmit more power when run hair side to the pulley. The reason is that the flesh side is more flexible and will more readily acconmodate itself to the curve of the pulley. If the more rigid hair side be obliged to stretch every time it goes around a pulley, it will crack, in time. When leather belts become hard, they should be softened with neatsfoot oil, for a flexible belt will transmit more power than a hard, stiff one. The mineral oils used for lubricating purposes rot leather rapidly and consequently, belts should be kept as free from them as possible.

A Rubber Belt should always be put on with the seam, which is near the center, and covered with a narrow strip of rubber, on the outside, and not next to the pulley. The cleaner a rubber belt is kept, the better. No dressing of any kind should be used. Anything of a sticky nature adhering to it, will have a tendency to pull off the outer coating of rubber and greatly injure the belt. Oils of all kinds should be carcfully avoided, and should a rubber belt accidentally become covered with oil, it is best to wash it off with soap and water. The best place to store rubber belts is in the cellar, as clampness and darkness tend to preserve them 
while light, especially direct sunlight, and extreme dryness tend to rot the rubber.

The Main Bclt is usually of rubber or stitched canvas in widths of six, seven or eight inches, and made endless in lengths of 120 , I50 or I60 feet. 'The object in having it so long is to place the engine far enough from the grain to be safe from fire. Accordingly, the 120 foot length may be used when the fuel is coal, but when burning wood or straw, the longer lengths should be used. The usual arrangement of the stacks in the locality the rig is to operate in, must also be taken into consideration in choosing the length of belt. Vith the engine having a forty inch fly-wheel and rumning at 250 revolutions per minute, the main belt will travel 2625 feet, or almost exactly one-half mile in a minute. A belt has a greater tendency to slip on the smaller of the two pulleys over which it runs and for this reason, the cylinder pulley is covered with leather or similar material. When the cover is worn out, a new one should be put on as no main belt will pull well on a bare cylinder pulley. Rubber belts pull well at all times, and do not require dressing, in fact, any dressing is injurious, because it has a tendency to pull off the outer coating of rubber. To obtain the best results. stitched canvas belts, however, should be treated to a coat of dressing once in about thirty days. Linseed oil paint is often used, and it is better than no dressing at all, but the regular dressing sold for this purpose is preferable, as it keeps the belt waterproof and pliable and greatly increases its power transmitting qualities. 
Lacing a Belt. Many make a mistake in thinking that the heavier and stronger a lacing is made, the more durable it will be. This leads them to make the lacing so thick and clumsy that the belt is strained in going around the pulleys, causing the lace to wear out in a short time and probably the belt to be torn between the holes. A good lacing is as similar as possible to the rest of the belt, so that it passes over the pulleys without shock or jar. To lace a belt begin by cutting off the ends of the belt square, using a try-square for this purpose on the wider belts. Use a punch small enough so that the lacing will fill the holes, but will not pull in so tightly as to tear the belt. Space the holes equally across the belt, leaving the outside holes far enough (about onehalf inch), from the edge of the belt to prevent the possibility of their tearing out. The cuts at top of page 206 show the position of the holes for the common widths of belts. In a leather belt the holes may be quite near the end ( $\mathrm{T} / 2$ to $5 / 8$ inches), without tearing out, and when so placed the belt will pass smoothly over the pulleys. A belt is much more apt to break or tear between the holes than it is to tear from the holes to the end.

The belt of a stacker-web laced by turning up the ends of the belt is shown by A and $\mathrm{B}$ of Fig. 50. Any rubber or stitched canvas belt that does not run over idler or tightener pulleys, causing both sides of the belt to be in contact with pulleys, may be laced in this way. For these this lacing has the advantage of lasting two or three times as long as the 
ordinary one. The reason is that the lace is not exposed to wear and the belt will pass around the smallest pulley without straining either holes or lace leather. If trouble be experienced in keeping an old main belt laced, this method may be used with success.

A four-inch belt laced in the ordinary manner is shown by $C$ and $D$. The side shown in $C$ should run next to the pulley. The lacing shown on the next page is very satisfactory where a belt passes over small pulleys or idlers, for it bends easily in either direction. It is therefore very durable and satisfactory for a rubber or stitched canvas wind stacker belt. Also the belt driving beater and crank should be laced this way, but as this is of leather, the holes may be nearer the end than in the cut, which shows the spacing for rubber or stitched canvas.

The holes to fasten the ends should be punched in line with the lace-holes so that they will be in the right place when the belt is cut off and they become lace holes. The best way to fasten an end is to draw it into a small hole, then back through the same hole, cutting off the end to leave about one-half inch. New belts stretch considerably the first few days and the ends of the lacing should not be cut off short until the stretch is taken out of the belts, so the same lacing may be used for re-sewing. If the belts have become wet and shrunk, the lacings should be let out before putting them on. If very tight, they cause undue friction on the 
bearings, making them heat. Then, too, tight belts have been known to break off a shaft.
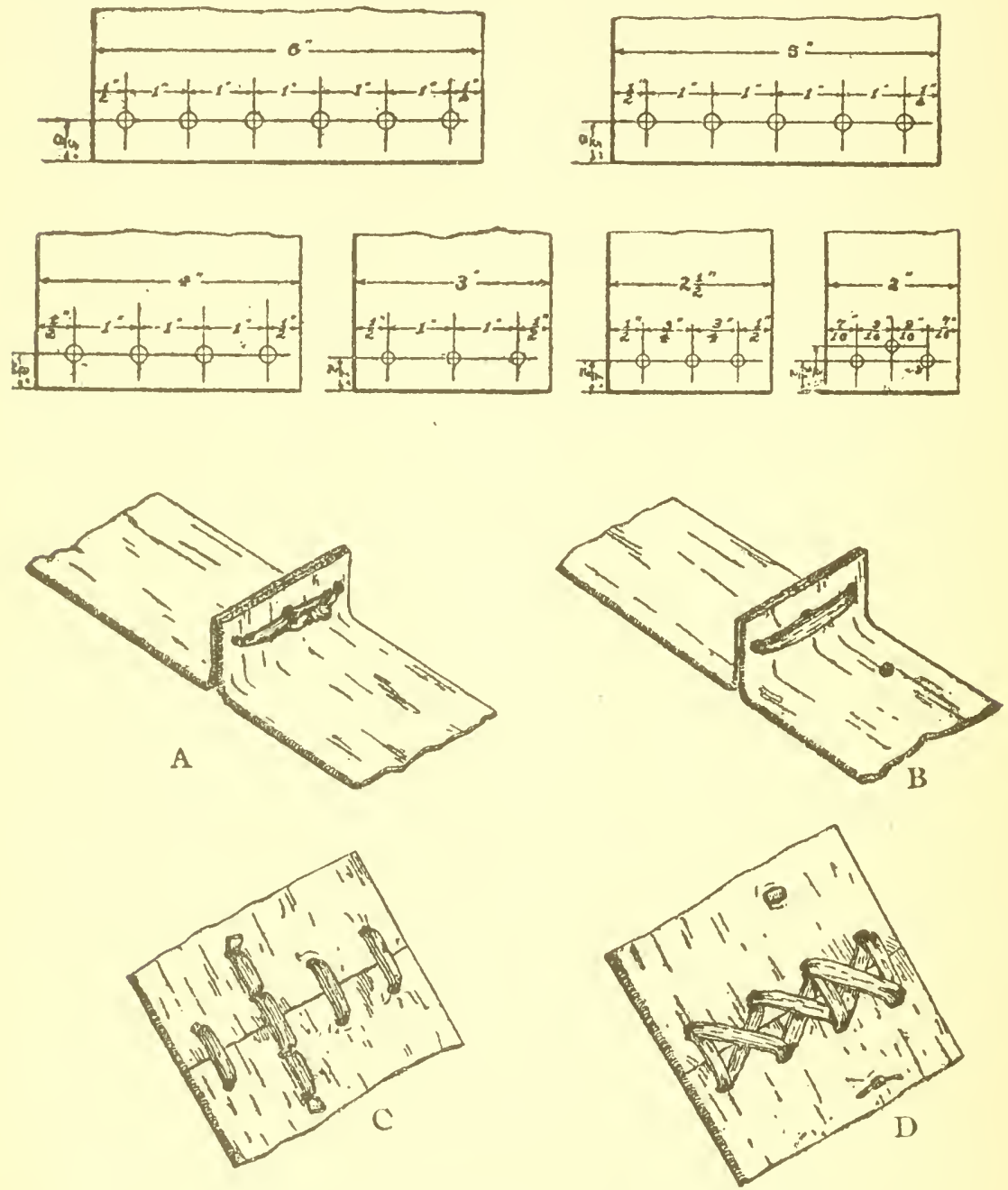

FIG, 5O. IEATHER BELT LACINGS.

Lacing Stitched Cani'as Belt. A stitched canvas belt, though highly satisfactory in other respects, is often condemned because the lacing will not hold. It can, however, 
be laced in several ways that are satisfactory. In any event, the holes for the lacing munst be made with an awl and not with a hollow punch, which cuts off many strands and greatly weakens the belt. The tine of an old pitchfork makes a very good awl for this purpose and the oval shape will be found convenient. The holes must not be nearer the end than seven-eighths of an inch or nearer the edge than fiveeighths of an inch.

The lacing illustrated we believe the best for canvas stitched belts, and we advise any thresheman having the running of these belts in charge to practice maling this lacing some rainy day until he can make it without difficulty. It is a hinge lacing which allows it to pass around small pulleys and tighteners without straining. The ends of the belt are protected against fraying. In the example illustrated, there are twenty-eight strands of lacing connecting two ends of the belt.

The illustrations show a 5-inch belt, the size used to drive the wind stacker. To make this lacing, first select a good lace, not too thick. three-eighths of an inch wide and 7 feet 8 inches

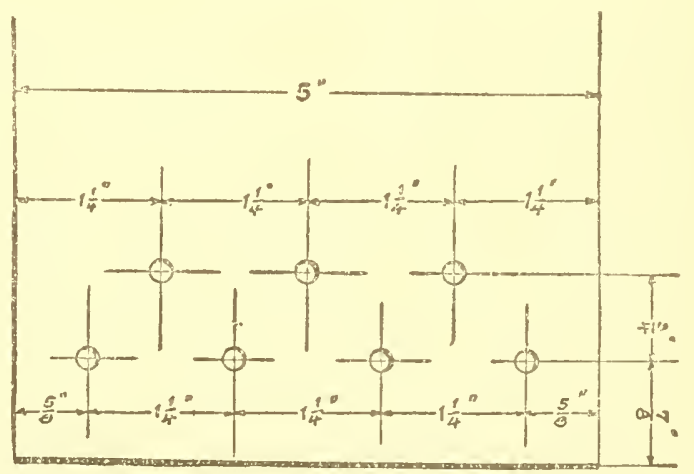

FIG. 5I. LOCATION OF HOLES FOR LACING CANVAS BELT.

long for 5-inch belt. Lay out the holes as shown in Fig. 5I. Begin at one edge of the belt, passing the lace up) 
through the outside hole in one end and then down between the ends of the belt and up through the hole in the other end of belt. Notice that the lace passes twice through each hole. When the ends of the lace have been put through the holes, both must be passed between the ends of the belt to the
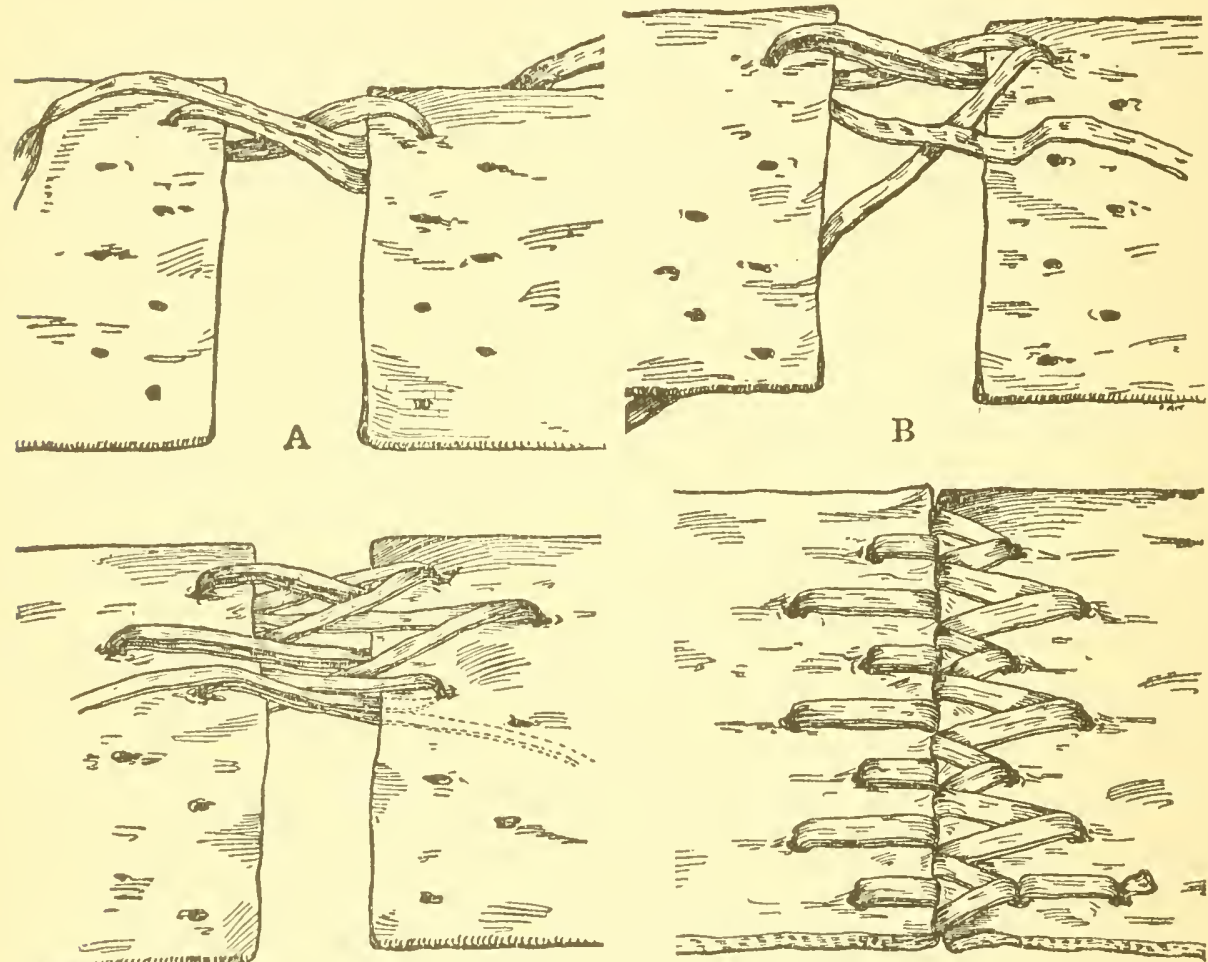

C

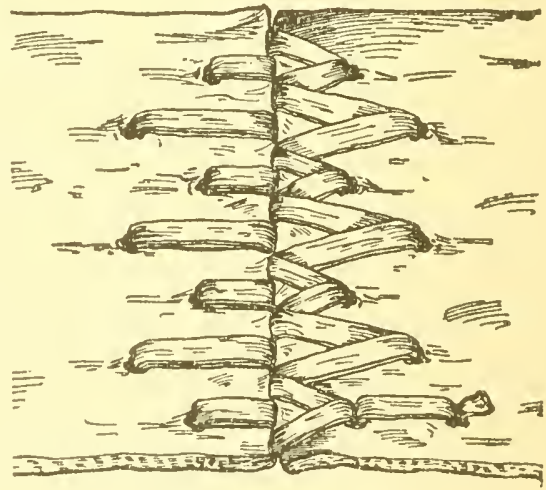

D

IIG. 52. STITCHED CANVAS BELT LACINGS

opposite side. as shown in A. When this is done, put the ends through the same holes again, then pass them both between the ends of the belt to opposite side as at $B$. One end should not be put through two holes in succession and both ends of the lace must be passed through between 
the ends of the belt to the opposite side before either is put through the hole.

Continue in exactly the same manner as at $\mathrm{C}$, until the lacing is finished as shown in $\mathrm{D}$. When lacing is complete the appearance is exactly the same on both sides, the straight strands being on one end of the belt on one side, and on the other end on the opposite side. Care must be taken to keep lacing as near the same tension throughout the width as possible, so that one edge will not be tighter than the other, in which case the belt would be crooked and not run true. For the same reason a trysquare should be used in cutting off the ends of the belt. 
BELTS FOR CASE SEPARATORS.

\begin{tabular}{|c|c|c|c|c|c|}
\hline NAME & 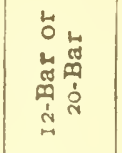 & 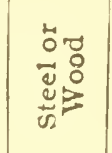 & 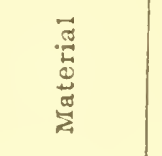 & $\begin{array}{l}5 \\
3 \\
3 \\
3 \\
3\end{array}$ & 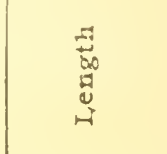 \\
\hline Crank and Beater............ & 20-Bar & Both & Leatlier & $6^{\prime \prime}$ & $18^{\prime} 4^{\prime \prime}$ \\
\hline Crank and Beater. .......... & I2-Bar & Steel & Leather & $4^{\prime \prime}$ & I $6^{\prime}$ II" \\
\hline Crank and Beater........... & I 2-Bar & Wood & Leather & $4^{\prime \prime}$ & $16^{\prime} 2^{\prime \prime}$ \\
\hline 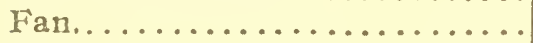 & $2 \mathrm{O}-\mathrm{Bar}$ & Both & Leather & $4^{\prime \prime}$ & $I g^{\prime} I I^{\prime \prime}$ \\
\hline Fan .......... & I 2-Bar $]$ & Both & Leather & $4^{\prime \prime}$ & $18^{\prime} 6^{\prime \prime}$ \\
\hline Elevator .............. & Both & Both & Leather & $21 / 2 " 1$ & I $4^{\prime}$ I I" \\
\hline Elevator ...... & 20-Bar & Steel & Leather & $21 / 2^{\prime \prime}$ & $15^{\prime} \quad 2 \pi / 2^{\prime \prime}$ \\
\hline Grain Auger... & I2-Bar & Steel & Leather & $28 / 2^{\prime \prime}$ & I I I I $1 / 2^{\prime \prime}$ \\
\hline Grain Auger & $\left|\begin{array}{l}\mathrm{I} 2-\mathrm{Bar} \\
20-\mathrm{Bar}\end{array}\right|$ & $\begin{array}{l}\text { Wood } \\
\text { Both }\end{array}$ & Leather & $2 y / 2^{\prime \prime}$ & $12^{\prime} 3^{\prime \prime}$ \\
\hline Shoe Shake & 20-Bar & Steel & Leather & $2^{\prime \prime}$ & $4^{\prime}$ I I $1 / 2^{\prime \prime}$ \\
\hline Shoe Shake........ & $20-\operatorname{Bar}$ & Wood & Leather & $2^{\prime \prime}$ & $5^{\prime} \quad 3^{\prime \prime}$ \\
\hline Feeder Drive................ & I2-Bar & Both & I eather & $4^{\prime \prime}$ & $14^{\prime}$ \\
\hline Feeder Drive... & $20-\operatorname{Bar}$ & Both & Leather & $4^{\prime \prime}$ & $15^{\prime}$ \\
\hline Feeder, small............... & Both & Both & Leather & $2^{\prime \prime}$ & $8^{\prime} \quad 2^{\prime \prime}$ \\
\hline Wind Stacker Drive.......... & I 2-Bar & Both & Rubber & $5^{\prime \prime}$ & $34^{\prime} 10^{\prime \prime}$ \\
\hline Wind Stacker Drive....... & 20-Bar & Steel & Rubber & $5 "$ & $36^{\prime} 6^{\prime \prime}$ \\
\hline Wind Stacker Drive.......... & 2O-Bar & Wood & Rubber & $5^{\prime \prime}$ & $38^{\prime}$ \\
\hline Wind Stacker Drive, geared.... & Both & Steel & Rubber & $5^{\prime \prime}$ & $28^{\prime}$ \\
\hline Wind Stacker Drive, geared.... & I2-Bar & Wood & Rubber & $5^{\prime \prime}$ & $27^{\prime}$ \\
\hline Wind Stacker Drive, geared... & 20-Bar & Wood & Rubber & $5^{\prime \prime}$ & $2 S^{\prime}$ \\
\hline Combined Stacker Drive.... & 20-Bar & Steel & Rubber & $5^{\prime \prime}$ & $37^{\prime}$ \\
\hline tacker Drive. .. & I 2-Bar & Both & Rubber & $5^{\prime \prime}$ & $35^{\prime}$ \\
\hline abined Stacker Drive. . . . . . & $20-\mathrm{Bar}$ & Wood & Rubber & $5^{\prime \prime}$ & $38^{\prime}$ \\
\hline Combined Stacker Drive, geared & Both & Steel & Rubber & $5^{\prime \prime}$ & $28^{\circ}$ \\
\hline ned Stacker Drive, geared & Both & Wood & Rubl & $5^{\prime \prime}$ & $30^{\prime} \quad o^{\prime \prime}$ \\
\hline Wind Stacker Turret Drive. . & Both & Steel & Rubl & $2^{\prime \prime}$ & $I I^{\prime} I^{\prime \prime \prime}$ \\
\hline Wind Stacker Turret Drive. & I 2-Bar & Wood & Rubber & $2^{\prime \prime}$ & $I^{\prime} \quad 9^{\prime \prime}$ \\
\hline Wind Stacker Turret Drive..... & 20-Bar & Wood & Rubber & $2^{\prime \prime}$ & $13^{\prime} 4^{\prime \prime}$ \\
\hline 1 Stacker Turret Drive & Both & Steel & Rubber & $21 / 2$ & $14^{\prime} 10^{\prime \prime}$ \\
\hline Combined Stacker Turret Drive & Both & Wood & Rubl & $21 / 2^{\prime \prime}$ & $16^{\prime} \quad 6^{\prime \prime}$ \\
\hline Attaclied Stacker Drive. . . . . . . & $\mathrm{I} 2-\mathrm{Ba}$ & Both & Rubl & $4^{\prime \prime}$ & $0^{\prime \prime}$ \\
\hline Stacker Drive........ & 20-Bar & Both & Rut & $4^{\prime \prime}$ & $32^{\prime}$ \\
\hline d Stacker Drive, geared. & Both & Both & Rubber & $4^{\prime \prime}$ & $25^{\prime}$ \\
\hline Attached Stacker, short........ & Both & Botli & Leather & $2^{\prime \prime}$ & $5^{\prime \prime}$ \\
\hline Attached Stacker, long..... . & Both & Botli & Ieat & $21 / 2^{\prime \prime}$ & I9' \\
\hline Con & Both & Both & Rubber & $3^{\prime \prime}$ & $22^{\prime} \quad 3^{\prime \prime}$ \\
\hline & Both & Both & Rubber & $3^{\prime \prime}$ & $35^{\prime} \mathrm{o}^{\prime \prime}$ \\
\hline
\end{tabular}




\section{CHAPTER XIII.}

\section{THE PULLEYS OF A SEPARATOR.}

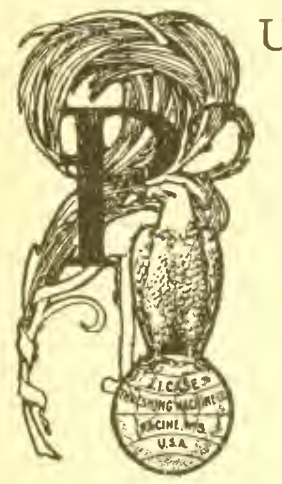

ULLEYS are usually held in place on the shafts either by taper-keys or by set-screws. Sometimes straight keys or "feather" keys, as they are called, are used, but as these only prevent the pulley from turning, set-screws or other means must be used to secure the pulley against sliding on the shaft. When used with feather-keys, set-screws are placed so their points rest on the key and thus do not score or mar the shaft.

Taper Key's. A taper key when properly fitted, holds a pulley very securely. To do this, however, such a key must be the same width throughout its length and accurately fit the slots or "seats" cut for it on the shaft and in the pulley. The thickness should vary to correspond with that of the key-way in the pulley. A key should be driven in hard enough to be safe against working loose, but when well fitted, it is not necessary to drive it so hard that it may not be readily removed. The hubs of most of the pulleys on the machine run against the boxes, and in keying these, about I/32 of an inch end play should be allowed the shaft, to prevent danger of heating from the pulley rubbing too hard against the end of the box. A key that is too thin, but other- 
wise fits properly may be made tight by putting a strip of tin or sheet-iron between it and the bottom of the way in the pulley.

Drawing Taper Key's. A taper key can usually be removed by driving the pulley toward the thin end of the key. Often, however, the pulley cannot be driven a sufficient distance to loosen the key hecause of its coming against a box or another pulley. If the encl of the key projects beyond the hub, it may be removed by catching it with a pair of horseshoe pinchers and prying with them against the hub, at the same time hitting the hub with a hammer so as to drive pulley on. Sometimes the end of a key may be caught with a claw hammer and loosenerl by driving on the hub of pulley as explained. If a pulley is against the box and key cut off flush with the hub, it may be necessary to remove the shaft, drive the pulley on until the key loosens or if key-seat be long enough, a "drift" may be used from the inside.

Corcring Pulleys. The smaller pulleys on which the belts are likely to slip are covered or lagged with leather or other similar material. The important thing in covering any pulley is to get the leather tight, because it will soon come off if there be any slack in it.

Nailed Cozers. Some pulleys are cast with recesses in their rims for the insertion of wooden wedges. These pulleys are easily lagged because the covers are fastened, simply by nailing to the wooden wedges. To re-cover a pulley fitted with wooden wedges, take off what remains of the old 
cover, pull out the nails and renew the wedges if necessary. Select a good piece of leather a little wider than face of pulley and about four inches longer than the distance around. Soak it in water about an hour. Cut off one end square and nail it to one pair of the werlges, using nails just long enough to clinch. To stretch the leather, use a clan?p made of two pieces of wood and two bolts: Block the shaft to keep it from turning, and stretch the leather by prying over the clamp with two short levers. The leather should not be stretched around the whole pulley at once, but the clamp should be so placed that there is only sufficient room to nail to the next pair of wedges. Now move the clamp and nail to cach pair of wedges in turn, finally nailing the leather again to the first pair before cutting off. Trim the edges even with the rim of the pulley.

Riveted Cor'ers. The same method of stretching the leather by means of a clamp may be used on pulleys with riveted covers or they can be covered in the following manner: Soak the leather in water for an hour. Cut off one end square, and rivet it on. Then draw the leather around the pulley and mark the next two pairs of holes. Punch holes in the leather a little back of the marks made by the first pair of holes and a little farther back of the marks made by the second pair of holes. Insert the points of two scratch awls through the second pair of holes in the leather and into the corresponding holes in the pulley rim. Using scratch awls as levers, draw the leather very tight and the first pair 
of rivets may be easily inserted. Move the awls to the third pair of holes, insert the second pair of rivets and so on around the pulley. The tines of an old pitchfork drawn down a little at the points and tempered make very suitable scratch awls for this purpose. 


\section{CHAPTER XIV.}

BABBITTING BOXES.

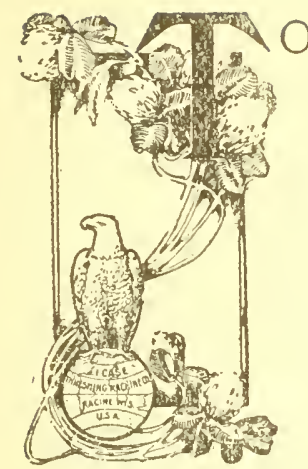

babbitt any kind of a box, first chip out all of the old babbitt and clean the shaft and box thoroughly with benzine or gasoline. It is necessary that the box be perfectly clean or gas will be formed from the grease when the hot metal is poured in and leave "blow holes."

A Solid Box may be babbitted in the field by covering the shaft with paper, draw it smooth and fasten the lapped ends with mucilage. If this be not done the shrinkage of the metal in cooling may make it fast so that the shaft cannot be turned. When this happens it is sometimes necessary to put the shaft and box together in the fire to melt the babbitt or else break the box to get it off. Paper around the shaft will prevent this and if taken out when the babbitt has cooled, the shaft will be found to be just loose enough to run well. The shaft is sometimes covered with smoke or painted with white lead as a substitute for paper. The usual shop practice in manufacturing is to use a mandrel or arbor from one one-hundredth to one sixty-fourth of an inch larger than the shaft to be run in the bearing.

Before pouring the box, block up the shaft until it is 
in line and in center of the box and put stiff putty around the shaft against the ends of the box to keep the babbitt from running out. Be sure to leave air-holes at each end on top, making a little funnel of putty around each. Also make a larger funnel around the pouring hole, or, if there be none, enlarge one of the air-holes and pour into it. These putty funnels should extend a little above the box so as to give pressure to the babbitt and to allow the metal to fill in, as it shrinks in cooling. The metal should be heated until it is just hot enough to run freely and the fire should not be too far away. When ready to pour the box, do not hesitate or stop, but pour continuously and rapidly until the metal appears at the air holes. The oil hole may be stopped with a wooden plug and if this plug extends through far enough to touch the shaft, it will leave a hole through the babbitt so that it will not be necessary to drill one.

A Split Bo.t is babbitted in the same manner except that strips of cardboard or sheet-iron are placed between the two halves of the box and against the shaft to clivicle the babbitt. To allow the babbitt to run from the upper half to the lower, cut four or six $I^{\circ}$ shaped notches, a quarter of an inch deep, in the edges of the sheet-iron or cardboard which touch the shaft. Insert three or font thicknesses of cardboard called "liners" between the halves of the box to allow for taking up wear. Bolt the cap on securely before pouring. When the babbitt has cooled, break the box apart by driving a cold chisel between the halves. Trim off the sharp edges of the 
babbitt and with a round-nose chisel cut oil grooves from the oil hole toward the ends of the box and on the slack side of the box or the one opposite to the direction in which the belt pulls. The shaft may be covered with paper, as explained for a solid box, but if this be not done, the babbitt should be scraped to fit the shaft.

The ladle should hold eight or ten pounds of lobbitt metal. If much larger it is awkward to handle and if too small it will not lieep the metal hot long enough to pour a good box. A cast-iron ladle will keep the metal hot longer than a wrought-iron or steel one. The 20 bar cylinder boxes each take about six pounds of metal, and the is bar cylinder boxes each take two to three pounds. If no putty is at hand, clay mixed to the proper consistency, may be used. Use the best babhitt you can obtain for the cylinder boxes. 


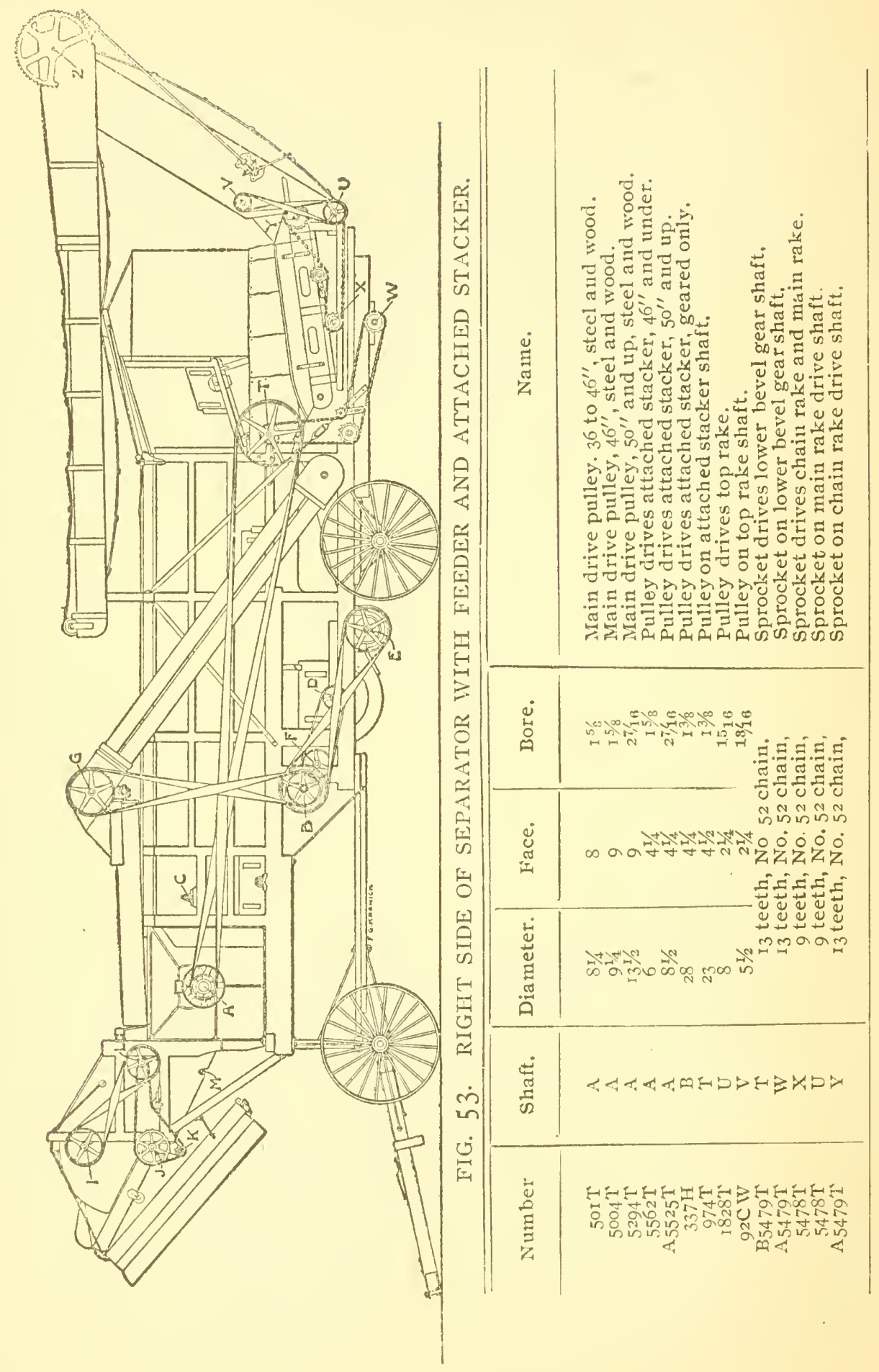




\section{CHAPTER XV.}

\section{THE WASTE IN TIRESHING.}

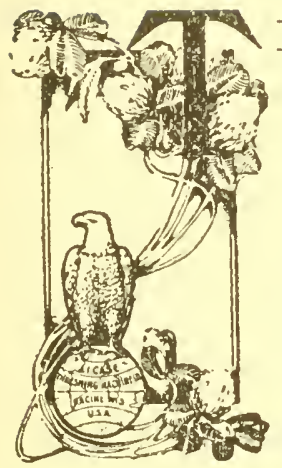

HERE is not a machine built at the present time that will save every kernel in all kinds and conditions of grain. The Case will separate the grain from the straw as well as any machine made, but to accomplish the best results it must be properly operated. When one detects a machine wasting grain he usually imagines that the quantity wasted amounts to many times more than it actually does. If a stream of wheat as large as that which runs out of a grain-drill tooth were discovered going into the straw the farmer would probably say that the machine was wasting half the grain. Yet he knows that he must drive very fast to get a bushel and a half of wheat through each grain drill tooth in a day. Roughly speaking, there are 600 handfuls or a million kernels of wheat in a bushel.* This amount wasted in ten hours indicates that a handful or I 700 kernels is being wasted every minute. If farmers realized the economy of finishing a job as quickly as possible, irrespective of the grain lost, they would not attach so much importance to the small amount ordinarily wasted.

"In the "Thresher World" contest of August 1903, the bushel of wheat counted contained $\$ 69,762$ kernels. 
However, it is true that any separator will waste considerable grain if improperly operated. When there is reason to believe that a machine is wasting more than it shoulci, first determine whether the grain is being carried over in the chaff or in the straw.

If the Waste be at the Shoe, catch some of the chaff from the conveyor sicve and if grain be found, see that the sieve is properly adjusted for the kind of grain being threshed. If a common sieve be used, it should be coarse enough for the grain and its lips should be sufficiently bent open. Too high a speed will cause grain to be carried over the conveyor sieve. Do not use any more concave teeth than are necessary as the extra amount of chaff makes difficult work for the sieves. See that the blinds are adjusted so that the blast is no stronger than is necessary to clean the grain and keep the sieves working freely. If grain be still detected, open the adjustable conveyor sieve a little more. It should not be opened so much, however, as to overload the shoe sieve. The wind-board should throw the strongest blast about half way back on the conveyor sieve. Carrying "traps" in the fan drum is liable to bend down this board which in some cases becomes so sagged that some kernels slide over it into the fan, are struck by the fan wings and thrown entirely out of the machine.

If araste be caused by failure to separate the grain from the straw, first see that the speed of the crank is 230 . The cause may be poor feeding which produces "slugging" of the 
cylinder and the resultant variable motion. See that the check-board is properly adjusted. The cylinder and concave tecth must be kept in sood order so that the grain will all be threshed from the heads and the straw chit up as little as possible. When heads missed by the cylinder aic threshed out by the wind stacker fan the machine is often criticised for poor separation when the trouble is actually caused by a neglected cylinder and concaves.

The set of the fish-backs on the straw-rack increase the separating capacity. They are nailed to the risers of the straw-rack, two on the first riser back of the beater, three to the next and four to the last riser.

Why it is difficult to scparate grain from straz: Straw and grain to the full capacity of the cylinder pass through the concave teeth at the rate of about one mile ( $5280 \mathrm{fect}$ ) per minute, and after passing the check-board the straw rack moves the straw about 102 feet per minute. At these three different speeds the straw passes the length of the machine, (about It fect 8 inches counting risers, or I 3 feet 4 inches straight), in approximately ten seconds. The intermingled straw and grain move in the same direction and at the same rate of speed. The problem of separation is, then, to check and divert the course of the grain, at the same time allowing the straw to continue its passage through the machine. If the grain be not interrupted in its course, it will pass out with the straw, while clogging will result if the movement of the straw be arrested for even a second. 
Shakespeare, with his many-sided wisdom, said: "Two grains of wheat hicl in two bushels of chaff; you shall seek all day ere you find them, and when you have them, they are not worth the search."

*Merchant of Tenice, Act I, Scene I. 


\section{INDEX.}

A

Page.

Adjustment of Concares .. $13 \mathrm{~s}$

Adjustment of ConnectingFiod ................ 41

Adjustment of Cross-Elead. 43

Adjustment of Eccentric-

Strap

Adjustment of Engine Bear-

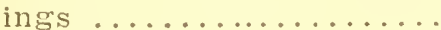

Adjustment of $\mathrm{Friction}$ Clutch ............. 97

Adjustment of Horse-Power 111 Adjustment of TailingsElevator ............. 150

Adjustable Sieves ........ 141

Admission, Steam ....... 55

Alfalfa Threshing ....... 167

Ascending Hills ......... 50

Ascertainins Cylinder-Speed 131

Attached Stacher........ $17 \mathrm{~s}$

Attached Stacker, Oiling... 17s

Attached Stacker, Operating $17 \mathrm{~S}$

Attaching Bralie to Horse

Power ................. 111

Attaching Combined Stacker 184

Attashing Ensine Fittings. 9

Attaching Engine Tender... 104

Attaching Feeder ........ 172

Attaching Grain Handlers.. 191

Attaching Oil-Pump ...... 37

Attaching "Swift" Lubrica-

tor

IB

Pabbitting a Solid Box..... 215

Eabbitting a Split Eox.... . 216

Bagser, Number Four.... 190

Ealancing Cylinder ...... 135

Barley, Threshing ....... 156

Peading Boiler Tubes...... 91

Beans, Cylinder for ...... 163

Beans, Threshing ........163

Beater, The ............... $13 \mathrm{~s}$

Beater, Fiemoving ....... 198

Eearings, Hot .......... 195

Learings, Adjustment of

Engine .............. 41

Bearings, Lubrication of

Engine ............. 35

Belts, Care of .......... 201

\section{$\mathbf{B}$}

Page.

Belts for Governor ....... 57

Belts, Lacing ........... 204

Belts, Lacing a Canvas.... 206

Belts, Leathe: ......... 202

Belts, Lengths of ...... 210

Belts, The Main ........ 203

Belts, Rubber .......... 202

Felting of a Separator..... 201

Elinds, The Fan......... 1t?

Blower, The .......... 87

Board, The Checli ....... 139

Eoard, The Wind ....... 14t

Boiler, The ............ \$3

Foiler, Cleaning the ...... $\$ 9$

Boiler, Using an Old...... 93

Boiler, Fittings for ...... S:

Foiler, Foaming ......... st

Boiler, Painting the ...... s9

Boiler, Pressure in an Old. 91

Boiler, Priming ......... ss

Boiler, Temp. of Tratcr in. 83

Boiler, Temp. of Steam in. S:

Boiler, Testing a ........ 93

Boiler Tubes, Expanding... 91

Boxes, Babbitting ....... 215

Boxes, Babbitting Solid ... 215

Boxes, Jabbitting Split ... 216

Boxes for Crlinder-Shaft .. 132

Bralie Horse Power ...... 61

Brake for the Horse-Power $11 \frac{1}{4}$

Brasses for Connecting-Rod $t 1$

Brass Fitting's, Attaching.. 9

Brick Arch ............ 31

Broken Water-Glass ..... 17

Burning Coal ........... 29

Burning Straw ......... 31

Burning Trood .......... 30

Buckwheat, Threshing ... 159

Bull-Pinion Boxes ....... 112

Bull-Pinion Shaft ....... 115

Burdon Tube .......... Só

C

Cable, The Use of........ 51

Calculating the Horse-Power 61

Calculating Grain in Wagon-

Box ................. 193

Cannon-Bearings, Oiling ... $\$ 5$ 
Canvas Cover for a Separator ................ $19 \mathrm{~s}$

Canvas, Stitched, Belt..... 206 Care of a Separator....... 197 Castings for Horse-Power's. $11 \mathrm{~s}$ Center-Head Pacling ..... 66 Centers, Finding the Dead.. 72 Chain for Grain Handlers.. 192 Chains for Engine, Steering $4 \mathrm{~S}$ Chain for Tailings Elevator 150 Check-Board ............ 139 Check-Valve ........... 25

Check-Valve, Regrinding . . 26

Cleaning Apparatus of Separator ............... 143

Cleaning the Boiler ....... S9

Cleaning the Tubes ....... 91

Clearance for Engine...... 43

Clinkers .............. 30

Clover, Hulling .......... 165

Clutch, Friction ......... 96

Clutch, Adjusting Friction.. 97

Coal, Firing with....... 29

Connecting the Equalizers.. 109

Connecting-Rod Brasses ... 41

Common Sieves .......... 145

Common Sieves, List of ... 147

Common Sieves, To Insert . 115

Compound Cylinder, Taking

Apart ............. 66

Compound Engines ....... 6 ?

Compound, The Woolf..... 64

Compound Valve, Setting.. 80

Concaves, The .......... 136

Concaves, Adjustment of .. $13 \mathrm{~S}$

Concaves, Setting the .... 136

Concaves, Special ........ 137

Conveyor, The ........... 139

Conveyor Extension ...... 145

Conveyol, Removing the ... 19!

Combination Stacker ...... 1S4

Combination Stacker, Attaching ............... 184

Combination Stacker, Oiling 1 S6 Combination Stacker, Opelating .............. 185

Common Stacker........ 177

Contents of Wagon-Box.... 193

Cost of Oils............. 36

Covering Pulleys ........ 212

Cracling Grain ......... 133

Cross-Head Adjustment .... 43
Cup, "Ideal" Grease....... 36 Cushion in Cylinder, Steam. 55

Cut-Off, Steam .......... 55

Cut-Off for Woolf Gear, Even so

Cylinders, Balancing ...... 135

Cylinder Boxes .......... 132

Cylinders, End-Play of .... 132

Cylinders, for Engines ..... 53

Cylinders, Lubrication of

Engine ............. 35

Cylinder Pulleys, Separator. 131

Cylinder, Separator ...... 129

Cylinder, Special Separator. $\mathbf{1 3 5}$

Cylinder, Speed of Separator 131

Cylinder Teeth, Separator.. 129

Cylinder Teeth Tracking,

Separator ........... 133

Cylinder Speed, Ascertaining 130

\section{D}

Dead-Centers, Finding the.. 72

Descending Hills ........ 50

Differential Gear ........ 99

Differential Gear, Locking.. 100

Difierential-Gear, Oiling ... 101

Disturbing Valve-Settings.. $\quad 75$

Dividing Clearance ....... 43

Drawing Taper Keys...... 212

Dressing for Belts....... 203

\section{E}

Eccentric Strap, Adjustingr. 45 Elevator, The Tailings.... 148 Emmer, Threshing ....... 1 ;0 End-play, Separator Cylinder 132 Fngine Bearings, Adjustment of ........... 41

Engine, Attention to a New 12 Engine, Compound ....... 63

Engine Cylinder ........ 5

Engine, Fittings for ..... 9

Engine, Handling the .... 47

Engine, Horse-Power of... $5 \mathrm{~S}$

Engine Proper .......... 53

Engine, Setting the ...... 49

Engine, Starting a New.... 11

Engine, Starting on Road.. $4 \mathrm{~S}$

Engine, Starting Traction

Parts .............. 11

Engine, Steaming Up ..... 10

Engine, Steering the ..... $4 \mathrm{~S}$

Fugine Tenrler ......... 103

Ingine Tender, $\Lambda$ ttaching.. 104 
Page.

Engine Tender Wheels ..... 105

Engine, Oiling the ....... 10

Engine Valve Gear ....... 69

Equal Leads, Woolf Gear... 80

Iqualizers. Connecting .... 109

Exhaust Nozzle ......... 33

Exhaust Ports .......... 54

Extension, The Conveyor .. 145

Expansion of Steam ...... 55

Expanding Boiler Tubes.... 91

\section{$\mathbf{F}$}

Fan Elinds ..............148

Fan, Removing .........200

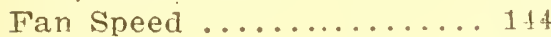

Feeder ................ 172

Feeder, Attaching ....... 172

Feeder, Folding the ...... 178

Feeder Governor ........ 174

Feeder, Oiling the ....... 173

Feeder, Speed of ........ 174

Feeding the Separator..... 171

Feeding by Hand.......... 171

Feed-Water, The ........ 13

Feed-Water Heater's ...... 27

Figuring the Horse-Power. 62

Finding the Dead Centers.. 72

Fire, Starting the........ 10

Firing with Coal ........ 29

Firing with Straw ....... 31

Firing with Wood ....... 30

Firing with Various Fuels. 29

Fish-Backs for Straw-Rack 221

Fittings for Boiler ....... 83

Fittings, Attaching Brass.. 9

Fitting up an Engine..... 9

Flax, Threshing ......... 15:

Flues, Cleaning ......... 91

Foaming ............. 87

Folding the Feeder....... 173

Friction-Clutch ......... 96

Friction-Clutch, Adjusting.. 97

Friction-Clutch, Oiling.... 98

Fuels, Firing with Various. 29

(;

Gage-Cocks

Gage-Glass

Gage, Steam

Gearing Greasing the .....

Gear, The Differential.....

Gearing, Traction .......

Gear, The Valve-.........
Glass, the Water-......... 10

Governor, for Engine..... 57

Governor, Belt for Engine. 57

Governor, Feeder ......... 174

Governor Jumps, If Engine. 58

Governor, Oiling the Engine 57

Governor, Packing Eingine. 57

Governor, Speed of Engine- 57

Grates in Separator....... 139

Grates, Warped Engine... 29

Grain, Cracking ......... 133

Grain Handlers ......... 187

Grain Handlers, Chain for. 192

Grain Handlers, Attaching.. 131

Grain, Headed .......... 151

Grain, Quantity of ....... 192

Grain, Threshing ........ 151

Grain, Quantity in Wagon-

Box ................ 193

Grain, Weight of ........ 194

Grain Weighers ......... 187

Gravel Hills ............ 51

Greàsing the Gearing..... 96

Grease-Cup, "Ideal" ...... 36

Greasing the Trucks...... 196

Grouters, Special High.... 52

\section{H}

Handling the Engine..... 47

Hand Feeding ........... 171

Hand-Hole-Plate, Packing.. 90

Hard Oil ............. 36

Heater for Feed-Water.... 27

Heater, Testing the...... 28

High Grouter .......... 52

Hills, Ascending ....... 50

Hills, Descending ...... 50

Hills, Gravel ........... 51

Holes, Mud ............ 51

Horse-Powers .......... 107

Horse-Powers, Adjusting .. 111

Horse-Powers, Brake for .. 114

Horse-Powers, Bull-Pinions

for $\ldots \ldots \ldots \ldots \ldots \ldots \ldots 112$

Horse-Powers, Jacks for .. 111

Horse-Powers, Horses for 116

Horse-Powers, Lubricating. 108

Horse-Powers. Parts for ... 118

Horse-Powers, Reversing .. 113

Horse-Powers, Setting the.. 108

Horse-Powers, Spur Pinions

for ................ 110 . 
Page.

Horse-Powers, Starting ... 10 Horse-Power Brake ...... 61 Horse-Power, Calculating... 61 Horse-Power of an Engine. 60 Horse-Power, Indicated .... 60 Horse-Power, Rated ...... $5 s$ Horses, Work of ........ 115 Hot Eoxes ........... 19. Hulling Clover ......... 16

\section{I}

"Ideal" Grease-Cup ......

Independent Pump ...... 20

Independent Stacker ..... 178

Independent Stacker, Operating ............... 1s 0

Independent Stacker, Setting ............... 179

Independent Stacker, Erecting ................ 179

Indian Corn. Threshing.... 169

Indicated Horse-Power .... 60

Injector ................ 18

Injector Failing to Work... 19

Inserting Common Sieves... 146

\section{J}

Jack for Horse-Power.... 111

15

Lafir-Corn, 'lhreshing ..... 16s Liers, Taper ............211

\section{L}

Lacings a belt ..........20 204

Lacins a Canvas Eelt ..... 206

Laying up the Separator... 19S

Lead of Valve.......... 79

I.eather Eelts .......... 202

Lengths of Belts ........ $21 \theta$

Leveling the Separator..... 125

Link Reverse, Setting Valre with ............... so

Lining Up Engine and Separator ............. 49

List of Common Sieves.... 147

Loader No. Five.......... 191

Loader No. Six........... 191

Locking the Differential... 100

Lost Motion in Engine.... 41

Low Water ............. 14

Lubrication of Engine .... 35

Lubrication of Cylinder ... 35
Lubrication of Horse-Powers .................. 108 Lubrication of Separator . . 195 Lubrication of the WindStacker ............. 1s? Lubricator, Attaching the "Swift" ............. 39 Lubricator, Failing to Work 40 Lubricator, Operating "Swift" 39 Lucerne Threshing ...... 16

\section{$\mathbf{M}$}

Main-Bearing, Engine .... 4.4 Main Drive Belt......... 203 Main Cylincier Pulley's..... 181 Maize, Threshing ........ 169 "Marsh" Pump, Starting... 21 Millet, Threshing ....... 160 Mud-Holes ............ 51 Mud-Hooks ........... 52

\section{$\mathbf{N}$}

Nailed Pulley Covers....... 212 New Separator, Starting.... 121 Nozzle, Exhaust ........ 33 Number One Weigher ..... 1ss Number Two Weigher .... 1 \$ 9 Number Three Weigher ... 190 Number Four Bagger ...... 190 Number Five Loader ...... 191 Number Six Loader ....... 191

\section{o}

Oats, Threshing ......... 155 Oiling' the Attached Stacker 178 Oiling the Cannon-Bearings $\mathbf{9 5}$ Oiling the Combined Stacker 186 Oiling the Engine ....... 10 Oiling the Differential-Gear 101 Oiling the Feeder ........ 178 Oiling the Friction-Clutch.. $9 \mathrm{~s}$ Oiling the Governor ..... 57 Oiling the Separator ..... 122 Oiling the Tallings-Elevator 150 Oiling the Trucks ........ 196 Oiling the Valve of Engine 39 Oiling the Wind Stacker... 183 Oil, The Cost of.......... 36 Oil, Hard .............. 36 Oil-Pump, Attaching ..... 37 Old Boller, Testing an..... 93 old Boiler, Danger of Using 93 
O

I'age.

Operating the Attaclued Stacker ............. 17s

Operating the Combined Stacker ............ 1s.

Operating the IndependentStacker ............. 1s 0

Operating the Swift Lubricator ................. 39

Operating the Wind-Stacker 180 Orchard-Grass, Threshing. . 167

\section{$\mathbf{P}$}

Packing the Center-Head of

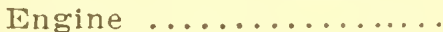

Packing the Governor ....

Packing the Hand-Hole Plates .............. 90

Packing the Pump ........ 24

Packing the "Swift" Lubricator ............... 40

Packing the Water-Glass... 17

Painting the Boiler....... 89

Parts for Horse-Power's.... 118

Peanuts, Threshing ....... 169

Peas, Threshing ........ 161

Peas, Special Cylinder for.. 163

"Penberthy" Injector"..... 1s

"Penberthy" Injector, Start. ing

"Penberthy" Injector", liails to Work ............. 19

Piston, Fngine ......... 55

Pop-Valve ............. $\$ 6$

Port, Exhaust ......... 54

Port, Steam ........... 54

Pounding of an Engine... 41

Pounding of a Straw-Fack. 142

Pressure for an old Eoilel. 94

Priming .............. s $s$

"Prony" Brake .......... 61

Pulleys for Cylinder-Shaft. 131

Pullers, Covering ........ 212

Pulley-Covers, Nailed ...... 212

Pulley-Covers, riveted ... 213

\section{$\mathbf{R}$}

Rated Horse-Power ...... $5 \mathrm{~S}$

Regrinaing Check-Valves .. 27

Removing the Beater ..... 198

Removing the Conveyor ... 199

Remnving the Fan ...... 200

Removing the Rock-Shaft.. 198
It

Page.

Iremoving the straw-Iack. 199

Removing the shoe ...... 199

Pemoving the Spur-Whetl

Shatt ................113

Tiemoving Taper-liers .... 212

Repairing and Testing Heat-

er ............... $2 s$

Reverse-Gear for kngine... 69

Reversing Gearing of Ilorse-

Powers ............... 113

Reversing rumbling - Fod

Motion ............. 113

Rice, Threshing ......... I6 4

Riveter Pulley-Covers .... 213

Rock-Shaft, Iemoring .... $19 s$

Rubber-Belts .......... 202

Rye, Threshing ........ 154

Safety-Valve .......... \$ 6

Scraping the Tubes....... 91

Screens ............... 1is

Self-Feeders ........... 172

Separator, Belts fol ......2 210

Separator, Belting .......201

Separator, Canvas Cover for $19 \mathrm{~S}$

Separator, Care of ....... 197

Separator Cylinder ....... 129

Separator, Feeding the .... 171

Separatol, Laying [p..... 198

Separator Lubrication ..... 195

Separator, Oiling the..... 122

Separator, Pulleys fol .... 211

Separator, Setting Ip ..... 121

Separator, Setting the .... 125

Separator, Starting a Niw. 121

Separator, Side-Gear ..... 110

Setting the Concares ..... 136

Setting the Engine ...... 49

Setting the Horse-Power .. $10 \mathrm{~S}$

Setting the Independent

Stacker ............. 179

Setting the Separator .... 125

Setting the Separator Tp... 121

Setting Separator with Wind 126

Setting the Valve, Compound 80

Setting the Valve, Link -

Reverse ............. so

Setting the Valve, Woolf-

Reverse ........... 76

Shoe, Removing the ...... 199

Shoe, Waste at ........ 220 
Side-Gear for Separator.... 110

Sieves ................ 144

Sieves, Adjustable ....... 144

Sieves, Common ......... 145

Sieves, To Insert ........ 146

Simple Engine ......... 53

Slide-Valve ........... 54

Slip of Valve, Woolf-Valve-

Gear ............... $7 \mathrm{~S}$

Solid-Boxes, Babbitting .... 215

Soy-Beans, Threshing .... 163

Special Concaves ........ 137

Special Cylinder, Rice .... 135

Special Cylinder for Beans. 163

Special High Grouters .... 52

Special Straw-Rack ...... 142

Speed, Ascertaining Cylinder 131

Speed of Separator Cylinder 130

Speed of Fan ......... 144

Speed of Feeder .......... 174

Speed of Governor on En-

gine ............... 57

Speed of Straw-Rack...... 141

Speed of Tumbling-roul ... 110

Speed of Wind-Stacker .... 1\$4

Speltz, Threshing ....... 160

Split-Box, Babbitting ...... 216

Spur-Pinions, Horse-Power. 110

Spur-Wheel Shaft, Horse-

Power ............... 115

Stackers, Straw ........ 177

Stackers, Attached ...... 178

Stackers, Combined ...... 184

Stackers, Common ........ 177

Stackers, Independent .... 178

Stackers, Wind .......... Is0

Stack Building ......... 1\$3

Starting Engine ....11 and 47

Starting Horse-Power .... 107

Starting Injector ........ 18

Starting Marsh Pump ..... 21

Starting Separator ....... 121

Starting Traction-Gearing.. 11

Steam Admission ........ 55

Steam Cut-Off ......... 55

Steam Expansion ........ 55

Steam Gage ............ 85

Steam Ports ........... 54

Steel Cable, Use of...... 51

Steering the Engine....... 48

Straining the Fori-Tater.. 13
Straw. Page.

Straw, Firing with....... 31

Straw-Rack ........... 139

Straw-Rack, Fish-Backs ... 221

Straw-Rack, Removing .... 199

Straw-Rack Pounding ..... 142

Straw-Rack, Speed of..... 141

Straw-Rack, Special ...... 142

Straw-Rack, "Texas" Special $16 \mathrm{~S}$

Straw-Stackers ......... 177

"Swift" Lubricator, Attach-

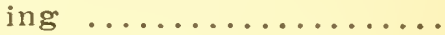

"Swift" Lubricator, Fails to Work ............. 40

"Swift" Lubricator, Operating .............. 39

"Swift" Lubricator, Packing 40

\section{$\mathbf{T}$}

Tanks ................ 103

Tank-Pump ............ 104

Tailings Elevator ....... 148

Tailings Elevator, Oiling .. 150

Tailings Elevator, Adjust-

ing ............. 150

Tailings Elevator Chain ... 150

Taper-Keys ........... 211

Taper-Keys, Drawing .... 212

Testing Water-Heater ..... 28

Temperature of Stean .... 83

Temperature of Water .... 83

Testing' a Boiler......... 93

Tenders, Engine ....... 103

Tenders, Attaching, Engine 104

Tender-Wheels, Engine .... 105

Teeth for Cylinders........ 129

Teeth-Tracking ......... 133

"Texas" Straw-Rack ..... 168

Throttle, The ......... 56

Threshing Alfalfa ....... 167

Threshing Barley ....... 156

Threshing Beans ........ 163

Threshing Buckwheat .... 159

Threshing Emmer ....... 160

Threshing Flax ........ 157

Threshing Headed Grain . 151

Threshing Indian Corn .... 169

Threshing Kafir-Corı .... 168

Threshing Lucerne ...... 167

Threshing Maize ........ 169

Threshing Millet ........ 160

Threshing Oats ........ 155

Threshing Olchard Grass . . 167 
Page.

Threshing Peas ......... 1:31

Threshing Peanuts ...... 169

Threshing Rice ......... 164

Threshing Rye ......... 15t

Threshing Soy Beans ..... 163

Threshing Speltz ........ 160

Threshing Timothy ...... 15

Threshing 'Turkey-Theat .. 154

Threshing Wheat ....... 152

Threshing, Waste ill..... 219

Timothy Threshing ....... 158

Tracking of Teeth....... 133

Traction-Parts, Starting the 11

Traction-Gearing ........ 95

Tubes, Cleaning the....... 91

Tubes, Expanding and Beading ................. 91

Tumbling-Rod, Reversing .. 113

Tumbling-Rod, speed of ... 110

Trucks, Greasing ........ 196

Turkey-Wheat, Threshing.. 154

\section{V}

Valve, Check ........... 25

Valve, Compound ........ 64

Valve-Gear, Engine ...... 69

Valve-Gear, Distulbing .... T0

Valve Lead ............. 79

Valve, Pop Safety........ \$6

Valve-seat ............. ju

Valve, Setting Woolf Gear. 76

Valve, Setting Link Geal.. 80

Valve, Setting Compound.. so

Valve-slip ............. is

Valve, If Disturbed ..... 75

Valve Lubrication ....... 55

Valve, slide........... 54

Various Fuels, Firing with. 29
W

Page.

Wason-Box, Contents of... 193

Trashing the Boiler...... 89

Waste in Threshing....... 219

Waste at Shoe..........220

Water, Feed ........... 13

Water, Foaning ......... 87

Trater-Gauge .......... 16

Water-Glass, Broken ...... 17

Watel Glass, Packing ..... 17

Water-Heater .......... 27

Trater, Low ............ 14

Water, Priming ......... 88

Water 'Tanks ............ 103

Water Temperature in Boiler 83

Weight of Grain......... 194

Weights of Grains....... 187

Weigher Number One ..... 198

Weigher Number Two .... 189

Weighing Bagger Number

Three .............. 190

Wheat, Threshing ....... 152

Wheels for Engine-Tender. 105

"White-Caps" in Theat... 153

Wind-Board ............ 144

Wind, Setting with....... 125

Wind-Stacker .......... 1so

Wind-Stacker Lubrication. 1\$3

Wind-Stacker Operation ... 180

Wind-Stacker Speed ...... 184

Wind-Stacker Stack Euilding 183

Wood, Firing with....... 30

Woolf Compound, The.... 64

Woolf Reverse-Gear, Set-

ting Valve ........... 76

Woolf Valve-Gear ....... 70 




IUN 29 lYUY 



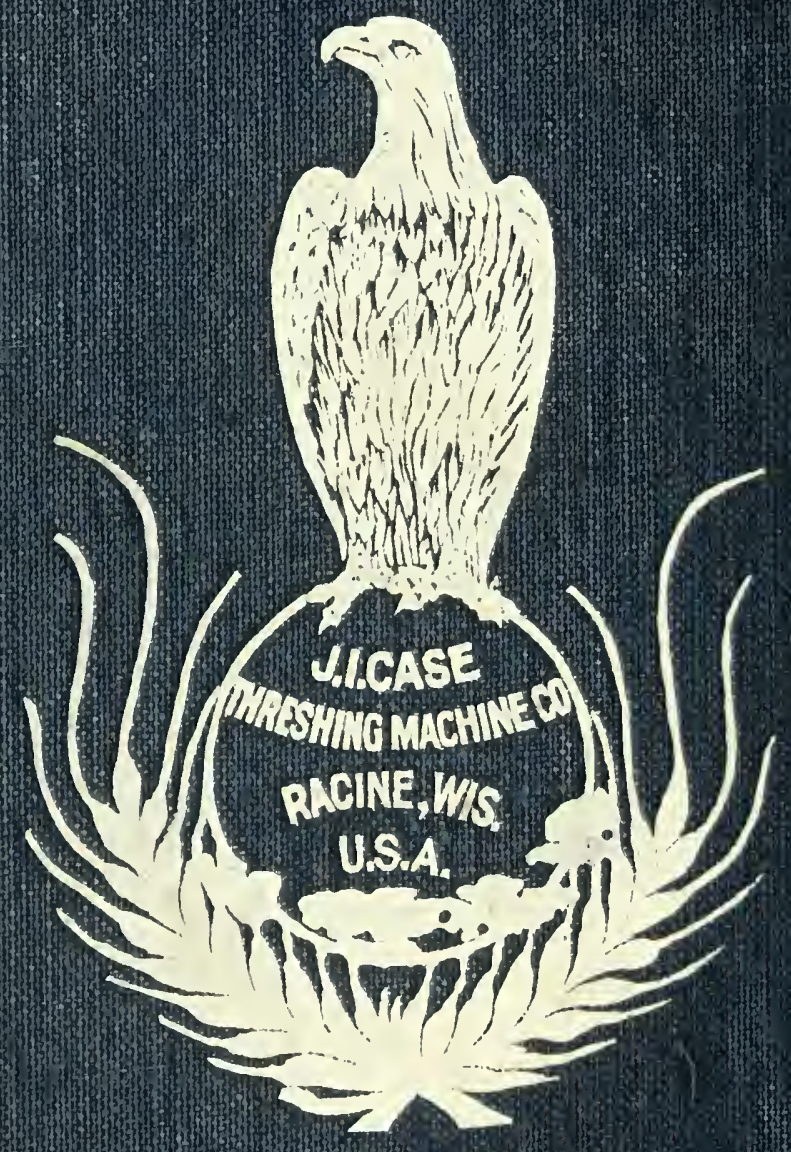

